\title{
- $\operatorname{las}$ a $C R-168,200$
}

DOE/NASA/0252-1

NASA CR-168200

Conirol of Large Wind Turbine

Generaiors Connecied io

Urilion Neingorlas

NASA-CR-168200

19830026180

E. N. Hinrichsen

Power Technologies, Incorporated

May 1983

Enamer rem

$\because 2999$

LIBOREY, NASA
HESTEK

H.H.TOU, Y!REIr!A

Prepared for

NATIONAL AERONAUTICS AND SPACE ADMINISTRATION

Lewis Research Center

Under Contract DEN 3-252

for

U.S. DEPARTMENT OF ENERGY

Conservation and Renewable Energy

Wind Energy Technology Division 


\section{DISCLAIMER}

This report was prepared as an account of work sponsored by an agency of the United States Government. Neither the United States Government nor any agency thereof, nor any of their employees, makes any warranty, express or implied, or assumes any legal liability or responsibility for the accuracy, completeness, or usefulness of any information, apparatus, product, or process disclosed, or represents that its use would not infringe privately owned rights. Reference herein to any specific commercial product, process, or service by trade name, trademark, manufacturer, or otherwise, does not necessarily constitute or imply its endorsement, recommendation, or favoring by the United States Government or any agency thereof. The views and opinions of authors expressed herein do not necessarily state or reflect those of the United States Government or any agency thereof.

Printed in the United States of America

Available from

National Technical Information Service

U.S. Department of Commerce

5285 Port Royal Road

Springfield, VA 22161

NTIS price codes 1

Printed copy: A05

Microfiche copy: A01

${ }^{1}$ Codes are used for pricing all publications. The code is determined by the number of pages in the publication. Information pertaining to the pricing codes can be found in the current issues of the following publications, which are generally available in most libraries: Energy Research Abstracts (ERA); Government Reports Announcements and Index (GRA and I); Scientific and Technical Abstract Reports (STAR); and publication, NTIS-PR-360 available from NTIS at the above address. 
ENTER:

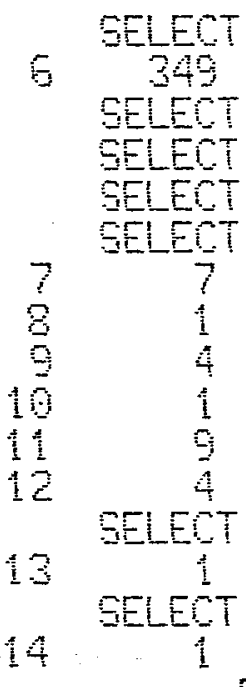

UTP HUPRICANES $* 2$ TROP 352 UTPUINO $* 1$ SHEAR

UTP HADOEOK * 2 PPEPAE

TILAIOES $* 2$ AIR $* 1$

UTP/GUIOE $* 2$ AIP $* 10$

UTPAULOE $* 2$ AIR $* 1$

7 AU/PETEREE, U. 8.

1 LIMIT $7 / 83-84$

4 AU/GATO, R. K.

1 LIMIT $9 / 83-84$

9 AU/ARULO, $\mathrm{I}$.

4 LIMIT $1183-84$

UTPAMLYS

1 UTP/WOELS $* 2$ VIGUAL $* 1$ PERCEPTIOH

GEIOB: MEU UGER GET HULL

GE108: NED UGER GET MULL

GE108: NEU USER GET WUL

GEIO8: NEU UGER SET WULL

GEDO: MEU USER SET MUL

TTL COUFEFENCE *2 WUEE SEIOS: NEU UEER SET MUL IOPL ROOE

Gom

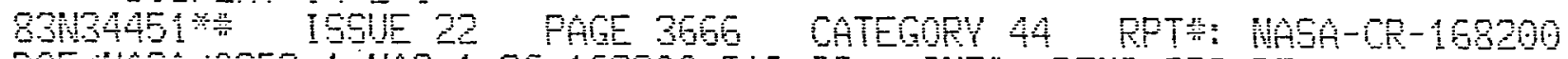

DOE HAGA O252-1 HAS $1.26: 16800$ RIO-83 ONT: OEN3-252 OE-AI01-76ET-20320 $83 / 0500$ GI PACES MUCAGSIFIFO DOCUMENT

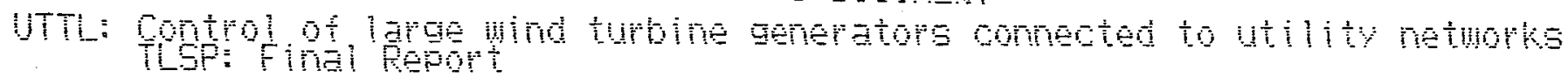

AUTH ARMVICHES, E. M.

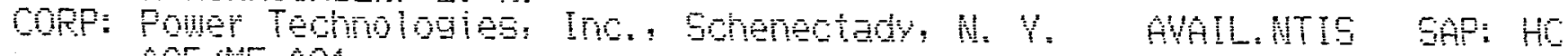
AOS/UF AOI

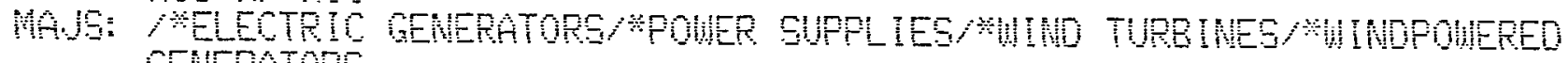
GEMERATORS

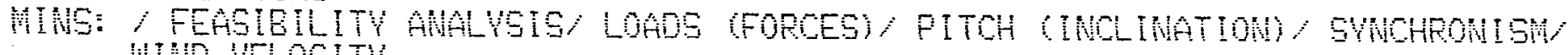

ABA: AUthor

ABS: The is an inestigetion of the control redirements for varioble pith

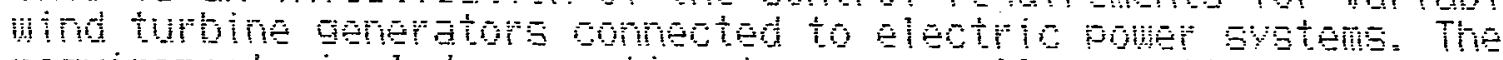

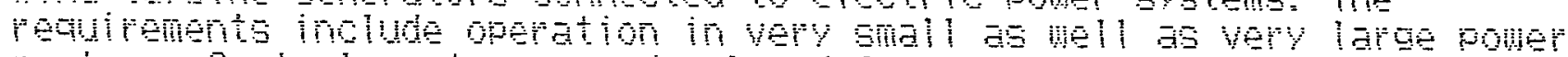

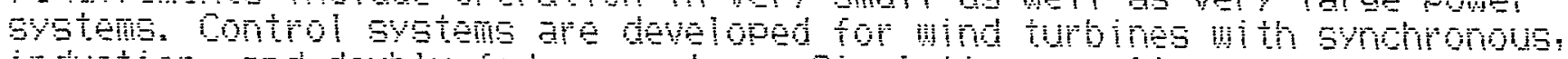

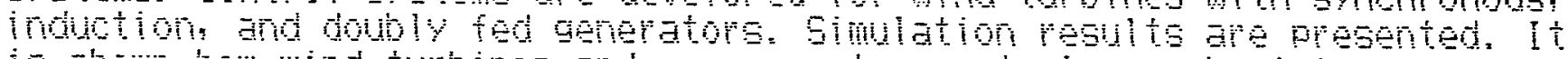
is shom hom und turbnes and pome systen controls can be integrated $A$

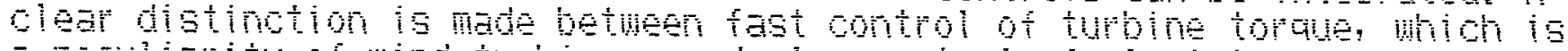

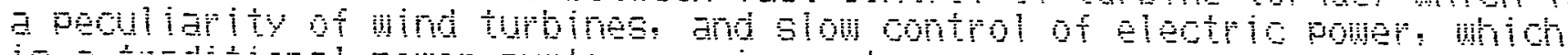
ENTER: is a tradtional pomer systen matrement. 


\section{Control of Large Wind Turbine Generators Connected to Utility Networks}

E. N. Hinrichsen

Power Technologies, Incorporated P.O. Box 1058

Schenectady, New York 12301

May 1983

Prepared for

National Aeronautics and Space Administration Lewis Research Center Cleveland, Ohio 44135 Under Contract DEN 3-252

for

U.S. DEPARTMENT OF ENERGY Conservation and Renewable Energy Wind Energy Technology Division Washington, D.C. 20545 Under Interagency Agreement DE-AI01-76ET20320 


\section{CONTENTS}

$\underline{\text { Page }}$

1.0 SUMMARY - 0 - 1

2.0 INTRODUCTION -

3.0 PURPOSE AND METHOD- 6

4.0 CONTROL REQUIREMENTS-- 0 - 9

5.0 CONTROL DESIGN--

5.1 Wind Turbines with Synchronous Generators--

5.2 Wind Turbines with Induction Generators-_-

5.3 Wind Turbines with Doubly-Fed Generators---

5.4 Frequency and Mode Shapes of Eirst Torsional Mode-- 15

5.5 Measured Electrical power in Wind Turbine Control-- 16

5.6 Steady-State Speed/Frequency Regulation with Load

(Droop) - - 17

6.0 SIMULATION-

6.1 Method--n-n-n- 18

6.2 Cases---n-n-

6.3 Interpretation of Results-

6.4 Results for Synchronous Generator System--------- 21

6.5 Results for Induction Generator System---------- 22

6.6 Results for Doubly-Fed Generator System----------- 23

7.0 CONCLUSIONS--- 
8.0 CONTROLS OE EXISTING WIND TURBINE GENERATORS---------- 27

8.1 Smith Putnam Wind Turbine- 27

8.2 MOD-O and MOD-OA Wind Turbines-

3.3 MOD-1 Wind Turbine- 28

8. 4 MOD-2 Wind Turbine- 28

9.9 DATA -

9.1 Wind Turbine- 29

9.2 Wind Turbine Control- 29

9.3 Drive Train-- 30

9.4 Generator

9.5 Generator Control 5

9.6 Electrical System--

10.0 REEERENCES--

EIGURES $1-133-0-0-1-0-13$

SIMULATION CASES SI-S3--

SIMULATION CASES II-I3--

SIMULATION CASES DI-D3- 58

11.0 APPENDIX - OPERATION OE MOD-0 WIND TURBINE WITH SPEED IN LIEU OE POWER CONTROL -

11.1 Introduction-

11.2 Analysis- 65

11.3 Objectives-- 67

11.4 Discussion of Test Results- 68

11.5 Conclusions $-1-0-11$

11.6 Eutlire Work- 71 
Page

11.7 Data-_-_ 71

FIGURES AI-A8 8 


\subsection{SUMMARY}

Large wind turbine generators for use in electric power systems have reached the prototype stage in sizes up to $4 \mathrm{MW}$. During the intensive development effort which has now been underway in the USA for about five years, the major goal has been to achieve good aerodynamic and structural design at competitive cost of energy production. The development of controls has been influenced more by this goal than by the need to integrate the equipment with existing power systems. During 1981 and 1982 investigations have been carried out for the wind Energy Projects office of the National Aeronautics and Space Administration to determine functions and structure of wind turbine controls. The goal of these investigations has been the integration of control systems for wind turbines with synchronous, induction, and doubly-fed generators into the structure of power system controls.

Particular emphasis has been given to the separation of machine and system control functions. For example, fast torque control during changes in wind speed is a necessary machine control function in wind turbines. This function should be structured so that it does not interfere with the slower system control function of maintaining equilibrium between generation and load.

Control requirements include stand-alone as well as interconnected operation. The unsteady nature of wind is not in conflict with this requirement. The problems associated with the variability of wind are dealt with by system control functions, remote from the controls of individual turbine generators.

The control requirements were translated into a control system for each of three generator types. Tests were performed in a simulation environment representing wind turbine, generator, and electrical system. Disturbances included step changes in wind speed and electrical load. The salient features of the control systems which evolved from the requirements and were tested by simulation are:

- Synchronous Generator

There are separate control loops for torque and speed. Both operate on turbine blade angle. The controlled variable of the torque controller is aerodynamic torque, not shaft torque and not electrical torque. Shaft torque and electrical torque are dependent on 
electrical load, aerodynamic torque is not. Proportional speed control provides damping of the first torsional mode and gives the wind turbine steady-state speed regulation. High torsional compliance in the drive train is desirable. Mechanical damping of the first torsional mode is needed because damping by speed control is not effective in all operating modes. Since synchronous generators are controllable var sources, they provide voltage support to the power system.

- Induction Generator

Since changes in aerodynamic torque cause changes in slip, torque and speed control are combined. The slip in the generator provides damping of the torsional mode, both in high and low penetration cases. Induction generators may require separate var sources. In most cases switched capacitors are adequate. When penetration is extremely high, controlled static var sources are needed.

- Doubiy-Fed Generator

Torque is controlled at the generator by adjusting phase position of rotor voltage. speed is controlled at the turbine. When viewed from the turbine, the generator is a constant torque device. When viewed from the power system, the wind turbine is an electrical source which adjusts frequency with power and follows changes in electrical load. Since doubly-fed generators are controllable var sources, they provide voltage support to the power system. 


\subsection{INTRODUCTION}

Large wind turbine generators for use in electric power systems have reached the prototype stage in sizes up to $4 \mathrm{MW}$ [1]. During the intensive development effort, which has now been underway in the USA for about five years, the major goal has been to achieve good aerodynamic and structural design at a competitive cost of energy production.

The development of controls has been influenced much more by this major goal of wind turbine development than by the need to integrate this equipment into existing power systems. This is the normal result of setting priorities during the evolution of a new technology. As wind turbines become more mature aerodynamically and structurally, additional attention will have to be given to the controls needed to achieve integration. The integration effort has two aspects. First, there is a need to identify the phenomena the controls have to deal with. There is not only parallel operation with the grid under steady-state conditions, but also the reaction to wind speed transients, response to changes in electrical load, behavior during electrical disturbances, and control of the wind turbine generator for the purposes of generation control and economic dispatch. This effort leads to a list of control functions. Second, it must be decided which control functions are to be implemented at the individual turbine generator and which at a higher level in the system control hierarchy.

The apparent deficiency of control systems in present prototypes is not a lack of control functions but rather their incorrect placement in the control hierarchy. Wind turbines presently in operation are designed to deliver constant rated power when wind speed is above rated and maximum possible power when wind speed is below rated power. Since generation must always provide the power demanded by the load, the control of power cannot be a machine function but must be a system function. Conventional power generating equipment is designed to follow the load under primary speed control. A system control function (automatic generation control - AGC) establishes new equilibria between generation and load by resetting desired power levels of the sources in the system. This system control function is guided by economic considerations (economic dispatch - ED), i.e. a source with the lowest incremental cost is given preference to supply the next load increment. Primary speed control is a fast acting machine function while power control by $A G C$ and $E D$ is a slow acting system function. Primary speed control can be very important in the case of isolated systems. 
There are two reasons for implementing the system control function of regulating power output at the machine level in present wind turbines. First, there is the need for torque control during wind gusts. Second, there is the desire to achieve the lowest cost of energy by maximizing energy capture. Albeit at the expense of system integration, both goals can be achieved by power control of individual wind turbine generators. The unfortunate consequence of combining the system control function of regulating generation with machine control functions is a narrow range of applications. Present wind turbines can only be connected to large interconnected systems which can tolerate injections of power unrelated to total load demand.

This report analyzes the steps which have to be taken to achieve full integration of wind turbine controls with existing power system controls. When this integration occurs, two results are likely:

- Wind turbines may be an attractive alternative in areas where fuel is unusually expensive and wind regimes are particularly favorable. These conditions are likely to occur in places which are geographically remote and which also have weak, autonomous power systems.

- When wind turbines have controls suitable for full integration into utility power systems, they can be dispatched as one resource among others. This will automatically lead to the most economical use of wind in a given environment and achieve the same net result as the present controls. Operational flexibility will, however, be considerably greater.

The unsteady nature of wind should not be used as an argument in favor of the current type of control. operators of electric power systems have long used variable energy sources, e.g. run-of-the-river hydro. While there are important quantitative differences between water and wind resources, e.g. the rate of change with time, the methods developed for one can also be used for the other. These methods rely on forecasting, scheduling, and availability of reserves. In all cases the problems associated with the unsteady nature of a resource are dealt with by system control functions, remote from the controls associated with individual power sources. 
The integration of machine and system controls pursued in this report is carried out for wind turbines with synchronous, induction, and doubly-fed generators. The principal differences between control systems described here and those currently in use are:

- When shaft torque must be controlled by adjusting turbine blade angle, the torque control loop is located inside the speed control loop, so that the system does not have a constant torque (power) characteristic when viewed from the network.

- Turbine control is entirely based on parameters measured at the turbine. Electric power is not used. Control of electric power is considered a system function. It is recognized that there will be cases, especially during early prototype installations, where the system will not provide power control. In such instances wind turbines should be equipped with a supplementary power control loop with slow integral behavior, emulating the action of AGC. 


\subsection{PURPOSE AND METHOD}

This study was conducted to analyze the machine and power system requirements of wind turbine controls, to transform the requirements into actual control systems, and to test these systems in a simulated system environment. It was not the purpose to review in detail the controls of existing wind turbines. This was done during prior work $[2,3]$ on the dynamics and stability of wind turbines. A brief review of existing controls is contained in section 9. Nor was it the purpose to improve specific features of existing wind turbine generators, such as power quality or torque loading. The main purpose was to determine what control systems evolve when wind turbine generators have to meet the same system requirements as other power sources. It has been the practice to exempt wind turbines and other intermittent power sources a priori from certain requirements. It is believed that such a practice is unnecessary and that it has led inadvertently to a narrow range of usefulness.

The method used has three parts:

- Definition of Control Requirements

The control requirements must reflect both the needs of the wind turbine generator, e.g. torque control during wind gusts, and the needs of the power system, e.g. the ability to maintain equilibrium between generation and load.

- Definition of Control Eunctions

The control functions are the elements which comprise the control system. The most important function in wind turbine controls are torque control, speed control, power control, and damping. A distinction must be made between functions performing a machine task, e.g. control of shaft torque, and functions performing a system task, e.g. control of power. The control functions have to be designed so that they can operate without interference. Appropriate bandwidths have to be chosen for each function. 
Control structures are groups of control functions assembled to satisfy the requirements for a given type of generator. The control structures for synchronous, induction, and doubly-fed generators are tested in a simulated system environment. The simulation uses a detailed non-linear representation of the wind turbine, wind turbine controls, generator, generator controls, drive train, and electrical system. During simulation, disturbances are introduced at the wind turbine in the form of step changes in wind speed and at the generator in the form of step changes in electrical load. Two electrical systems are used in the simulation. One is a strong system, in which the wind turbine generator operates against a nearly infinite bus. The other is an isolated system, in which the wind turbine generator represents the only source of power. While it may be difficult to imagine the actual operation of such a system, it has great advantages from a design and test viewpoint because it is the ultimate high penetration case. It should be noted that the controls for conventional power sources in utility systems are generally designed for stand-alone operation. Hence, the procedure used in this study is merely an extension of a well established practice.

The wind turbine data used for simulating control systems is taken from the 2.5 MW MOD-2 built by the Boeing Engineering and Construction Company for NASA/DOE. Since the MOD-2 turbine was designed to be used with a synchronous generator, it has a hollow shaft between hub and gearbox (quill shaft) for additional drive train compliance. For the simulation of wind turbines with synchronous generators (Figure 1) no change was made to the MOD-2 data. For the simulation of wind turbines with induction and doubly-fed generators (Figures 2 and 3 ), drive train compliance was decreased by a factor of ten to approximate the elimination of the quill shaft. Additional drive train 
compliance is not necessary when induction or doubly-fed generators are used. 


\subsection{CONTROL REQUIREMENTS}

The goals defined in the introduction can be transformed into five principal requirements:

1. Variations of electrical power due to changes in wind speed should be as small as possible.

2. The wind turbine generator should always operate within its design limits.

3. The wind turbine generator should participate in the short term adjustment of generated power that occurs when there is a change in load. Short term implies the reaction of individual turbine generators during the first few seconds after a load change, before system control functions, such as automatic generation control, have readjusted turbine generator setpoints to match the load.

4. The wind turbine generator should be able to participate in the long term adjustment of generated power in response to commands from a local or remote control center.

5. A wind turbine generator with a given set of controls should be able to operate in a small power system where it represents the only or the major source of power as well as in a large power system where it represents an insignificant part of the total power. The unsteady nature of wind is not in conflict with this requirement. It is recognized that scheduling and dispatch of wind turbines must be cognizant of the variability of wind speed and the resulting changes in electric power. 


\subsection{CONTROL DESIGN}

5.1 Wind Turbines with Synchronous Generators

A synchronous generator provides a low compliance elastic link between generator rotor and electrical system. The mechanical compliance in the drive train is always higher than the electrical compliance. This is an idiosyncrasy of wind turbines caused by the large gear ratio between turbine and generator. Low drive train stiffness and high rotor inertia are typical of wind turbines and give rise to a lightly damped, low frequency torsional mode. Drive train compliance is often increased intentionally to help isolate the generator from wind speed transients at the turbine (Requirement 1 ). Since the drive train is torsionally more constrained at the generator than at the turbine, the mode shape of the first torsional mode has relative amplitudes which are high at the turbine and low at the generator. This implies that the mode can be stimulated easily by wind speed transients.

While the controlled variables are turbine speed and shaft torque, the control acts on turbine blade angle. The purpose of controlling speed is twofold. First, speed control of the turbine hub is an effective way to provide damping of the first torsional mode. Second, proportional speed control gives the wind turbine generator steady-state speed regulation with load (droop) necessary for load sharing between interconnected generators (Requirement 3). Control of shaft torque is necessary to meet Requirement 2. Torque control must be implemented so that it does not give the wind turbine generator constant torque (power) behavior when viewed from the electrical system. Such a characteristic would violate Requirement 3.

A control system for wind turbines with synchronous generators, designed to satisfy the requirements discussed in section 4, is shown in Figure 1. The system has an inner torque control loop and an outer speed control loop. The torque loop controls aerodynamic torque, the speed loop controls turbine speed. The measured quantities are turbine speed and shaft torque. Aerodynamic torque is synthesized from shaft torque and the first derivative of turbine speed. The synthesis is based on the sum of the torques acting on turbine inertia (Figure 1 ):

$$
\mathrm{T}_{\mathrm{AC}}=\mathrm{T}_{\mathrm{AE}}-\mathrm{T}_{\mathrm{SH}}
$$

Accelerating torque acting on turbine inertia is: 


$$
\mathrm{T}_{\mathrm{AC}}=\mathrm{dN}_{\mathrm{T}} / \mathrm{dt} \cdot 2 \mathrm{H}_{\mathrm{T}}
$$

(2) into (1):

$$
\mathrm{T}_{\mathrm{AE}}=\mathrm{dN}_{\mathrm{T}} / \mathrm{dt} \cdot 2 \mathrm{H}_{\mathrm{T}}+\mathrm{T}_{\mathrm{SH}}
$$

where:

$\mathrm{T}_{\mathrm{AE}}$ aerodynamic torque
$\mathrm{T}_{\mathrm{AC}}$ accelerating torque at turbine rotor
$\mathrm{T}_{\mathrm{SH}}$ measured torque at turbine hub
$\mathrm{N}_{\mathrm{T}}$ measured turbine speed
$\mathrm{H}_{\mathrm{T}}$ turbine inertia

The pertinent features of the control system of Figure 1 are:

- Control is entirely based on parameters measured at the turbine. The drive train transfer function with its lightly damped, low frequency torsional mode lies outside the control loops. This reduces the likelihood of exciting torsional modes with blade angle movement. Electric power is not used.

- Since the torque loop is located inside the speed loop, the wind turbine is a speed controlled device when viewed from the electrical system. Power generated is adjusted to follow the load.

- The speed control loop performs the speed setting function before the breaker is closed, and the combined speed regulation and load setting function after the breaker is closed. The load set point (speed reference) can be transmitted from a remote control center. The speed control loop also provides damping of the first torsional mode. A lead/lag compensating network in the speed control loop provides a transient gain for damping which is higher than the steady-state gain determining the speed droop with load.

- The synchronous generator is a controlled source of reactive power. It provides 
voltage/reactive power support for the electrical system.

The response of the torque control loop is limited by blade and pitch actuator dynamics, in particular blade natural frequencies and pitch actuator lag. These limitations exist no matter how torque control is structured. Hence, one should not assume that the inner torque loop of Eigure 1 is inherently superior to other methods of torque control. The main advantages in the context of this work are the separation of torque and power control and the elimination of drive train dynamics from the control loop.

\subsection{Wind Turbines with Induction Generators}

Unlike synchronous generators, induction generators are high compliance couplings between machine and electrical system. This is true for induction generators with slip of at least $1-2 \%$ at rated power. For smaller values of slip, rotor flux dynamics can give induction generators low torsional compliance, much like synchronous generators $[5,6]$. High torsional compliance between generator and grid, coupled with the damping provided by energy dissipation, helps meet Requirement 1. This eliminates the need for additional compliance in the drive train. Since the torsional constraint at the generator is low and generator inertia is much smaller than turbine inertia, the mode shape has relative amplitudes which are low at the turbine and high at the generator. This implies that the mode cannot be stimulated easily by wind speed transients. The controlled variables are the same, i.e. turbine speed and shaft torque. Control also acts on the same variable, i.e. turbine blade angle. Since the torque-speed characteristic of the induction generator is nearly linear in the operating region, torque changes are reflected as speed changes. The control designer has a choice: he can provide a single speed controller to control speed as well as torque, or he can. Eurnish separate controllers for the two controlled variables. Separate torque control requires a torque control loop similar to that used for wind turbines with synchronous generators (Figure 1). The turbine speed controller can be isochronous (constant speed with varying loads) because the slip-torque characteristic provides steady-state speed regulation needed to meet Requirement 3. This implies that the speed controller may have integral as well as proportional characteristics.

A control system for wind turbines with induction generators, designed to satisfy the requirements discussed in section 4, is shown in Figure 2. This system has a single control loop which controls speed as well as torque. The only 
measured quantity is turbine speed. The principal features are:

- Changes in aerodynamic torque as well as changes in generator torque are sensed as speed changes. A single speed controller responds to both wind speed and load changes. Electric power is not used. Slip of the induction generator must be approximately the same as the desired steady-state speed regulation with load.

- Damping of the first torsional mode of the drive train is provided by slip in the induction generator. This method of damping is effective whether the principal torsional displacement occurs at the turbine or at the generator.

- The speed control loop controls speed when the circuit breaker is open and speed/load when the circuit breaker is closed. The load setpoint (speed reference) can be transmitted from a remote control center.

- The induction generator requires separate reactive power (var) support, either with switched capacitors or with static var sources. The reactive requirements can often be supplied by the load.

The control system shown in Eigure 2 is also applicable to wind turbines with a synchronous generator and a mechanical slip device in the drive train.

\subsection{Wind Turbines with Doubly-Fed Generators}

The torque of a doubly-fed ac generator with a variable frequency exciter is controlled so that it is independent of the torque produced by the turbine. The doubly-fed generator is a synchronous machine in which the magnetic poles of the rotor rotate at a speed other than that of the rotor structure [7]. The rotational speed of the magnetic poles with respect to the rotor structure is changed by changing the frequency of the rotor voltage. As the rotor structure changes speed and position, the machine is held in synchronism at constant torque by adjusting the frequency and the phase angle of the rotor voltage. The magnitude of rotor voltage is also adjusted as rotor frequency 
changes to maintain constant electromagnetic flux. The torque level is modified by adjusting the phase angle of the rotor voltage. Reactive power is controlled by adjusting the magnitude of rotor voltage. The electromagnetic changes associated with changing frequency and phase angle have time constants much shorter than those of inertial transients in the arive train. A change in equilibrium between turbine torque and generator torque leads to acceleration or deceleration of the drive train.

A doubly-fed generator provides a link between wind turbine and electrical system with very high compliance. There is no need for additional mechanical compliance in the drive train. since the torsional compliance at the generator is very high and generator inertia is much smaller than turbine inertia, the relative amplitudes of the first torsional mode are low at the turbine and high at the generator. As with the induction generator, this implies that the mode cannot be stimulated easily by wind speed transients.

While the controlled variables are turbine speed and shaft torque, the control acts on turbine blade angle and phase angle of the generator rotor voltage. Unlike drive trains with synchronous and induction generators, torque control can act on one variable, i.e. phase angle of rotor voltage, and speed control can act on the other, i.e. turbine blade angle.

A doubly-fed generator in a wind turbine operates with constant torque angle as frequency of rotor voltage with respect to stator frequency is adjusted. This control concept assumes constant stator Erequency. It gives the generator constant torque behavior when viewed from the turbine and makes the generator appear to be an infinite electrical source when viewed from the electrical network. An infinite electrical source does not change frequency with load. While the constant torque behavior is desirable (Requirement 1), the electrical source characteristic is in conflict with Requirement 3. The necessary change of stator frequency with load is introduced by using a separate frequency source as the reference for rotor voltage control. The reference frequency is changed as a function of load.

Since the load-stator frequency relationship needed to satisfy Requirement 3 is created as a part of rotor frequency and phase control, the turbine speed controller for a wind turbine with a doubly-fed generator can be isochronous.

A control system for wind turbines with doubly-fed generators, designed to satisfy the requirements discussed in section 4, is shown in Figure 3. Turbine control consists of a 
single speed control $100 \mathrm{p}$ controlling turbine speed with blade pitch. The generator controls perform the functions described above and are shown in simplified form by the block entitled "Rotor Phase Control". The principal features of this system
are:

- The constant torque characteristic of the generator when viewed from the turbine satisfies Requirement 1 . Torque control at the generator is inherently faster than torque control at the turbine because the dynamics are determined by electromagnetic rather than mechanical time constants.

- A change in electrical load causes a change in power produced by the generator. Reference frequency of the generator is adjusted with power. The turbine responds to the resulting speed change by adjusting blade angle.

- Unlike systems with synchronous and induction generators, the remote load setpoint does not determine the speed reference but rather sets the angular position of the voltage supplied to the generator rotor.

- A doubly-fed generator is a controlled source of reactive power. It provides voltage/reactive power support for the electrical system.

\subsection{Erequency and Mode Shapes of First Torsional Mode}

In wind turbines with synchronous generators the open-10op frequency of the first torsional mode is determined by the inertia of the turbine and the compliance of the drive train. Torsional displacement is large at the turbine and small at the generator, i.e. the torsional mode can be stimulated by wind gusts. If the torque control loop is closed around the drive train, e.g. torque control based on electric power, the flosed-loop frequency is considerably higher than the open-loop frequency [2]. If torque control is based on aerodynamic torque, with the drive train outside the control loop, open-loop and closed-loop frequency are nearly the same. 
In wind turbines with induction and doubly-fed generators the frequency of the first torsional mode is much higher. First, high torsional compliance is not desirable. This leads to the selection of relatively stiff drive trains. Second, the coupling between generator rotor and electrical system is torsionally soft and generator inertia is much lower than turbine inertia. Hence the frequency of the mode is primarily determined by generator inertia and shaft stiffness. If there are no torque control loops closed around the drive train, open- and closed-loop frequencies are nearly the same. In these machines, most of the torsional displacement is at the generator. It is much more likely that this mode will be stimulated by electrical events than by changes in wind speed. Wind turbines with synchronous generators and mechanical slip devices in the drive train behave similarly.

\subsection{Measured Electrical Power in Wind Turbine Control}

The use of measured electrical power for control of shaft torque or turbine power is widespread in current variable pitch wind turbines. The disadvantages of this practice are not apparent as long as design and simulation efforts concentrate on wind turbines connected to strong electrical systems with disturbances originating only at the turbine in the form of wind speed variations. In this common scenario electrical power is nearly the same as shaft torque, both dynamically and steady state. Electrical power follows shaft torque with excellent fidelity during mechanical disturbances because generator dynamics are determined by short electromagnetic time constants, while turbine dynamics are determined by much longer mechanical time constants. For the same reason, electrical power is a very poor representation of shaft torque when the disturbance originates in the electrical system. During a change of load or a short circuit, electrical power can change abruptly and does not have any similarity with mechanical torque during the ensuing transient. This has been demonstrated elsewhere [2,3]. The consequence of transiently incorrect representation of shaft torque by electrical power during electrical aisturbances is incorrect control action, i.e. incorrect blade angle movements.

Controlling electrical power in lieu of shaft torque has the additional disadvantage that the wind turbine generator becomes a constant power source. Since power sources must participate in short term (Requirement 3) as well as long term (Requirement 4) adjustment of generation to match load, constant power sources are of limited value. They can only be tolerated if their contribution is small with respect to the system. The current method of controlling power in lieu of torque restricts the use of wind turbines to low levels of penetration. 


\subsection{Steady-State Speed/Frequency Regulation With Load (Droop)}

The short term adjustment of generated power to accommodate changes in load (Requirement 3 ) requires a method for dividing load changes into appropriate shares for the participating power sources. The method in common use is a decrease of stator frequency with an increase in load (droop). This enables a group of generators to reach a new common frequency with the load increment divided in accordance with drooping frequency/load characteristics. If all generators have similar characteristics, typically 3-5\% frequency droop from zero to full load, load changes will be shared in proportion to ratings.

The most common method for creating frequency droop with load in utility generators is proportional speed control of the prime mover. The steady-state error of proportional speed control is inversely proportional to gain and changes linearly with load.

There are other methods to Iink an increase in load to a decrease in frequency. A fluid coupling between turbine and synchronous generator provides slip as a function of torque and thereby creates a decrease in frequency with load. The same is true for an induction generator, because slip of the generator rotor changes linearly with load in the operating region near synchronous speed. In both cases the droop in frequency is created by equipment characteristics, not by a control adjustment.

In a doubly-fed generator the link between load and stator frequency cannot be established through rotor speed. Rotor speed can vary at constant stator frequency. Stator frequency is determined by the controls of the variable frequency exciter. Dependence of stator frequency on load must be created by a load dependent, steady state bias of the frequency source which determines stator frequency. 


\subsection{SIMULATION}

\subsection{Method}

The frequency spectrum which is of interest in this study extends approximately from $0.1 \mathrm{~Hz}$ to $10.0 \mathrm{~Hz}$. The lower limit is determined by the frequency of the lowest torsional mode of the drive train, the upper limit by the frequency of system modes (interactions between generator and network).

The simulation used here includes representations of the following components:
- Turbine
- Turbine Control
- Drive and Gear Train
- Generator
- Voltage Control at Generator Terminals
o Electrical Network, with and without other sources of generation

The aerodynamic torque input to the turbine is modeled by the equation:

$$
\begin{aligned}
& T_{A E}=c_{p} \cdot d \cdot V^{3} / N \cdot A \\
& c_{p}=f(\lambda, \beta)
\end{aligned}
$$

$\begin{array}{ll}T_{A E} & \text { aerodynamic torque } \\ \mathrm{d} & \text { air density } \\ \mathrm{C}_{\mathrm{p}} & \text { power coefficient } \\ \mathrm{V} & \text { wind speed } \\ \mathrm{N} & \text { turbine rotor speed } \\ \mathrm{A} & \text { area swept by rotor } \\ \lambda & \text { tip speed/wind speed } \\ \beta & \text { turbine blade angle }\end{array}$

The power coefficient $c_{p}$ is a non-linear function of tip speed ratio $\lambda$ and blade angle $\beta$. This function is stored in tabular form. 
The drive train is represented as a torsional system of three lumped inertias (blades, hub, generator) and two connecting springs (Figure 4). The generator models are based on operational impedances in direct and quadrature axes, representing steady state, transient, and subtransient behavior. Magnetic saturation and rotor resistance are included. Block diagrams of the generator models are shown in Figures 5 and 6 . In the case of synchronous and doubly-fed generators voltage control at the generator terminals acts on the magnitude of the excitation (rotor) voltage. In the case of the induction generator voltage control acts on a separate static var source near the generator terminals.

Since the frequency range of interest in this study is much lower than the fundamental frequency of the power system, the equations for generator stator and electrical network are solved algebraically for fundamental frequency, voltages and currents. The network reactances are made frequency dependent. This approach is computationally more efficient because the integration time step is determined by the highest frequency of interest, not by the fundamental frequency.

It should be noted that Figures 1,2 and 3 are simplified, linearized representations of wind turbine generator systems considered in this study. The simulation is more detailed and includes the major non-linearities such as the $c_{p}=f(\lambda, \beta)$ relationship and generator saturation.

\subsection{Cases}

For each of the three control systems described in section 5 simulation results for three events are presented and discussed:

1. The wind turbine generator is connected to a large power system producing rated power at rated wind speed. A 5 MPH step increase in wind speed occurs. This scenario tests the ability to control torque in the drive train and the extent to which the first torsional mode is excited by wind gusts.

2. The wind turbine generator is the only source of power in a weak, autonomous system, producing half of its rated power at rated wind speed. The load increases abruptly from 50\% to $75 \%$ of rated. This test determines the ability of the wind turbine generator to respond to changes in load under primary speed control. While it is unlikely that a wind turbine generator will be the only source of power, the ability to follow changes in 
load is needed whenever the wind turbine generator is a source of significant size in an autonomous system.

3. The wind turbine generator is connected to a large power system producing rated power at rated wind speed. There is a complete loss of load for 0.25 sec. This test demonstrates how the turbine generator responds to very severe electrical disturbances.

The three above tests create worst case situations and do not represent anticipated operating conditions. However, they differ from actual operating conditions only quantitatively and are, therefore, good indicators of the ability to meet the requirements set forth in section 4 .

\subsection{Interpretation of Results}

Quantities plotted in the simulation results are:

\section{DESCRI PTION}

Turbine Blade Angle Line Frequency Deviation Turbine (Aerodynamic) Power Generator (Electrical) Power Turbine Speed Deviation Generator Speed Deviation

Shaft Torque Generator Voltage Wind speed
UNITS

deg
pu
pu
pu
pu
pu
pu
pu
mph

Each quantity is identified by name. The scale of the ordinate from bottom edge to top edge is included with each trace. Per unit quantities for power and torque refer to machine base which is customarily determined by the rated volt-amperes of the generator. It has been assumed that the volt-ampere rating of all generators investigated in this study is 3.125 MVA at 0.8 power factor, i.e. per unit power is 0.8 when the turbine generator is at its real power rating of $2.5 \mathrm{MW}$.

It will be noted that in the simulation results shown for wind turbines with synchronous generators, turbine power and generator power are practically the same during steady state conditions. This is not always the case for induction and doubly-fed generators. Generator power in these results is stator power. When rotor power becomes a significant portion of shaft power, as is the case in high slip induction generators or doubly-fed generators operating with rotor frequencies other than zero, shaft power and generator stator power aiffer. Since the 
simulation cases for induction and doubly-fed generators shown here are for super-synchronous operation, shaft power exceeds generator stator power. The difference is either dissipated in the rotor (induction generator) or is transmitted to the variable frequency rotor power supply (doubly-fed generator).

\subsection{Results for Synchronous Generator System}

Case SI shows the response of a WT with a synchronous generator to a step increase in wind speed from 26.5 to $31.5 \mathrm{MPH}$. The machine produces rated power prior to the transient. The response is reasonably well damped. The transient speed deviation of the turbine is much greater than that of the generator. This is typical of wind turbines with synchronous generators connected to strong electrical systems. It is indicative of the low torsional compliance between generator rotor and electrical system.

In Case 52 the wind turbine is the only source of power in a small, isolated system. System load changes abruptly from 50\% to $75 \%$ of rated while wind speed remains constant at $27 \mathrm{MPH}$. The control system adjusts blade angle from 12 to 6.5 degrees to accommodate the additional load. Speed decreases by approximately $1 \%$. The abrupt increase in demand causes an oscillation of the generator rotor with respect to the turbine. A wind turbine with a synchronous generator has very little torsional constraint at the generator when the electrical system is small and isolated. Damping of the torsional mode at the turbine provides no relief because oscillations now occur at the generator. Under these conditions only mechanical damping in the wind turbine drive train can reduce the magnitude of oscillations.

The frequency of the torsional mode is approximately 4.5 $\mathrm{rad} / \mathrm{sec}$ compared with $1.2 \mathrm{rad} / \mathrm{sec}$ in Case sl. In Case sl the turbine is oscillating with respect to the generator, in Case 52 the generator is oscillating with respect to the turbine. In Case 51 , the modal frequency is determined by turbine inertia and shaft stiffness; in Case 52 by generator inertia and shaft stiffness. The ratio of frequencies for 51 and 52 is approximately equal to the square root of the ratio of inertias.

Case 53 shows the response to a 0.25 sec loss of load. The unit is connected to a strong electrical system and is producing rated power prior to the disturbance. Power, torque and blade angle excursions after restoration of load are moderate. The recovery is stable. 
Since the dynamics of turbine blades and pitch control mechanism are not represented in the simulation, care has to be taken to give the torque control loop realistic response characteristics. Open loop gain at rated wind speed was set to:

$$
\mathrm{GH}=0.5+2.5 / \mathrm{S}
$$

with a gain crossover frequency of $2.9 \mathrm{rad} / \mathrm{sec}$.

\subsection{Results for Induction Generator System}

Case Il shows the response of a WT with an induction generator to a step increase in wind speed from 26.5 to $31.5 \mathrm{MPH}$. The machine produces rated power prior to the transient. Slip of the generator at rated power is $2.6 \%$. The response is well damped and there is less excitation of the first torsional mode then in Case sl. Reset action of the speed controller returns speed and torque slowly to the old value. During the transient turbine and generator speed deviations are almost the same. This is typical of wind turbines with induction generators which have a high compliance coupling between generator rotor and electrical system.

In Case I2 the wind turbine is the only source of power in a smali, isolated system. System load changes abruptly from 50\% to $75 \%$ of rated while wind speed remains constant at $27 \mathrm{MPH}$. The control system adjusts the turbine blade angle from 12.0 to 7.0 degrees to accommodate the additional load. Under the influence of the reset action of the speed controller, turbine and generator speed return slowly to the old value after the transient. Stator frequency, however, is approximately $0.65 \%$ lower after the transient due to the increase in slip in the generator. The drop in stator frequency provides the steady-state speed regulation required for sharing load changes with other generators. The maximum speed deviation of the generator rotor due to excitation of the torsional mode is about $1.4 \%$ peak to peak, considerably smaller than the $4.5 \%$ peak to peak speed deviation in Case S2. Generator slip provides effective damping whether the torsional oscillation occurs at the turbine (I1) or at the generator (I2). A static var supply provides var/voltage support near the generator. Since the wind turbine generator in this case is the only source of power and the induction generator is a var consumer rather than a var producer, separate var/voltage support must be provided. This is not a normal application of an induction generator and the use of a static var source should not be considered typical. When there are other sources of power, it is usually adequate to provide var 
support with capacitors, either fixed or switched. It may also be possible to meet the reactive requirements with vars supplied by the load.

Case I 3 shows the response to a 0.25 sec. loss of load. The unit is connected to a strong electrical system and is producing rated power prior to the disturbance. As in Case S3, the power, torque, and blade angle excursions after restoration of load are moderate and the recovery is stable.

\subsection{Results for Doubly-Fed Generator System}

Case DI shows the response of a WT with a doubly-fed generator to a step increase in wind speed from 26.5 to $31.5 \mathrm{MPH}$. The machine produces rated power prior to the transient. Initial speed is 5\% above synchronous speed. This case demonstrates the principal advantage of the doubly-fed generator. While the mechanical power developed at the turbine rises from 0.85 pu to $1.15 \mathrm{pu}$, the electrical power produced by the generator remains essentially constant. The excess of mechanical over electrical torque leads to acceleration until the proportional-integral speed controller has acted sufficiently on blade angle to restore the old speed. Blade angle adjustment is relatively slow. Since torque control is now accomplished at the generator, there is no need for fast blade angle changes. Maximum speed increase during the transient is 2\%. Turbine and generator speed deviation during the transient are essentially the same. This indicates the torsional softness of the link between generator and system. Shaft torque oscillates slightly at the frequency of the first torsional mode, indicating that the constant torque characteristic implemented in the generator phase control algorithm produces very little damping. The constant torque characteristic is not inherent in the doubly-fed generator, but it is the characteristic chosen for this study because it is the most useful for a wind turbine application of doubly-fed generators. If the characteristic were modified to include variation of torque with speed, damping of the first torsional mode could be achieved.

In Case D2 the wind turbine is the only source of power in a small isolated system. System load changes abruptly from 50\% to $75 \%$ of rated while wind speed remains constant at $27 \mathrm{MPH}$. The control system adjusts the turbine blade angle from 12.0 to 8.0 degrees to accommodate the additional load. Under the influence of the reset action of the speed controller, turbine and generator speed return slowly to the old value after the transient. In the simulation case shown here stator frequency remains constant. The adjustment of stator frequency with load, shown functionally in Figure 3, was not implemented in the simulation system. 
Stimulation of the torsional mode of the drive train as indicated by speed and torque oscillation is similar in frequency and magnitude to Case I2, signifying that induction and doubly-fed generator have similar characteristics in terms of torsional compliance between generator rotor and electrical network.

Case D3 shows the response to a $0.25 \mathrm{sec}$. loss of load. The unit is connected to a strong electrical system and is producing rated power prior to the disturbance. Unlike the synchronous and the induction generator (Cases 53 and I3) oscillation of generator speed and shaft torque are not very well damped. As indicated before, the doubly-fed machine simulated here develops constant torque, independent of speed, i.e. there is no mechanical damping. Furthermore, a doubly-fed machine cannot provide electrical damping with armortisseur windings because it is designed to operate at speeds other than synchronous.

Cases DI and D3 demonstrate that the constant torque characteristic which is desirable for isolating the electrical system from events at the turbine (Requirement 1) may create dynamic behavior which is not satisfactory. Fortunately, the constant torque characteristic is not an inherent feature of the doubly-fed machine. Damping can be provided by changing the controis so that torque is not constant with speed. This is a tradeoff between minimizing variation of electrical power during wind gusts and achieving acceptable damping of the generator rotor during electrical disturbances. 


\subsection{CONCLUSIONS}

The control requirements for variable pitch wind turbines have been analyzed. They include the full range of applications from stand-alone source in an autonomous system to a source of insignificant size in an interconnected system. Based on these requirements control systems were designed for wind turbines with synchronous, induction, and doubly-fed generators. They were tested in a detailed, non-linear time response simulation by applying step change in wind speed as well as electrical load.

The systems described here perform well, whether penetration of a power system with wind power is low or high. The controls allow wind turbines to respond to changes in electrical load. They do not create constant torque (power) behavior when viewed from the grid. Turbine control is entirely based on parameters measured at the turbine. The use of measured electrical power for control of the turbine is avoided. Since wind turbine drive trains have unusually high torsional compliance, turbine control based on parameters measured at the generator is considered undesirable. It has been shown that a clear distinction can be made between fast control of aerodynamic torque, which is a necessary machine function in wind turbines, and slow control of electric power, which is a system function.

The salient features of the control systems developed in this study for each of the three types of generators are:

- Synchronous Generator

There are separate control loops for torque and speed. Both operate on turbine blade angle. The controlled variable of the torque controller is aerodynamic torque, not shaft torque and not electrical torque. Shaft torque and electrical torque are dependent on electrical load, aerodynamic torque is not. Proportional speed control is needed to provide damping of the first torsional mode and to give the wind turbine steady-state speed regulation. High torsional compliance in the drive train is desirable. Mechanical damping of the first torsional mode is needed because damping by speed control is not effective in all operating modes. Since synchronous generators are controllable var sources, they provide voltage support to the power system. 
- Induction Generator

since changes in aerodynamic torque cause changes in slip, torque and speed control are combined. Slip in the generator provides damping of the torsional mode, both in high and low penetration cases. Induction generators may require separate var sources. In most cases switched capacitors are adequate. When penetration is extremely high, controlled static var sources are needed.

- Doubly-Fed Generator

Torque is controlled at the generator by adjusting phase position of rotor voltage. speed is controlled at the turbine. When viewed from the turbine, the generator is a constant torque device. When viewed from the power system, the wind turbine is an electrical source which adjusts frequency with power and follows changes in electrical load. Since doubly-fed generators are controllable var sources, they provide voltage support to the power system. 


\subsection{CONTROLS OE EXISTING WIND TURBINE GENERATORS}

Since the controls of some of the existing wind turbine generators were the point of departure for this study [2, 3], a review of existing controls is included. This review includes the Smith-Putnam wind turbine of the 1940 s and the family of large horizontal axis wind turbines that has emerged from the us federal wind energy program since 1977.

\subsection{Smith Putnam Wind Turbine}

This machine uses a $600 \mathrm{rpm}$ synchronous generator. There is a fluid coupling between turbine and generator. Speed of the turbine at rated power of $1 \mathrm{MW}$ is $625 \mathrm{rpm}$. The turbine blade angle is controlled by a speed governor. Loading and unloading of the unit is accomplished by changing the speed adjustment of the governor. $[8,9]$.

The controls of the Smith-Putnam machine are very similar to the controls recommended in this study for wind turbines with induction generators. As indicated in section 5.2, the combination of synchronous generator and mechanical slip device is functionally equivalent to an induction generator. slip at rated power is $4.2 \%$, a value well suited to give the drive train compliance with respect to the electrical network and to provide speed/frequency regulation (droop) with an isochronous speed controller (governor). The speed controller performs both the speed/load control and the torque control function. This machine can follow changes in load. It is not a constant power device when viewed from the grid.

\subsection{MOD-O and MOD-OA Wind Turbines}

The MOD-OA machines use synchronous generators and fluid couplings with a slip of approximately 3\% at rated power. The MOD-O is operated with synchronous as well as induction generators. When a synchronous generator is installed, a fluid coupling is inserted into the drive train. When an induction generator is used, the fluid coupling is removed.

This group of wind turbines uses proportional-integral control of speed when off-line (circuit breaker open) and proportional- integral control of electrical power when on-line (circuit breaker closed) [10]. There is no speed control when power is delivered to the grid. The power control loop provides control of shaft torque. When viewed from the electrical network, this machine is a constant power device. 


\subsection{MOD-1 Wind Turbine}

The MOD-1 uses a synchronous generator but does not have a slip device in the drive train. The machine is designed to provide damping of the first torsional mode by varying generator excitation in phase with speed variations at the turbine [3]. The MOD-l controls are similar to the controls of the MOD-OA, i.e. there is speed control when the circuit breaker is open and power control when the circuit breaker is closed. This machine is also a constant power device when viewed from the grid.

\subsection{MOD-2 Wind Turbine}

The MOD-2 uses a synchronous generator. There is no slip device in the drive train. Per unit drive train compliance (angular deflection/rated torque) is about one order of magnitude higher than in the MOD-OA and the MOD-1. This is accomplished with a hollow shaft between turbine and gearbox (quill shaft). When the circuit breaker is closed, the MOD-2 uses proportional-integral control of electric power and proportional control of turbine speed. The MOD-2 is the first horizontal axis wind turbine in the US federal wind energy program to use on-line turbine speed control. Speed control was added to provide damping of the first torsional mode. Its introduction coincided with the increase in drive train compliance. When the drive train is made softer, oscillatory motion in the first torsional mode shifts to the turbine. Control of this motion is accomplished by sensing turbine speed deviations and by changing turbine blade angle in phase with the speed deviations. Due to the presence of the power controller, the MOD-2 is also a constant power device when viewed from the electrical network. In some installations of the MOD-2 the derivative of electrical power is now being used as a substitute for turbine speed. This practice is based on the assumption that the electrical system is quiescent. 
9.0 DATA

9.1 Wind Turbine

The characteristic curves of the MOD-2 wind turbine used in the simulation are given in Figure 9. They express the power coefficient $c_{p}$ as a function of tip speed ratio $\lambda$ and blade angle torque:

The following constants are used to calculate aerodynamic

Radius of turbine rotor (FT) 150

Air density (LB/FT3)

0.0765

Nominal turbine speed (RPM)

17.55

Pitch angle rate 1 imit (DEG/SEC)

8.0

Minimum pitch angle (DEG)

$-1$

\subsection{Wind Turbine Control}

Figure 10 is a detailed block diagram of wind turbine controls used in the simulation. Values of the constants are:

$\frac{\text { SYNCHRONOUS }}{\underline{\text { GENERATOR }}} \quad \underline{\text { INDUCTION }} \quad \underline{\text { DOUBLATOR }} \quad \underline{\text { GENERATOR }}$

$\mathrm{K} 1$

1200.0

0.5

K6

K7

K 8

K9

T 1

T2

T 4

T6
0.1

0.0

$-50.0$

$-1.0$

5.1

3.0

0.25

0.16
800.0

200.0

40.0

400.0

$-1.0$

$-1.0$

$-$

$-$

0.25

0.25

0.16

0.16 


\subsection{Drive Train}

Drive train constants are shown in Eigure 4. There are two drive train configurations, one for synchronous generators, and one for induction and doubly-fed generators. The difference is the stiffness of the shaft between turbine and generator.

\section{4 Generator}

Block diagrams of the generator representations are shown in Figures 5 and 6 . The constants are:

\begin{tabular}{|c|c|c|}
\hline SYNCHRONOUS & INDUCTION & DOUBLY-EED \\
\hline$T^{\prime} \mathrm{do}=4.76$ & $T^{\prime}{ }_{0}=0.29$ & $T^{\prime}{ }_{0}=1.36$ \\
\hline $\mathrm{T}^{\prime \prime} \mathrm{do}=0.06$ & $\mathrm{~T}{ }^{\prime \prime} \mathrm{O}=0.05$ & $\mathrm{~T}{ }^{\prime} \circ=0.1$ \\
\hline $\mathrm{T}$ "qo $=0.06$ & - & - \\
\hline $\mathrm{x}_{\mathrm{d}}=1.942$ & $x=3.0343$ & $x=5.06$ \\
\hline$x_{q}=0.975$ & - & - \\
\hline$x^{\prime} d=0.231$ & $x^{\prime}=0.2036$ & $x^{\prime}=0.18$ \\
\hline $\mathrm{x}_{\mathrm{d}} \mathrm{d}=0.150$ & $x^{\prime \prime}=0.2036$ & $x^{\prime \prime}=0.12$ \\
\hline$x " q=0.150$ & - & - \\
\hline$x_{\ell}=0.081$ & $x_{l}=0.1073$ & $x_{\ell}=0.06$ \\
\hline$S(1.0)=0.136$ & $S(1.0)=0.0$ & $S(1.0)=0.3157$ \\
\hline$S(1.2)=0.390$ & $S(1.2)=0.0$ & $S(1.2)=1.303$ \\
\hline
\end{tabular}

The model parameters given for induction and doubly-fed generators can be derived from conventional induction machine constants. The derivation is shown in Figure 7.

The $S(1.0)$ and $S(1.2)$ parameters define the difference between airgap I ine and open circuit magnetization curve at 1.0 pu and 1.2 pu terminal voltage (Figure 11). 


\subsection{Generator Control}

An IEEE Type 2 excitation system is used for the synchronous generator. Block diagram and constants are shown in Figure 12 . Block diagram and constants of the static var supply connected near the terminals of the induction generator are shown in Figure 13.

In the simulation environment the excitation controls for the doubly-fed generator are quite simple. By choosing a reference frame for the generator which rotates synchronously with stator frequency, frequency of the rotor voltage with respect to the rotor is always equal to the difference between rotational speeds of the rotor and the reference frame, i.e rotor frequency is always equal to slip frequency. Magnitude of rotor voltage is varied with speed to maintain constant flux. This simple open loop adjustment of rotor voltage with speed achieved adequate control of voltage at the generator terminals for the purposes of this study.

\subsection{Electrical System}

Figure 8 shows the electrical systems to which the wind turbine generators are connected during the simulation. 


\subsection{REFERENCES}

1. "Wind Turbines at Work," J. B. Cadogan, D. F. Ancona, spectrum, August 1981, pp 46-51.

2. "MOD-2 Wind Turbine Farm stability study," E. N. Hinrichsen, P. J. Nolan, NASA Report CR-165156, June 1980 .

3. "Dynamics of Single- and Multi-unit wind Energy Conversion Plants Supplying Electric Utility Systems," E. N. Hinrichsen, P. J. Nolan, DOE Report $\mathrm{DOE} / \mathrm{ET} / 20466-78 / 1$ (DE82000666), November 1981 .

4. "Test Status and Experience With the 7.5 Megawatt MOD-2 wind Turbine Cluster," R. A. Axell, H. B. Woody, Proceedings of the Fifth Biennial Wind Energy Conference and Workshop (WWV), Volume I, pp 143-156, October 1981.

5. "Differences in Dynamic Behavior of Synchronous and Induction Machines in wind Turbine Generators," E. N. Hinrichsen, proceedings of the Fifth Biennial Wind Energy Conference and Workshop (WWV), Volume II, pp 407-412, October 1918 .

6. "Application of Induction Generators in Power Systems," F. P. de Mello et al, IEEE Transactions on Power Apparatus and Systems, Vol PAS-101, No. 9, pp 3385-3393, September 1982 .

7. "Development and Evaluation of a Model Doubly-Fed Machine, F. R. Schleif, Bureau of Reclamation Report, Contract No. 9-07-83-V0713, September 1979 .

8. "The Smith-Putnam Wind Turbine," G. H. Voaden, Turbine Topics, Volume 1, No. 3, pp 1-6, June 1943.

9. "Putnams' Power from the Wind," G. W. Koeppl, Van Nostrand Reinhold Company, 1982.

10. "Microprocessor Control System for 200-Kilowatt MOD-OA Wind Turbines," T. W. Nyland, A. G. Birchenough, NASA Report TM-82711, January 1982 . 


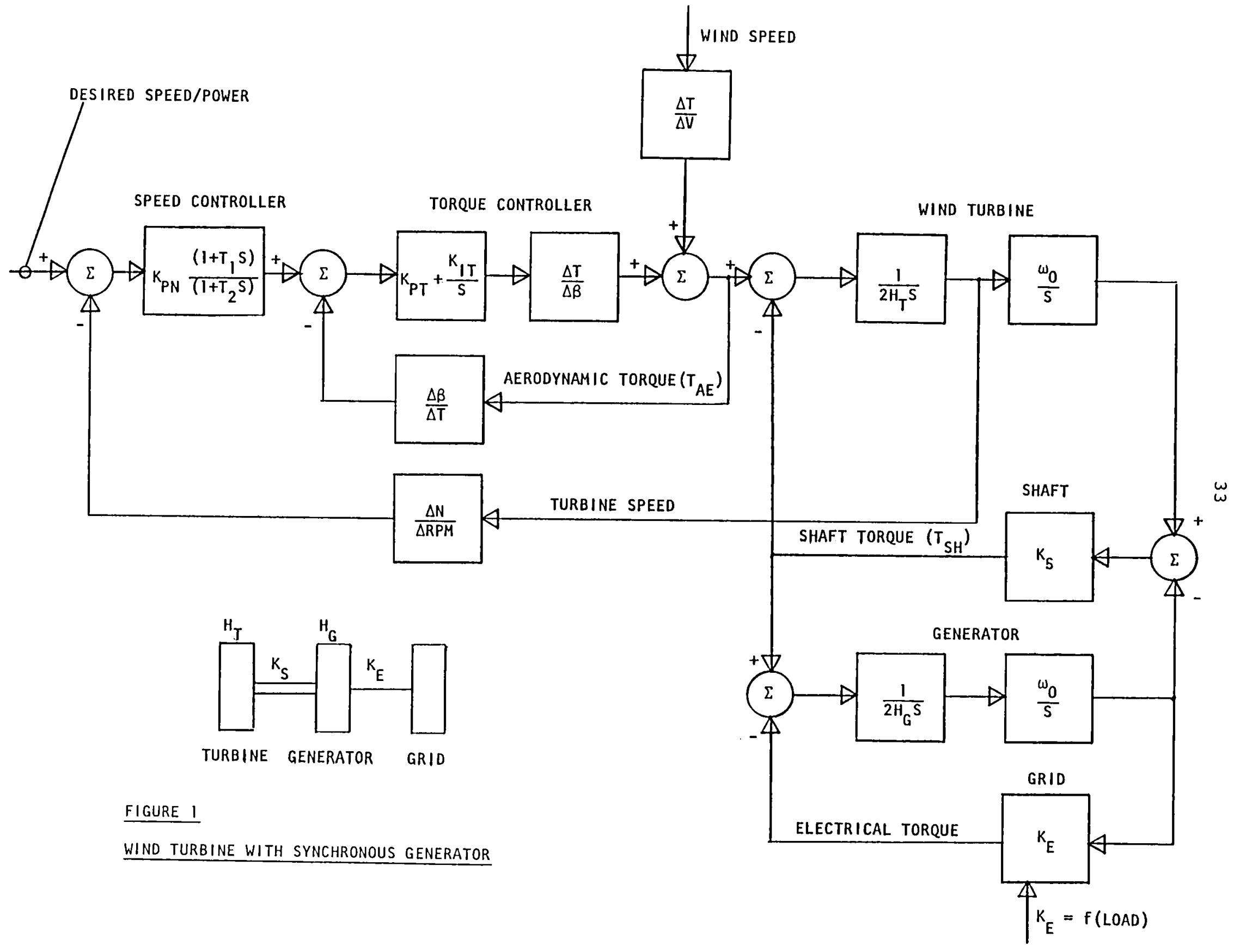




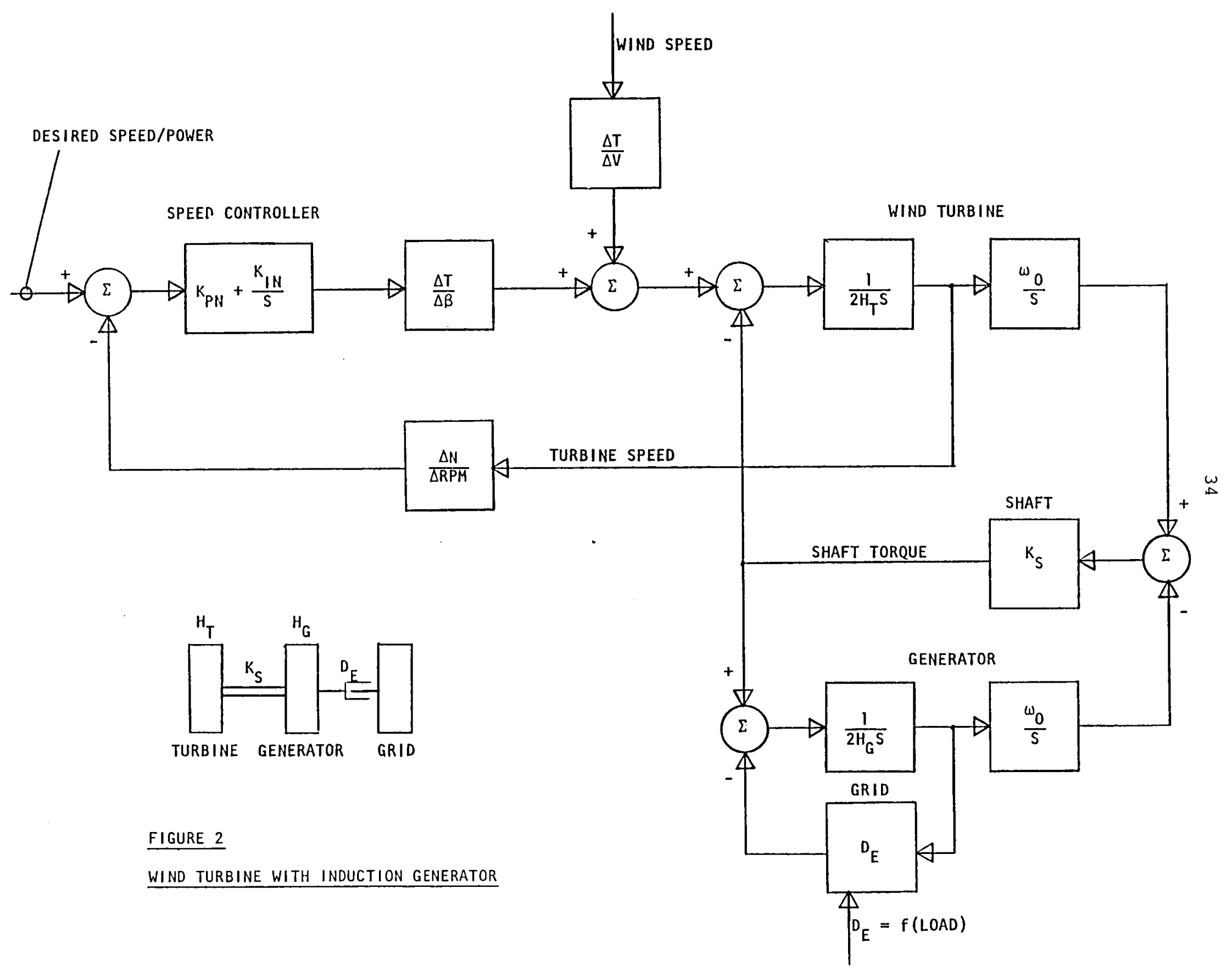




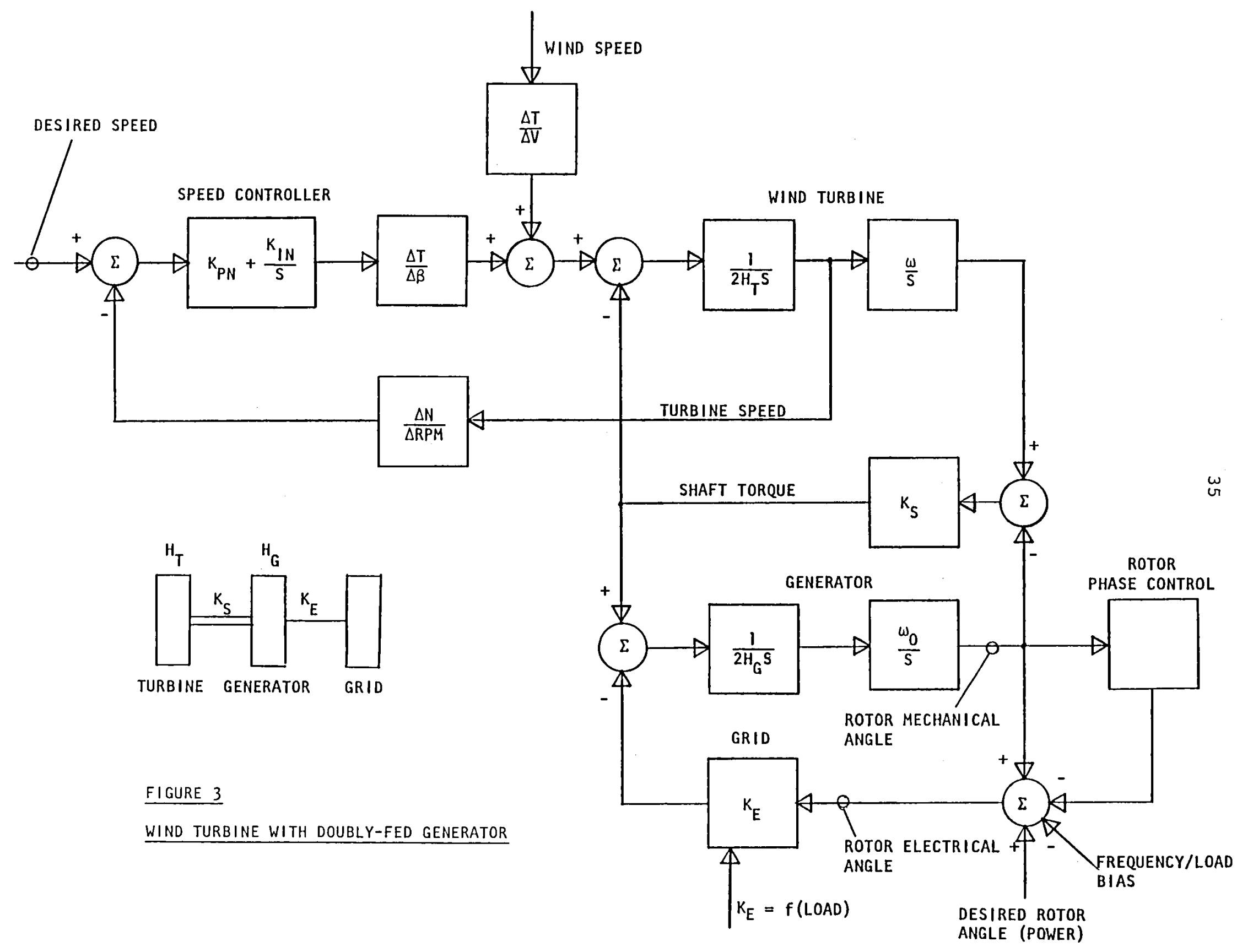




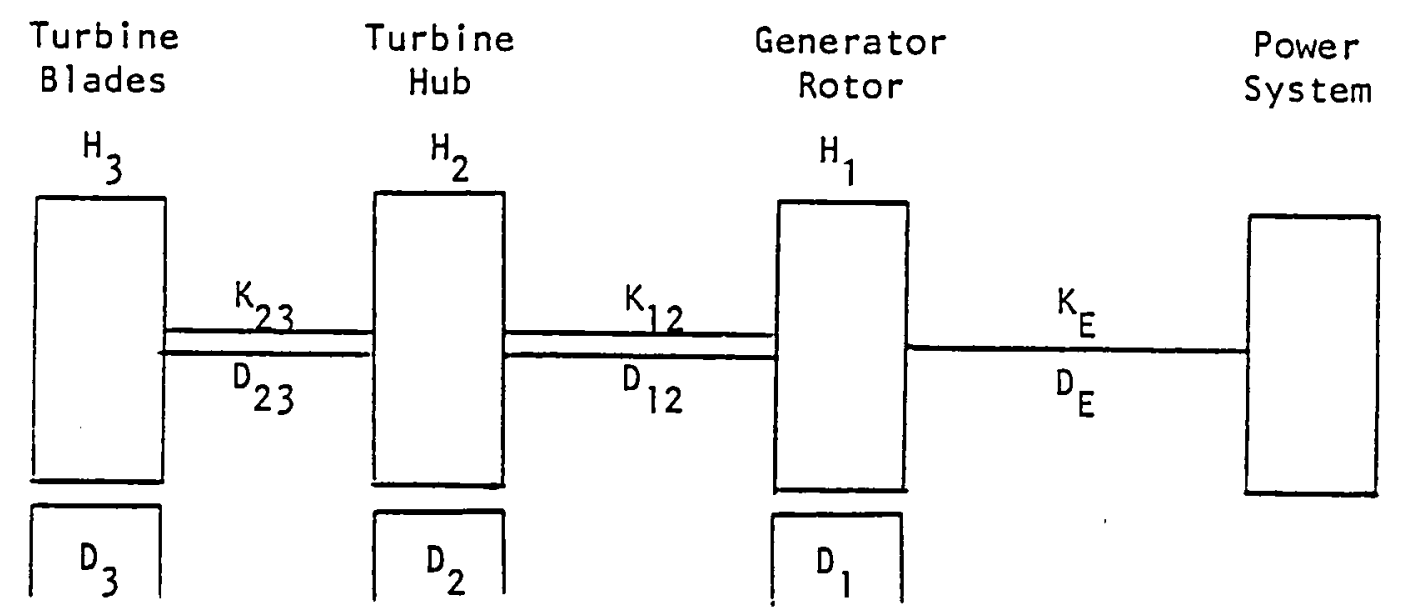

All values in per unit on machine base ( 3.125 MVA) and referred to high speed shaft.

INERTIA
[SECONDS]

$H_{1}=0.562$

$H_{2}=0.384$

$\mathrm{H}_{3}=15.34$
STIFFNESS

[PU TORQUE/EL RAD]
DAMPING

[PU TORQUE/PU SPEED]

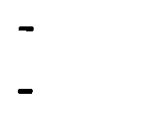

$D_{1}=0.029$

$D_{2}=0.009$

$D_{3}=0.007$

$D_{12}=1.467$

$D_{23}=46.94$

Source: Boeing/NASA (except modification of $k_{12}$ )

Note: For synchronous generator $k_{12}=0.0646$

For induction and doubly-fed generator $k_{12}=0.646$

FIGURE 4

DRIVE TRAIN REPRESENTATION 

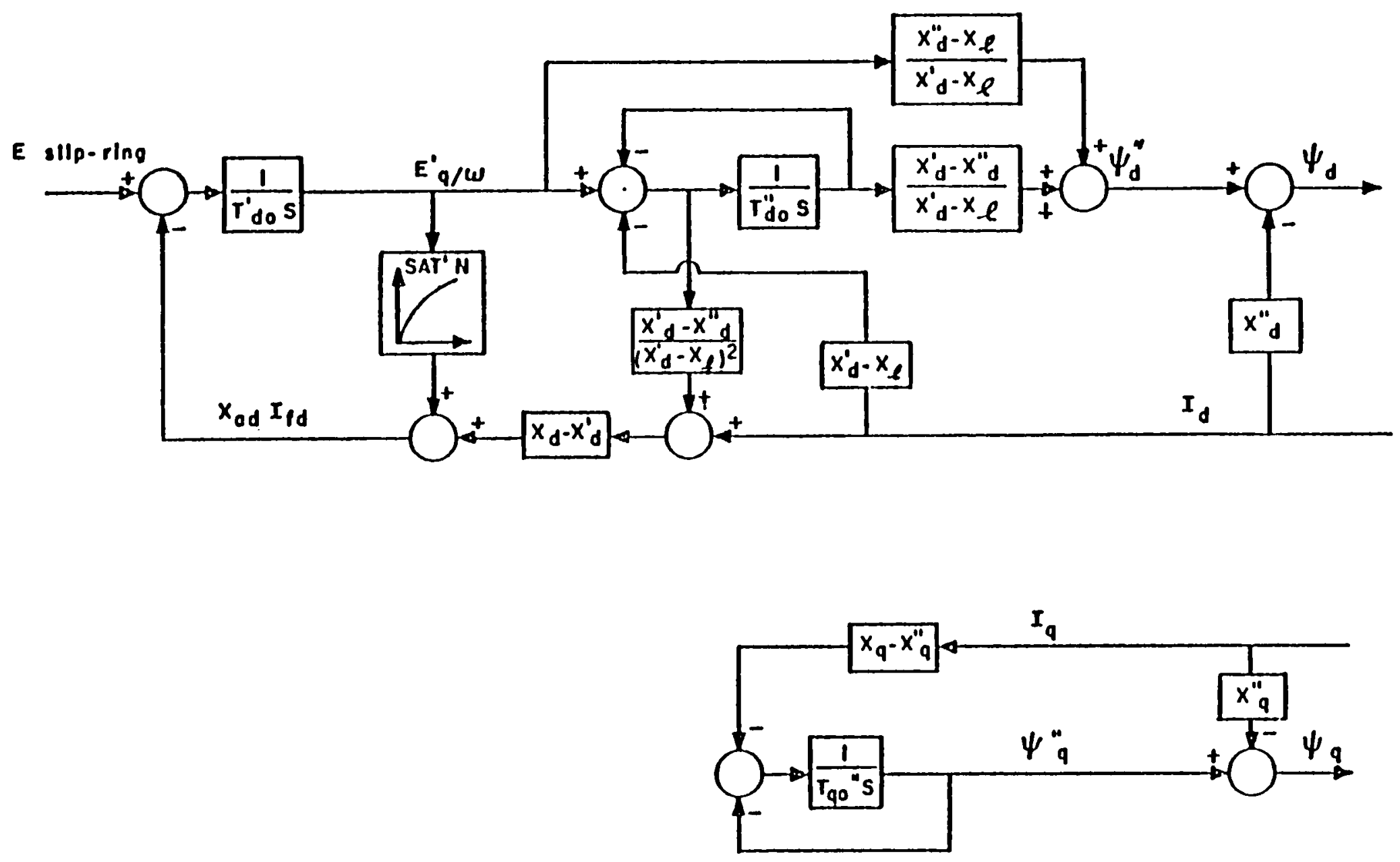

Source: Reference 3

FIGURE 5

MODEL OF SYNCHRONOUS MACHINE 


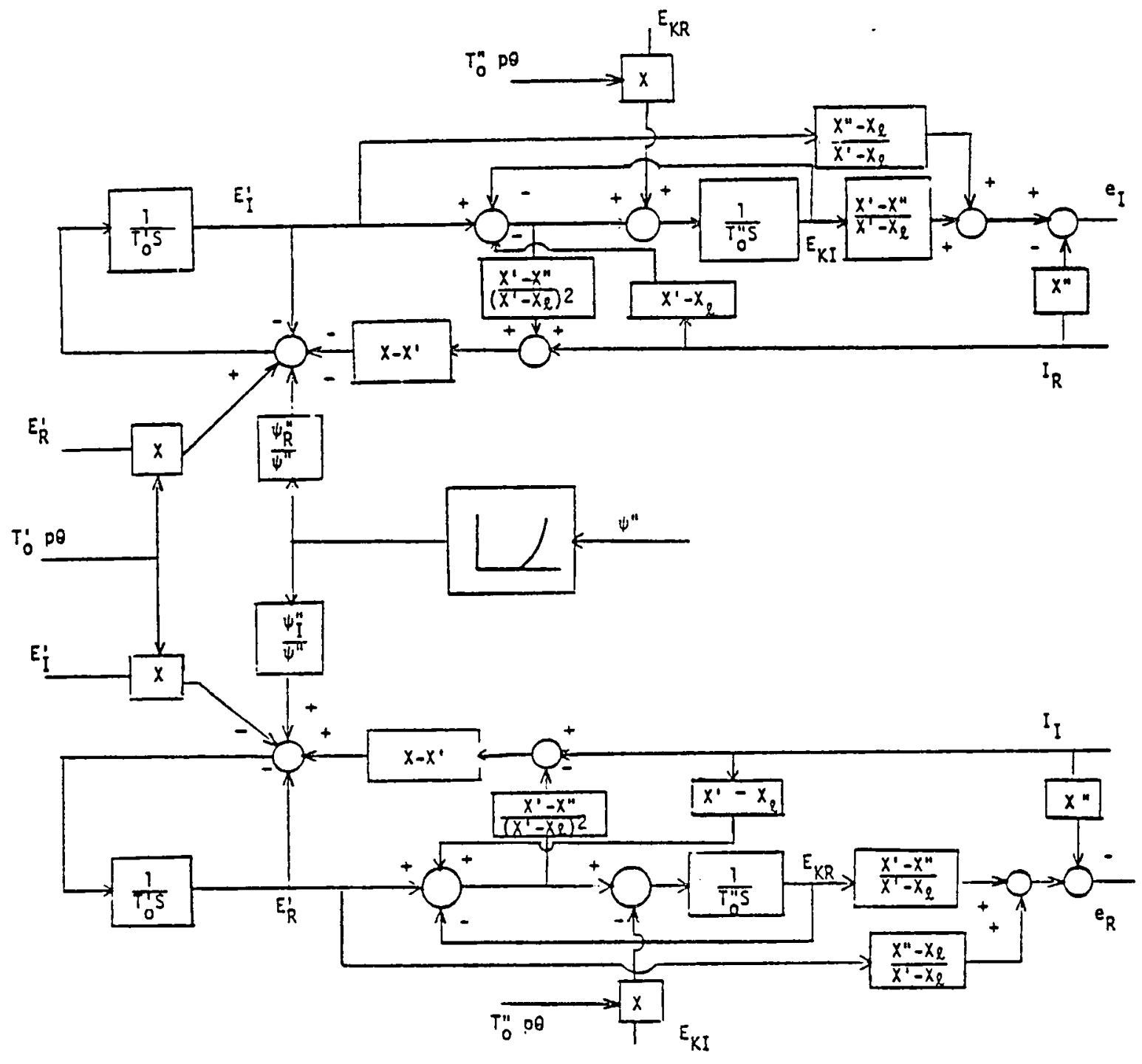

Source: Reference 6

\section{FIGURE 6}

MODEL OF INDUCTION AND DOUBLY-FED MACHINES

WITH VARIABLES REFERENCED TO SYNCHRONOUSLY ROTATING PHASOR 
39

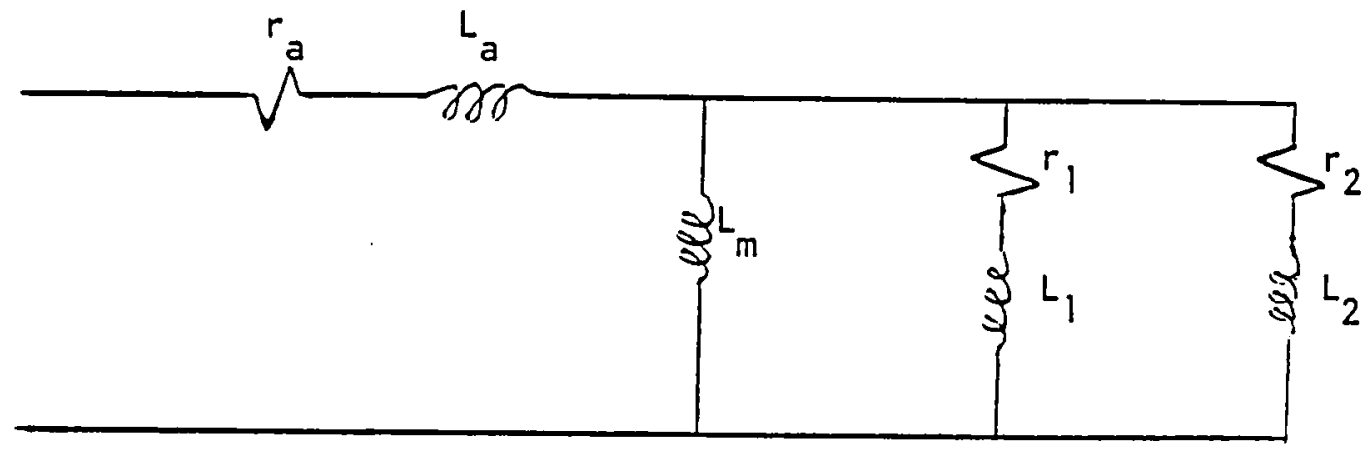

$$
\begin{aligned}
& T_{0}^{\prime}=\frac{L_{1}+L_{m}}{\omega_{0} r_{1}} \\
& T_{0}^{\prime \prime}=\frac{\frac{L_{m} L_{1}}{L_{m}+L_{1}}+L_{2}}{\omega_{0} r_{2}} \\
& x^{\prime}=\left(L_{a}+L_{m}\right) \omega_{0} \\
& x^{\prime}=\left(L_{a}+\frac{1}{\frac{1}{L_{m}}+\frac{1}{L_{1}}}\right) \omega_{0} \\
& x^{\prime \prime}=\left(L_{a}+\frac{I}{\frac{I}{L_{m}}+\frac{1}{L_{1}}+\frac{1}{L_{2}}}\right) \omega_{0} \\
& x_{l}=L_{a} \omega_{0}
\end{aligned}
$$

FIGURE 7

MODEL PARAMETERS FOR INDUCTION AND DOUBLY -FED GENERATORS DERIVED FROM CONVENTIONAL INDUCTION MACHINE CONSTANTS 


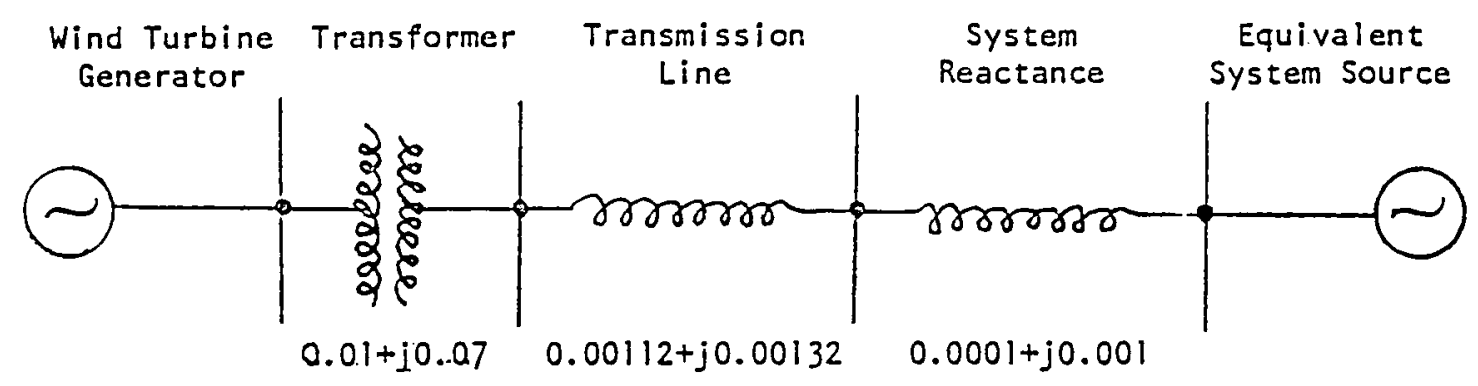

(a) Wind Turbine Generator Connected to Strong Electrical System

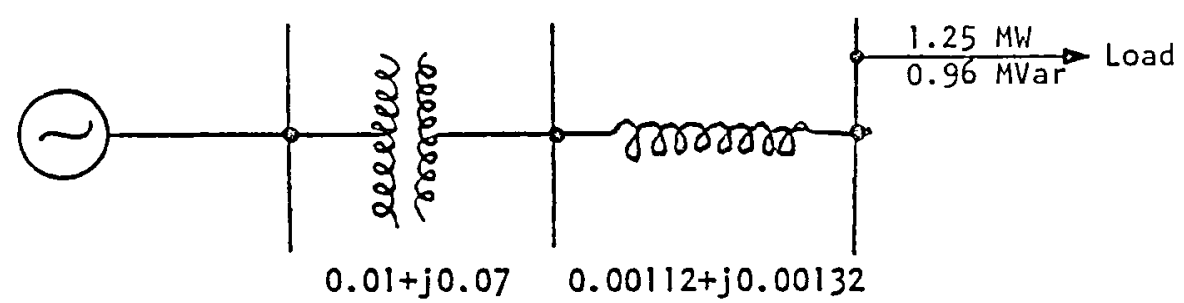

(b) Wind Turbine Generator in Isolated System (Synchronous and Doubly-Fed Generator)

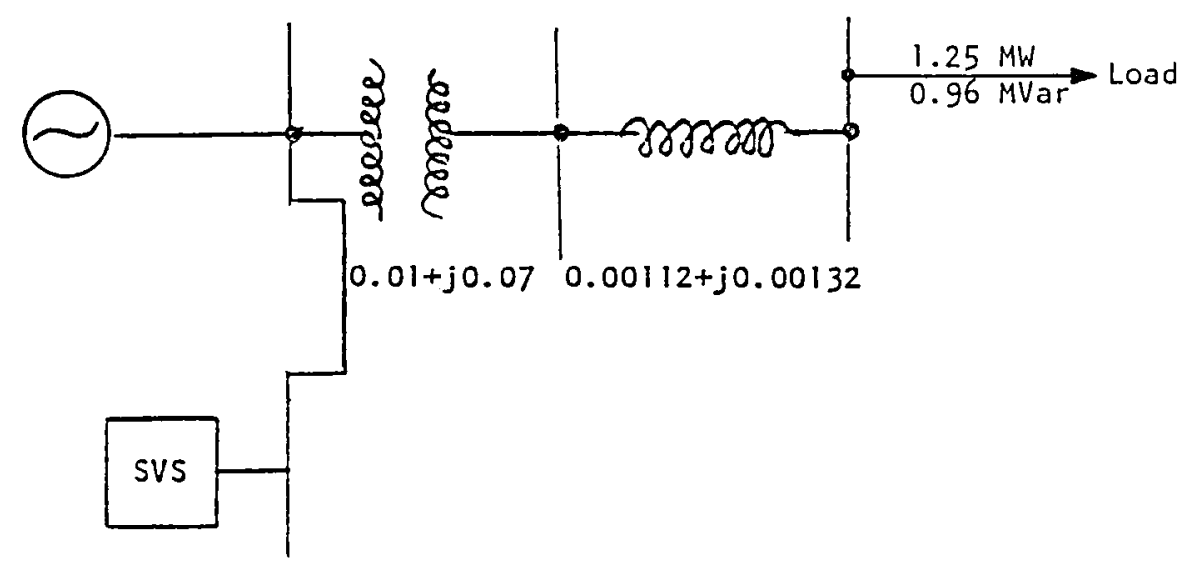

Static Var

Supply

(c) Wind Turbine Generator in Isolated System (Induction Generator)

\section{FIGURE 8}

ELECTRICAL SYSTEM REPRESENTATION (3.125 MVA BaSe) 


\begin{tabular}{|c|l|l|l|l|l|l|l|l|}
\hline$B$ & 2.69 & 3.76 & 4.70 & 5.87 & 7.83 & 9.40 & 11.75 & 15.66 \\
\hline-1 & 0.008 & 0.06 & 0.175 & 0.303 & 0.412 & 0.420 & 0.265 & 0.045 \\
\hline 0 & 0.011 & 0.076 & 0.185 & 0.300 & 0.405 & 0.423 & 0.295 & 0.015 \\
\hline+2 & 0.018 & 0.10 & 0.185 & 0.285 & 0.385 & 0.41 & 0.36 & 0.05 \\
\hline+4 & 0.025 & 0.11 & 0.175 & 0.265 & 0.355 & 0.382 & 0.34 & 0.123 \\
\hline+6 & 0.036 & 0.108 & 0.165 & 0.243 & 0.32 & 0.335 & 0.28 & 0.045 \\
\hline+8 & 0.046 & 0.1010 & 0.145 & 0.220 & 0.28 & 0.275 & 0.195 & -0.115 \\
\hline+10 & 0.053 & 0.09 & 0.13 & 0.19 & 0.235 & 0.21 & 0.08 & -0.335 \\
\hline+12 & 0.053 & 0.078 & 0.11 & 0.165 & 0.182 & 0.13 & -0.05 & -0.45 \\
\hline+14 & 0.05 & 0.066 & 0.09 & 0.135 & 0.125 & 0.045 & -0.2 & -0.45 \\
\hline-16 & 0.044 & 0.054 & 0.07 & 0.100 & 0.065 & -0.05 & -0.373 & -0.45 \\
\hline
\end{tabular}

Source: Boeing/NASA

FIGURE 9

MOD-2 WIND TURBINE POWER COEFFICIENT $C_{p}$ 


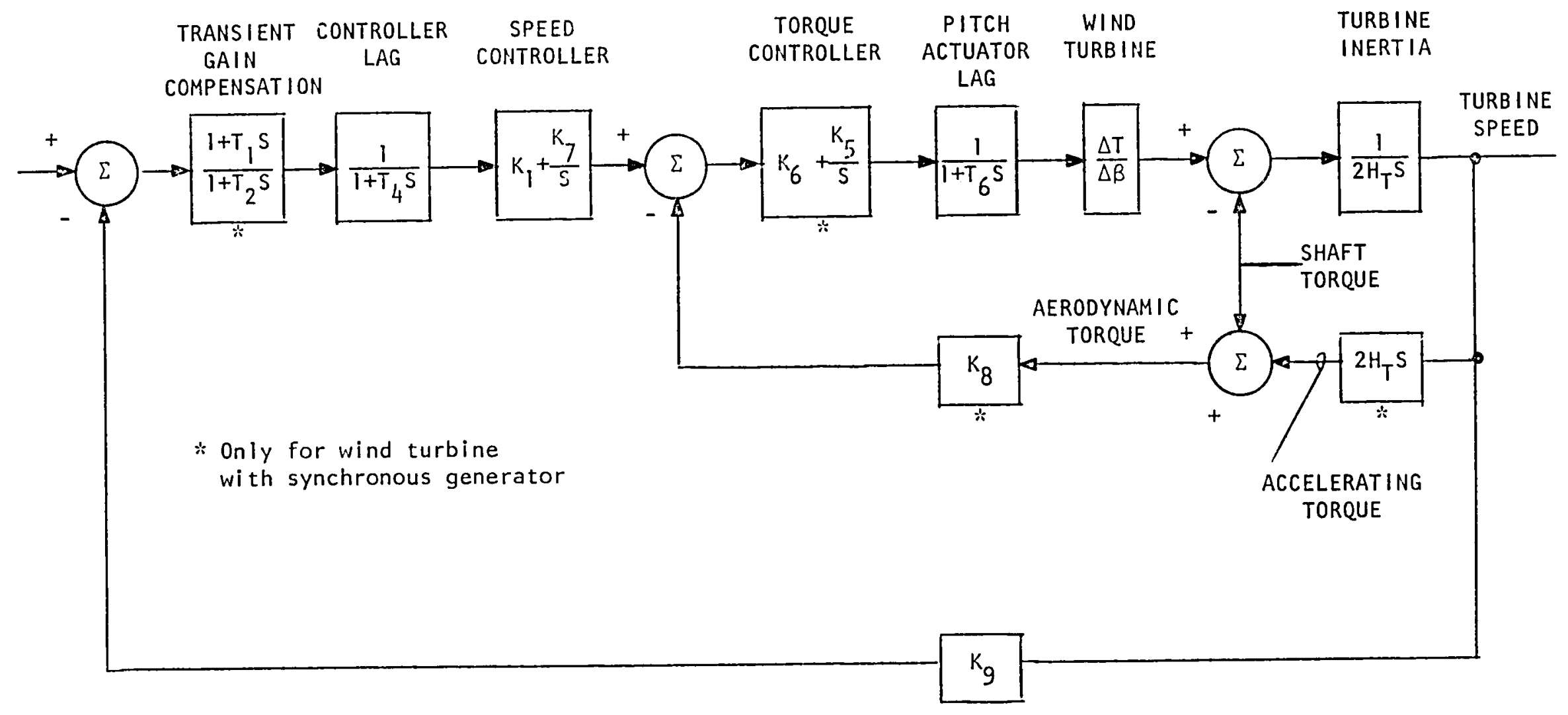

\section{FIGURE 10}

WIND TURBINE CONTROL 


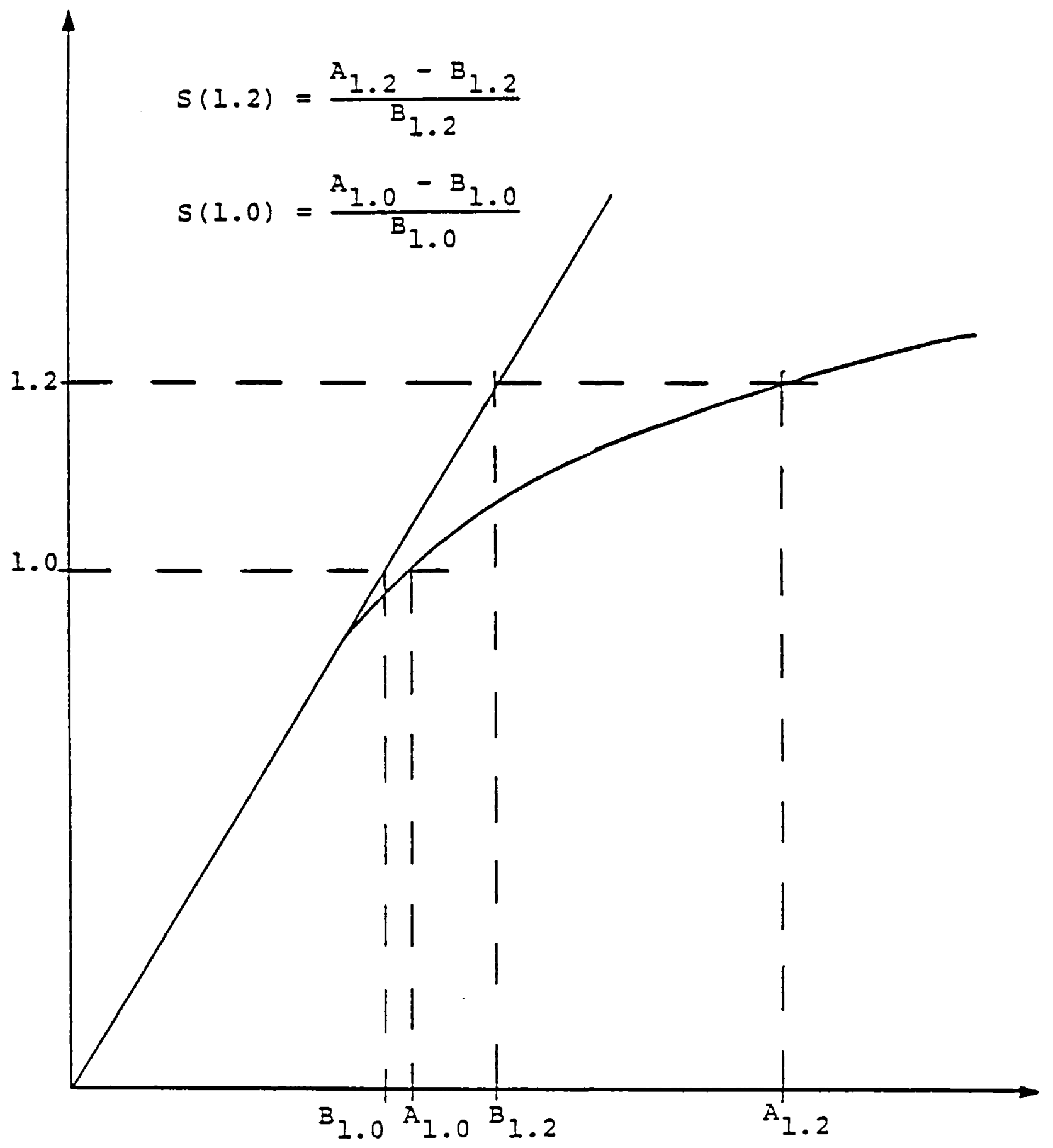

FIGURE 11

GENERATOR SATURATION 


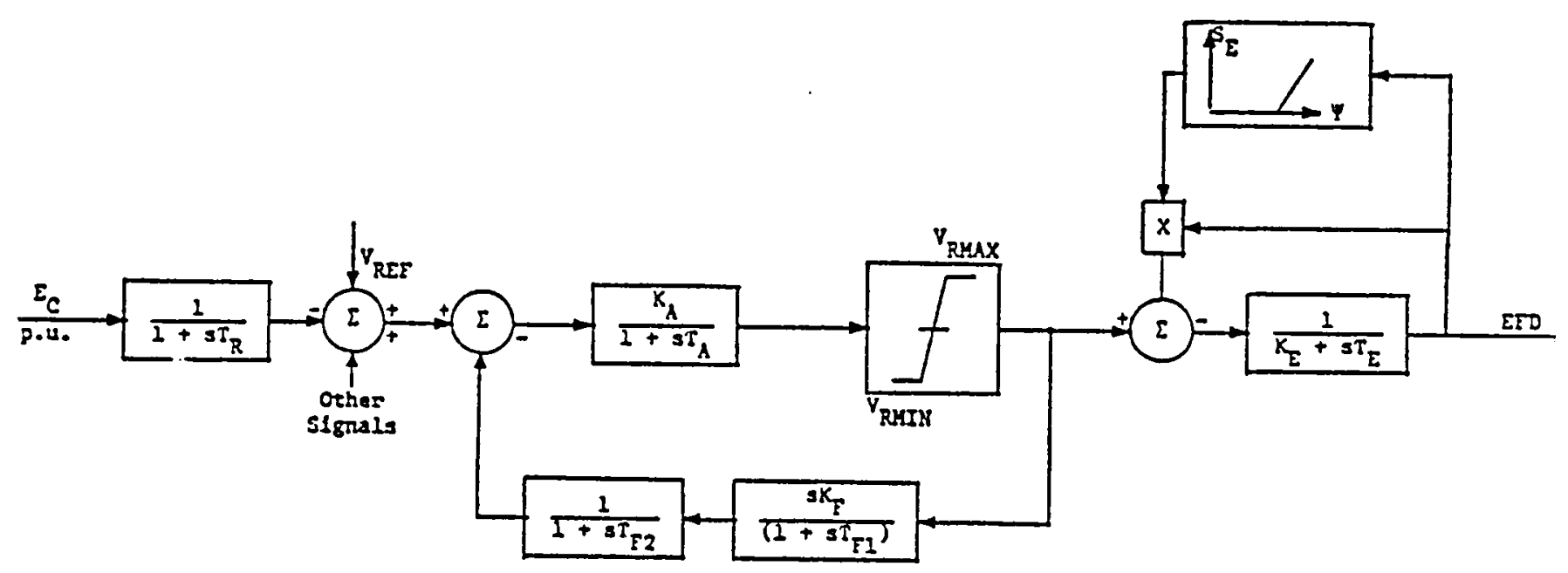

$$
\begin{array}{ll}
T_{R} & =0.05 \mathrm{sec} \\
K_{A} & =975 \\
T_{A} & =0.26 \mathrm{sec} \\
V_{R M A X} & =+19.0 \\
V_{R M I N} & =-19.0 \\
K_{E} & =1.16 \\
T_{E} & =0.30 \\
K_{F} & =0.08 \\
T_{F I} & =0.26 \\
T_{F 2} & =1.5 \\
E_{1} & =8.7 \\
S_{E}\left(E_{1}\right) & =0.16 \\
E_{2} & =11.5 \\
S_{E}\left(E_{2}\right) & =0.48
\end{array}
$$




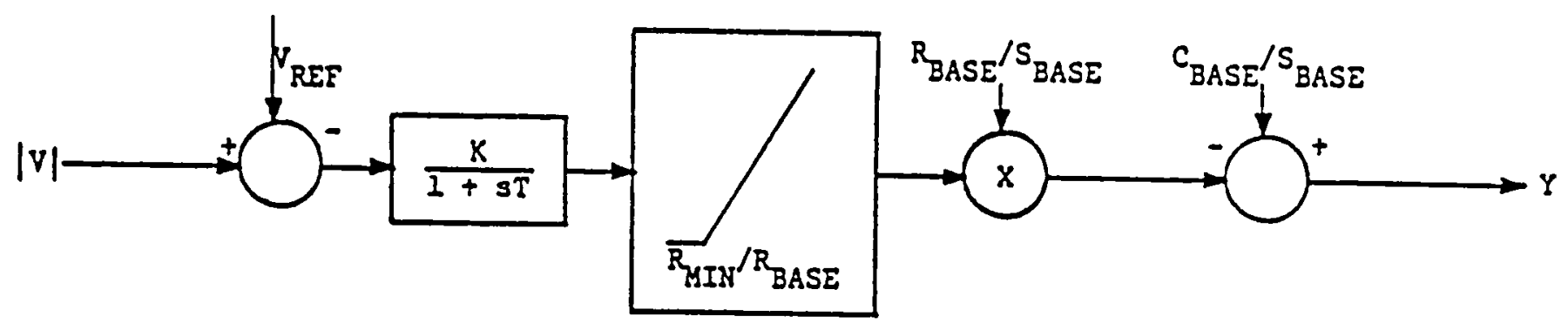

$$
\begin{array}{lll}
K & =50.0 & \\
T & =5.0 & \\
R_{M 1 N} & =0 & \text { (Reactor Minimum MVAR) } \\
C_{\text {BASE }} & =3.125 & \text { (Capacitor MVAR) }
\end{array}
$$




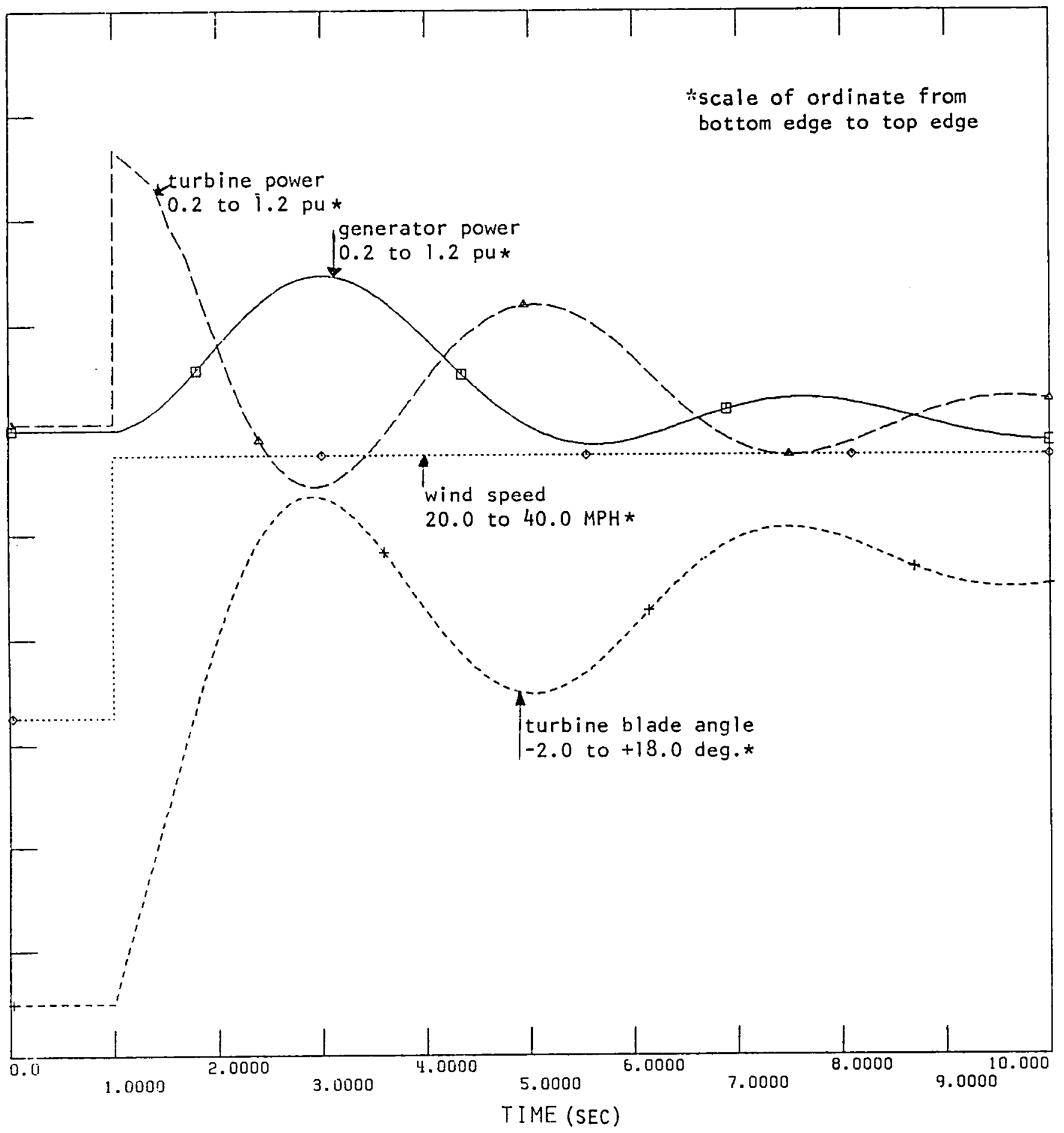

SI-A SYNCHRONOUS GENERATOR

STRONG ELECTRICAL SYSTEM

5 MPH WIND SPEED INCREASE 


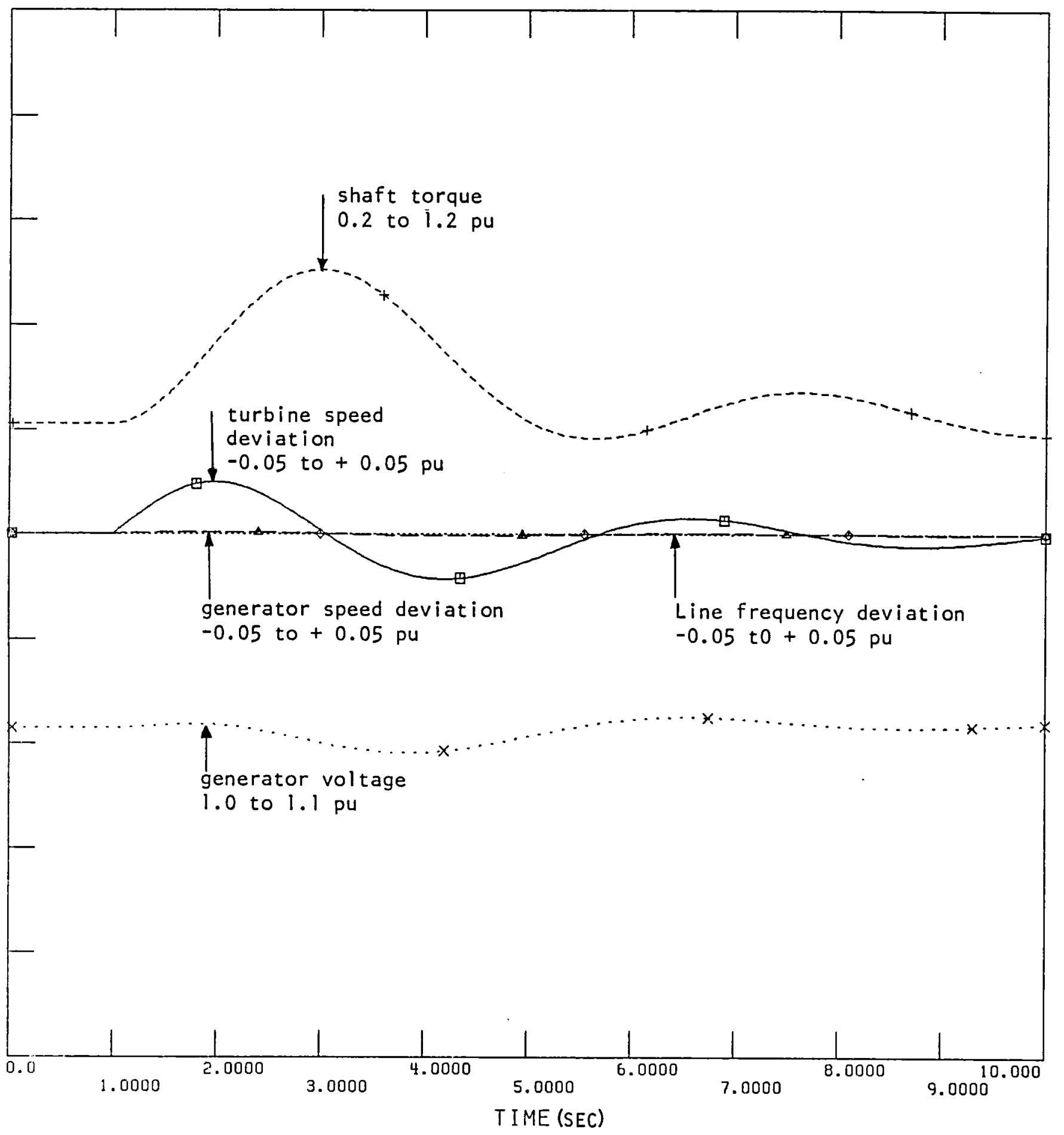

SI-B SYNCHRONOUS GENERATOR

STRONG ELECTRICAL SYSTEM

5 MPH WIND SPEED INCREASE 


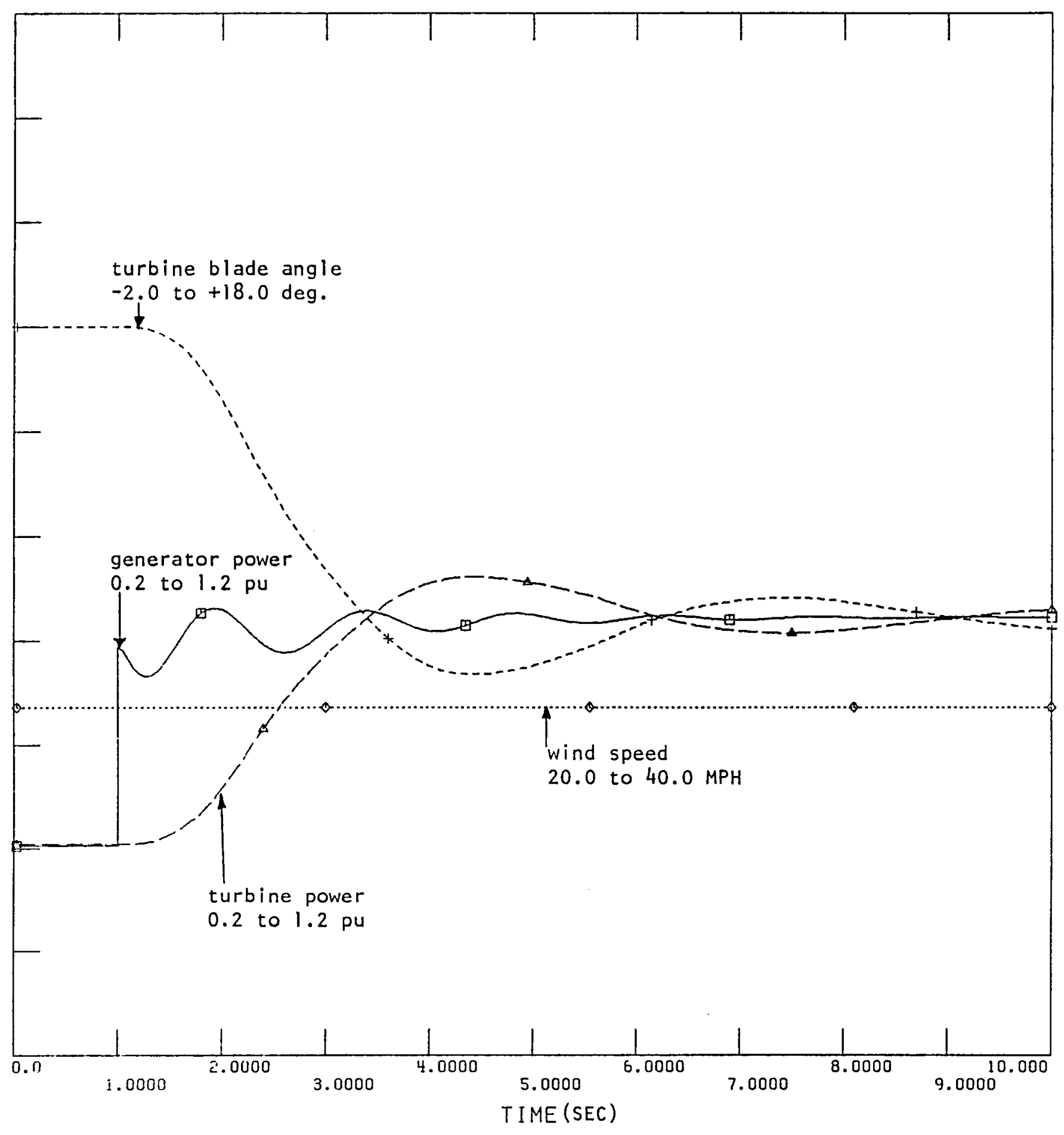

S2-A SYNCHRONOUS GENERATOR ISOLATED ELECTRICAL SYSTEM

LOAD INCREASE FROM 50 to $75 \%$ OF RATED 


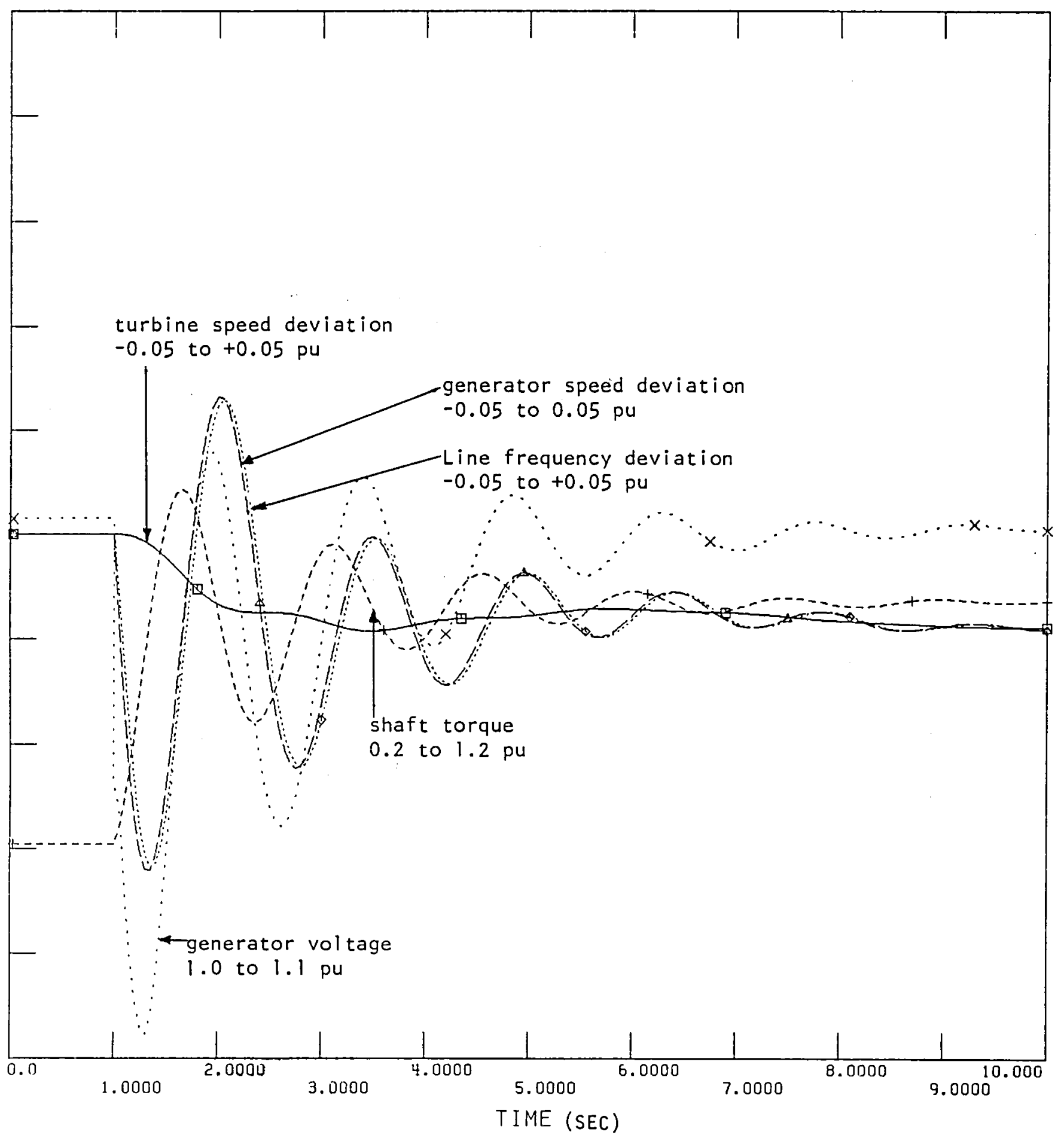

S2-B SYNCHRONOUS GENERATOR

ISOLATED ELECTRICAL SYSTEM

LOAD INCREASE FROM 50 to $75 \%$ OF RATED 


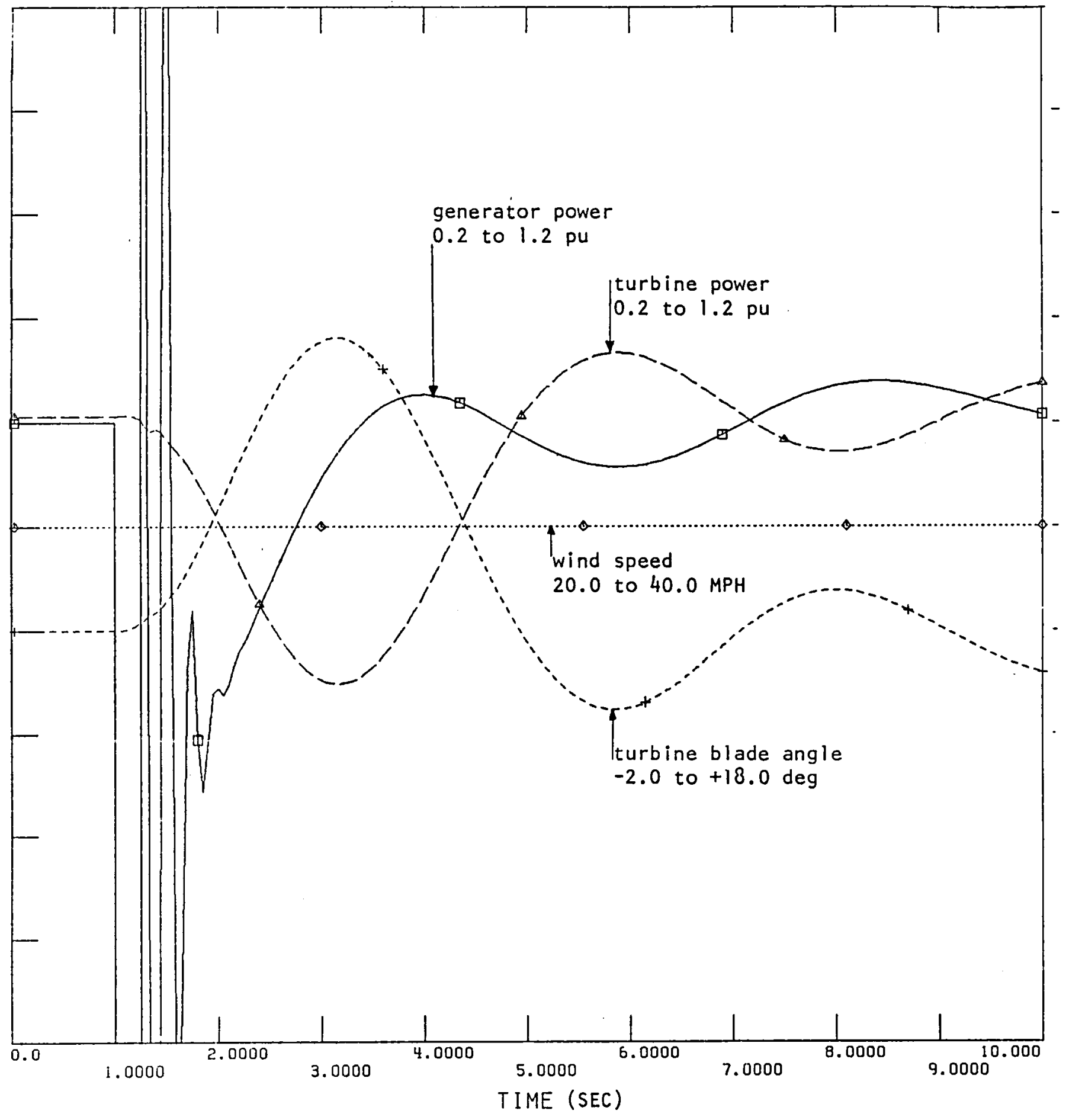

S3-A SYNCHRONOUS GENERATOR

STRONG ELECTRICAL SYSTEM

LOSS OF LOAD FOR 0.25 SEC 


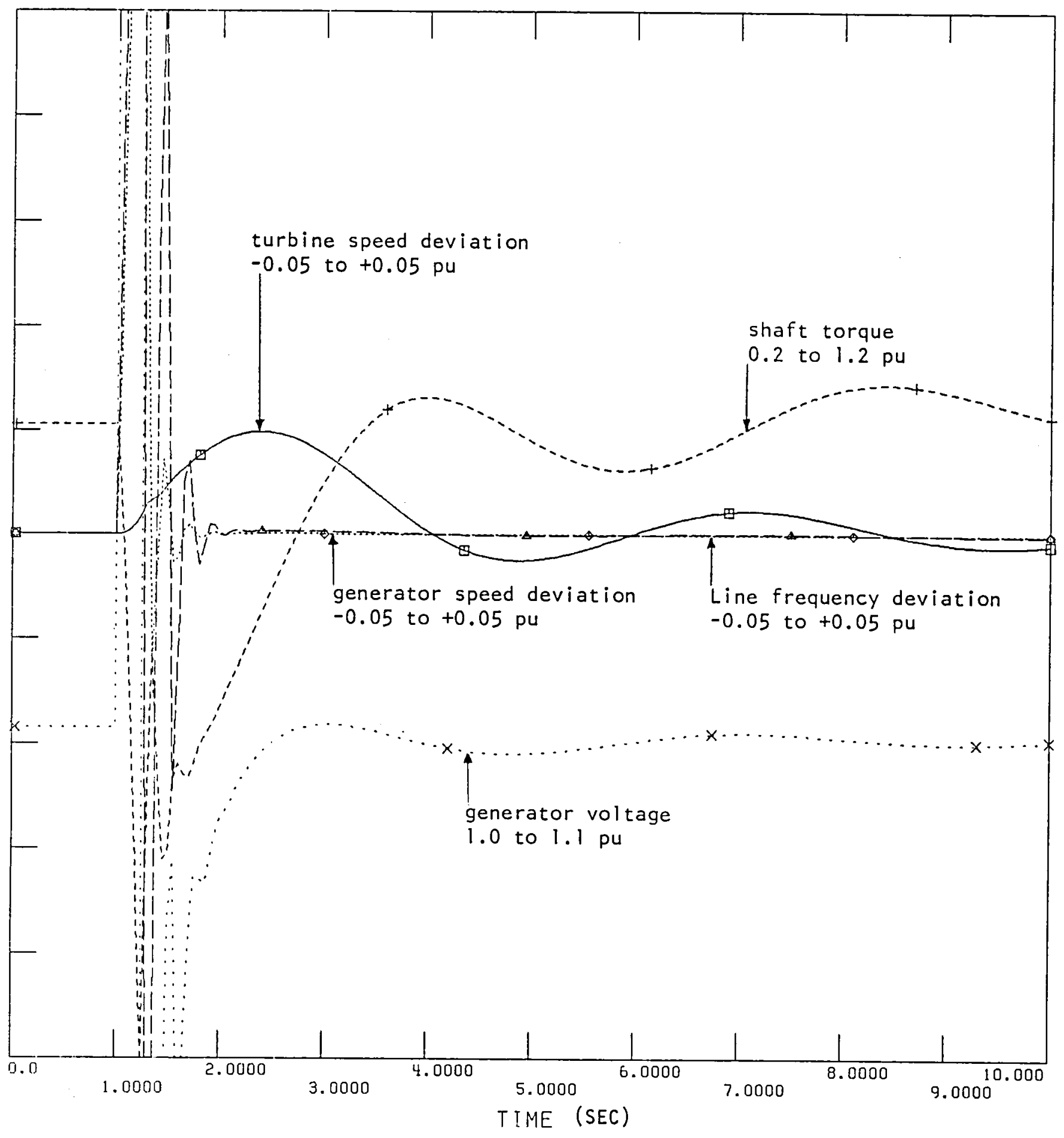

S3-B SYNCHRONOUS GENERATOR

STRONG ELECTRICAL SYSTEM

LOSS OF LOAD FOR 0.25 SEC 


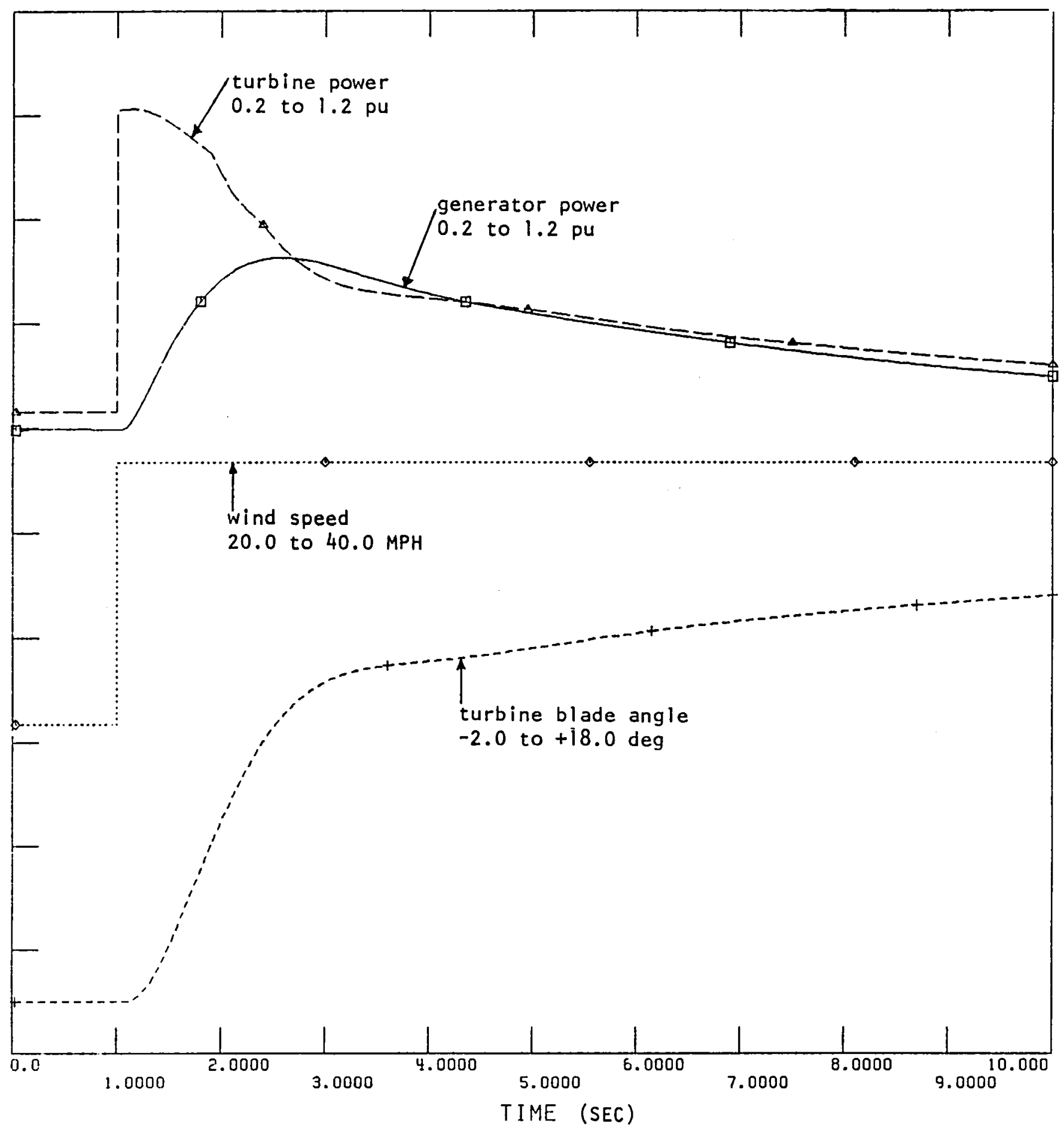

II-A INDUCTION GENERATOR

STRONG ELECTRICAL SYSTEM

5 MPH WIND SPEED INCREASE 


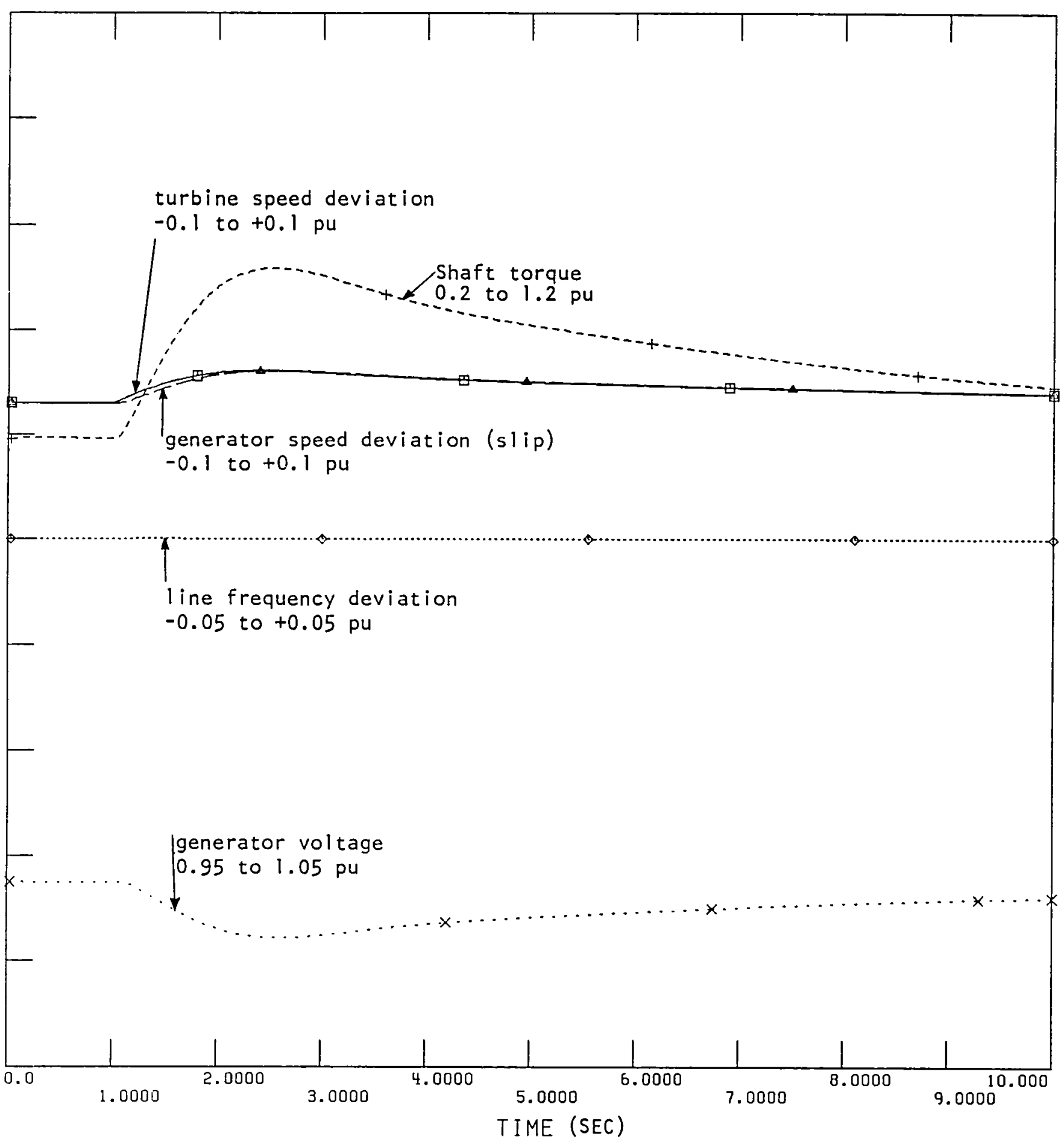

II-B INDUCTION GENERATOR

STRONG ELECRICAL SYSTEM

5 MPH WIND SPEED INCREASE 


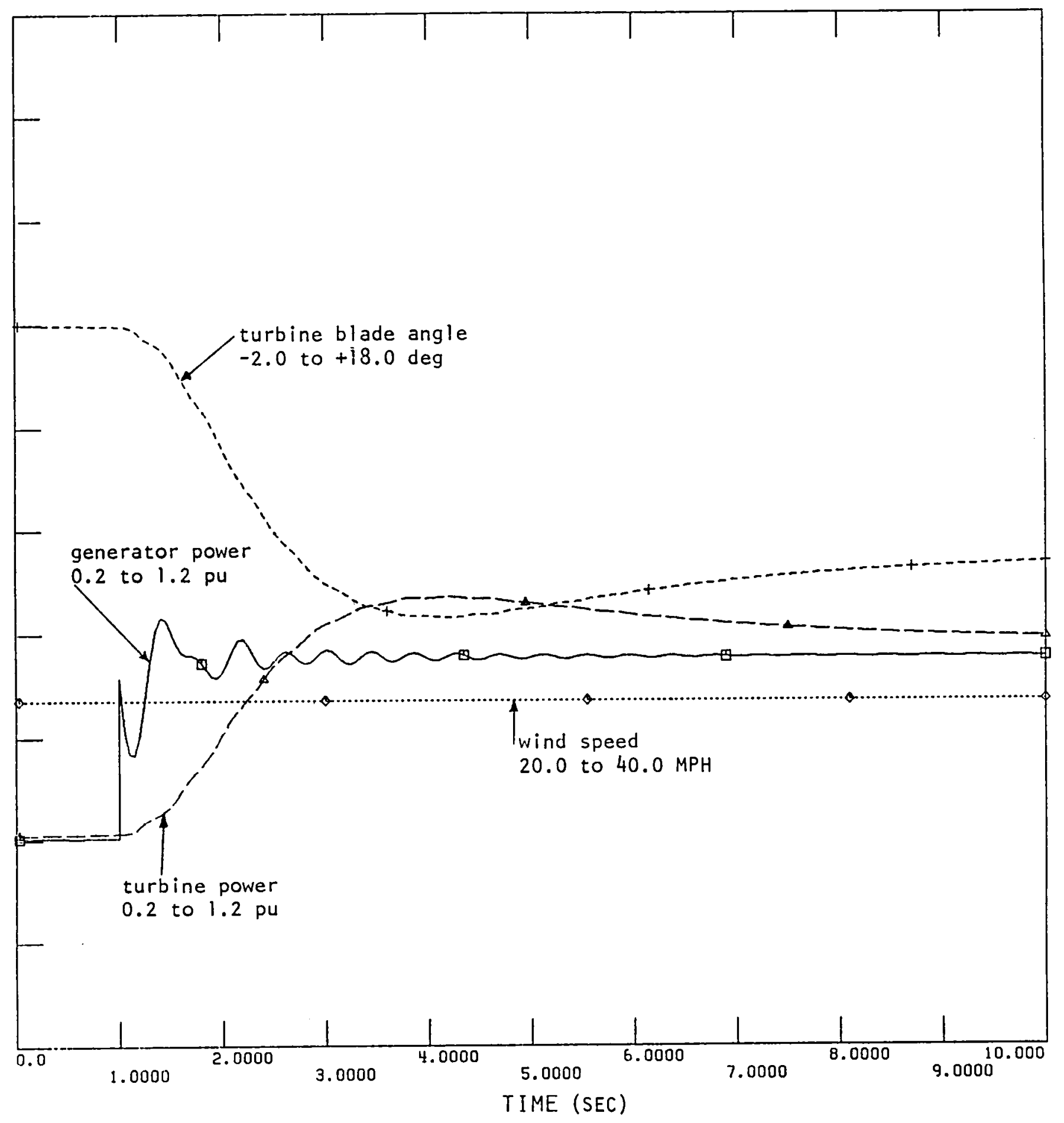

I2-A INDUCTION GENERATOR

ISOLATED ELECTRICAL SYSTEM

LOAD INCREASE FROM 50 to $75 \%$ OF RATED 


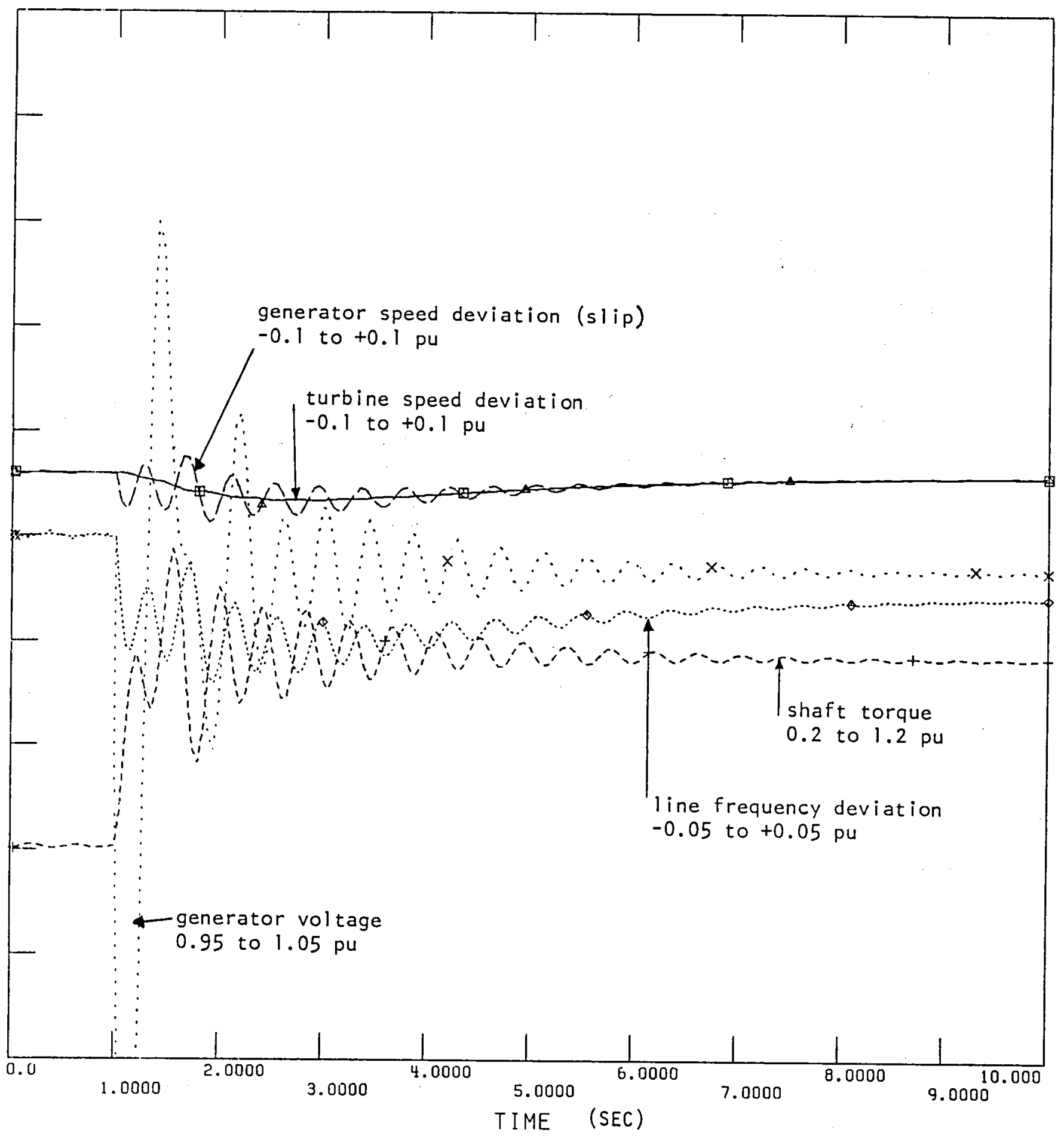

I2-B INDUCTION GENERATOR

ISOLATED ELECTRICAL SYSTEM

LOAD INCREASE FROM 50 to $75 \%$ OF RATED 


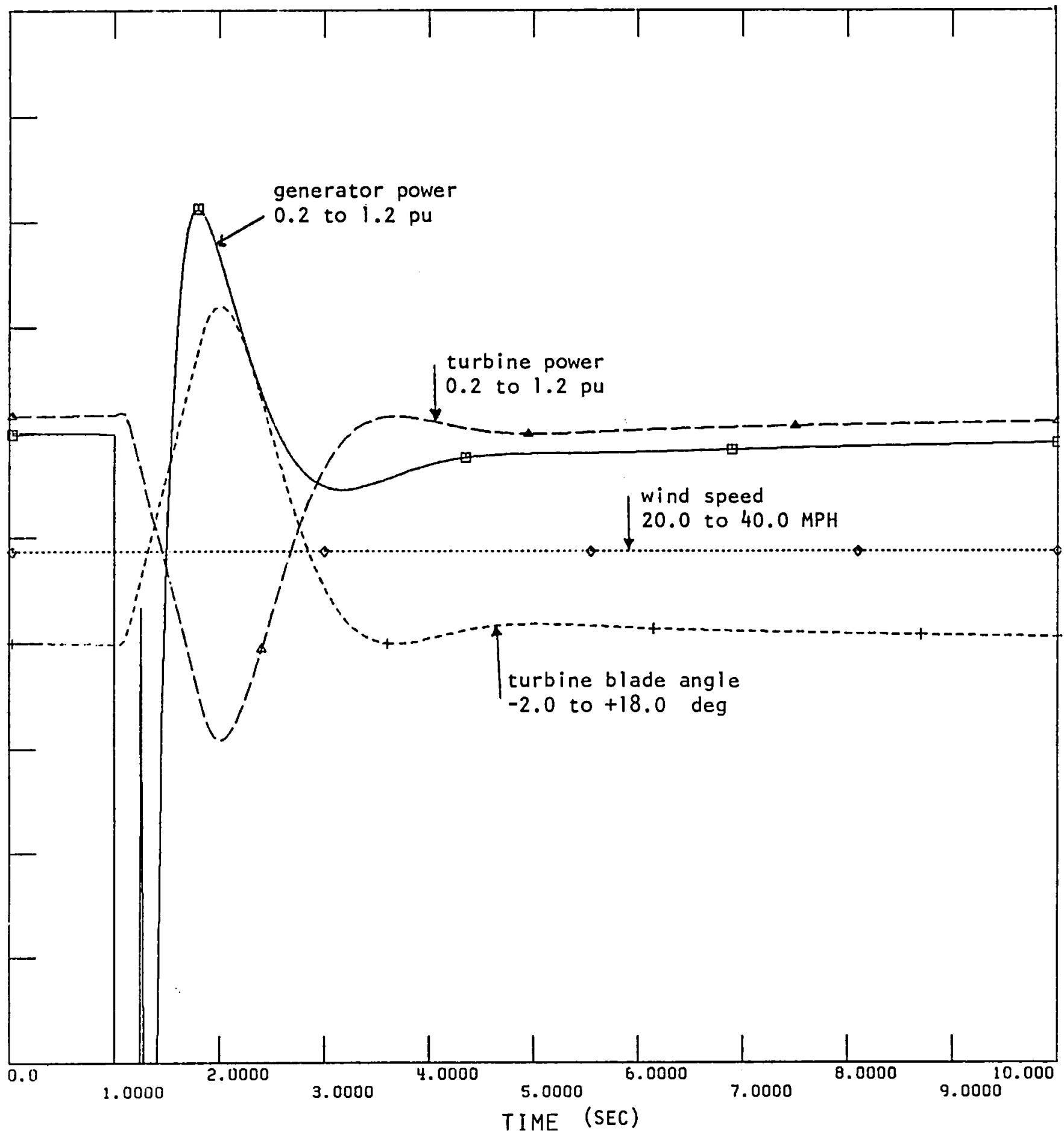

I3-A INDUCTION GENERATOR

STRONG ELECTRICAL SYSTEM

LOSS OF LOAD FOR 0.25 SEC 


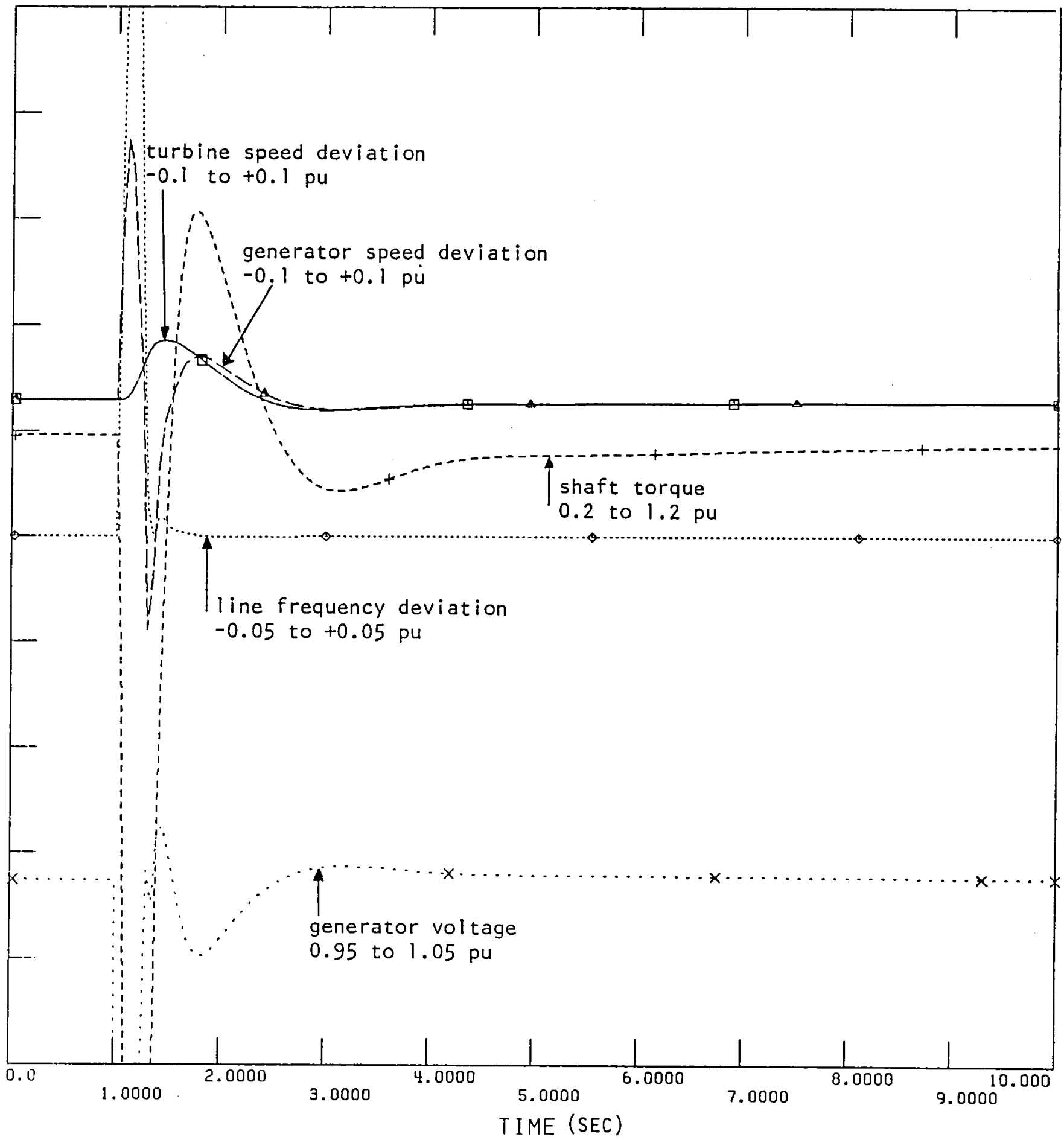

I3-B INDUCTION GENERATOR

STRONG ELECTRICAL SYSTEM

LOSS OF LOAD FOR 0.25 SEC 


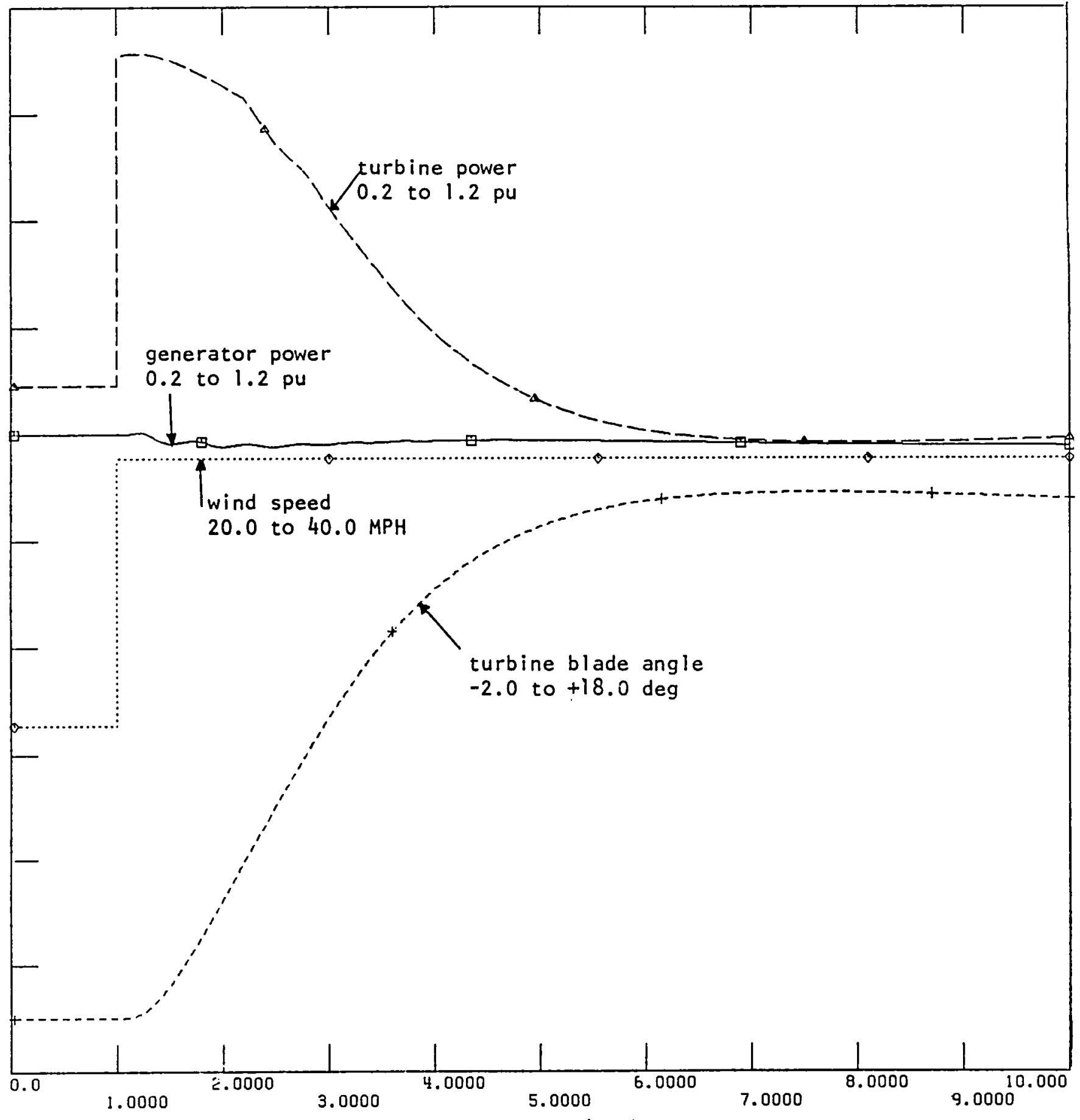

TIME (SEC)

\author{
DI-A DOUBLY-FED GENERATOR \\ STRONG ELECTRICAL SYSTEM \\ 5 MPH WIND SPEED INCREASE
}




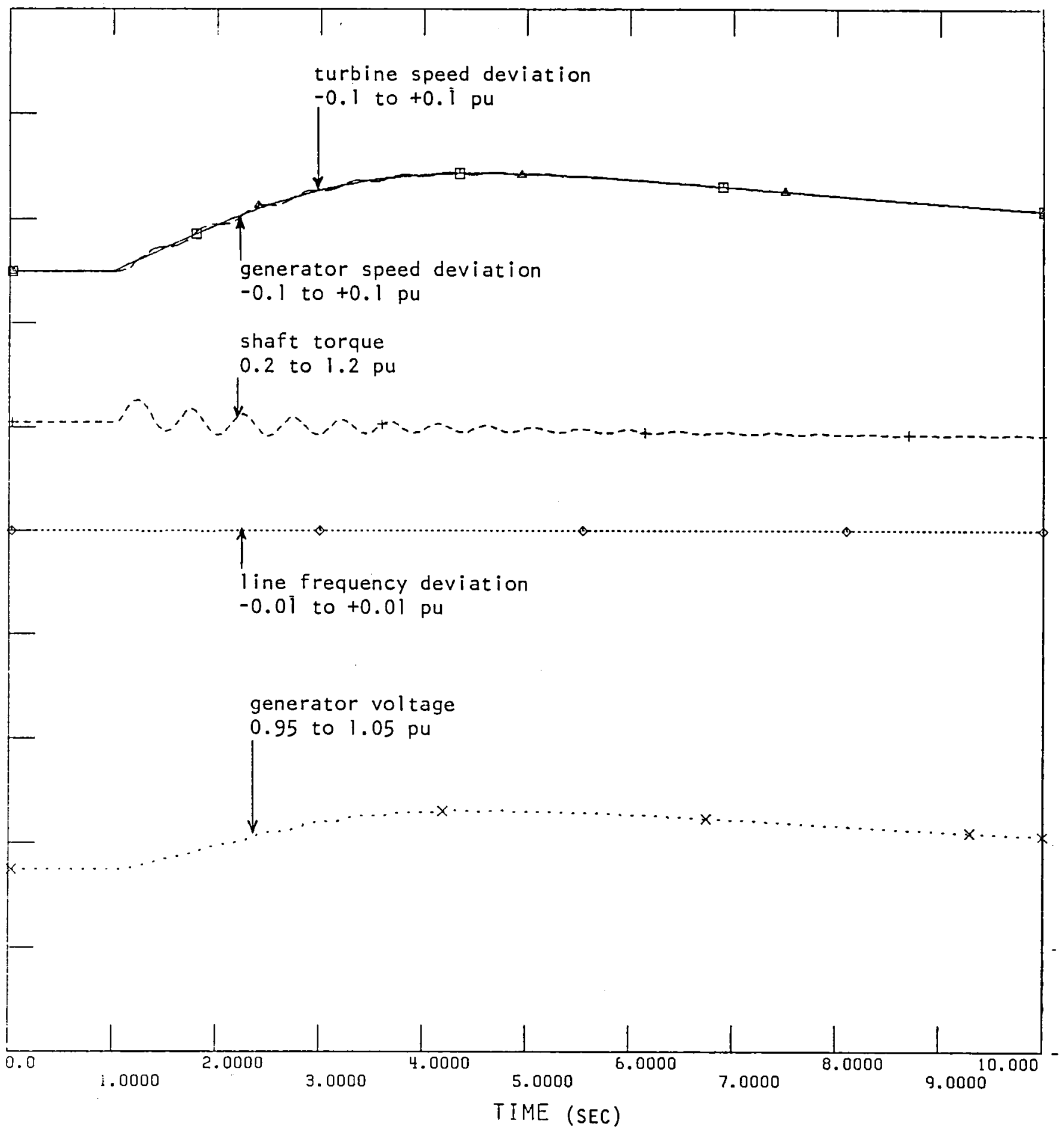

$$
\begin{array}{ll}
\text { DI-B } & \text { DOUBLY-FED GENERATOR } \\
& \text { STRONG ELECTRICAL SYSTEM } \\
& 5 \mathrm{MPH} \mathrm{WIND} \mathrm{SPEED} \mathrm{INCREASE}
\end{array}
$$




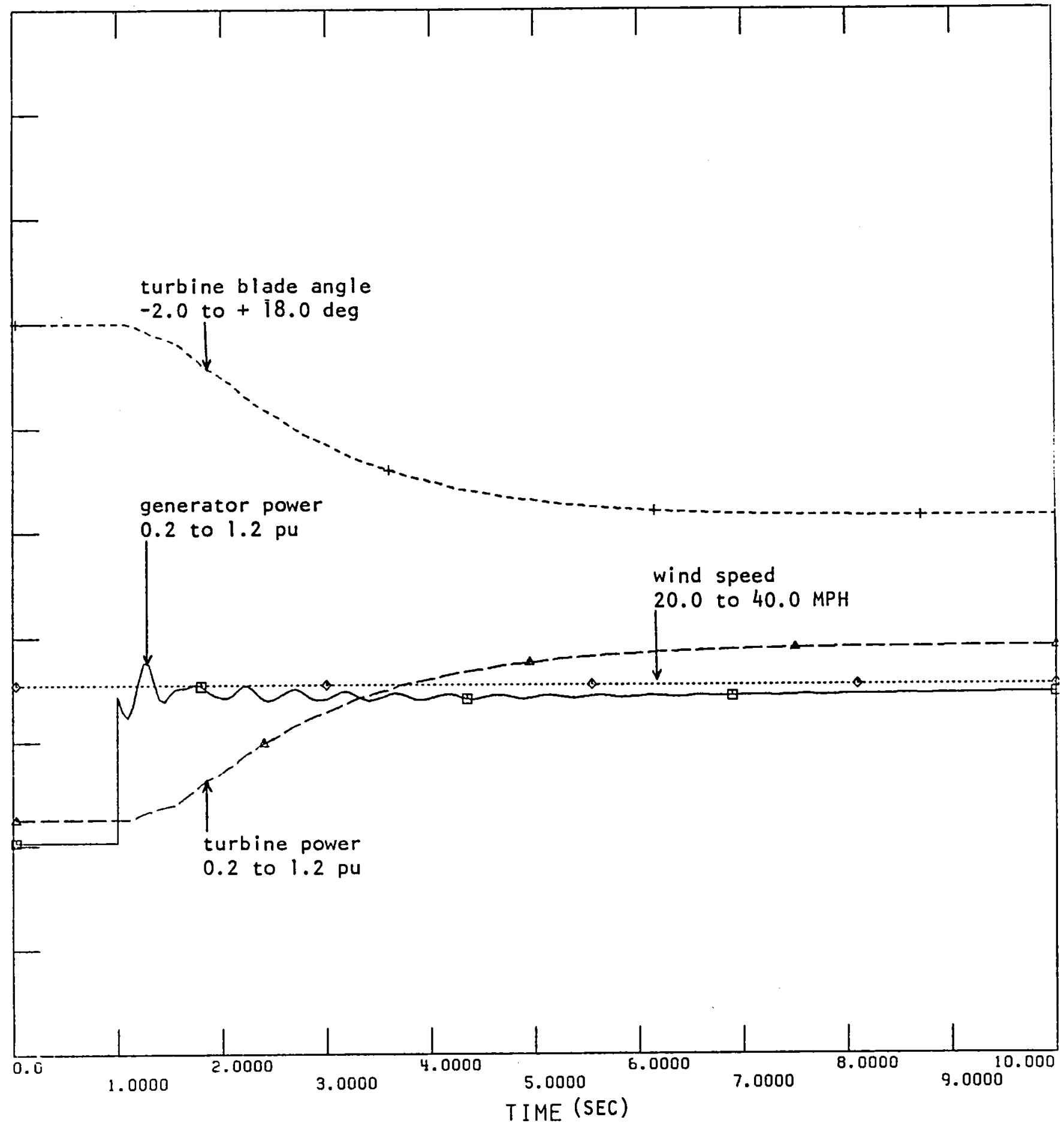

\author{
D2-A DOUBLY-FED GENERATOR \\ ISOLATED ELECTRICAL SYSTEM \\ LOAD INCREASE FROM 50 to $75 \%$ OF RATED
}




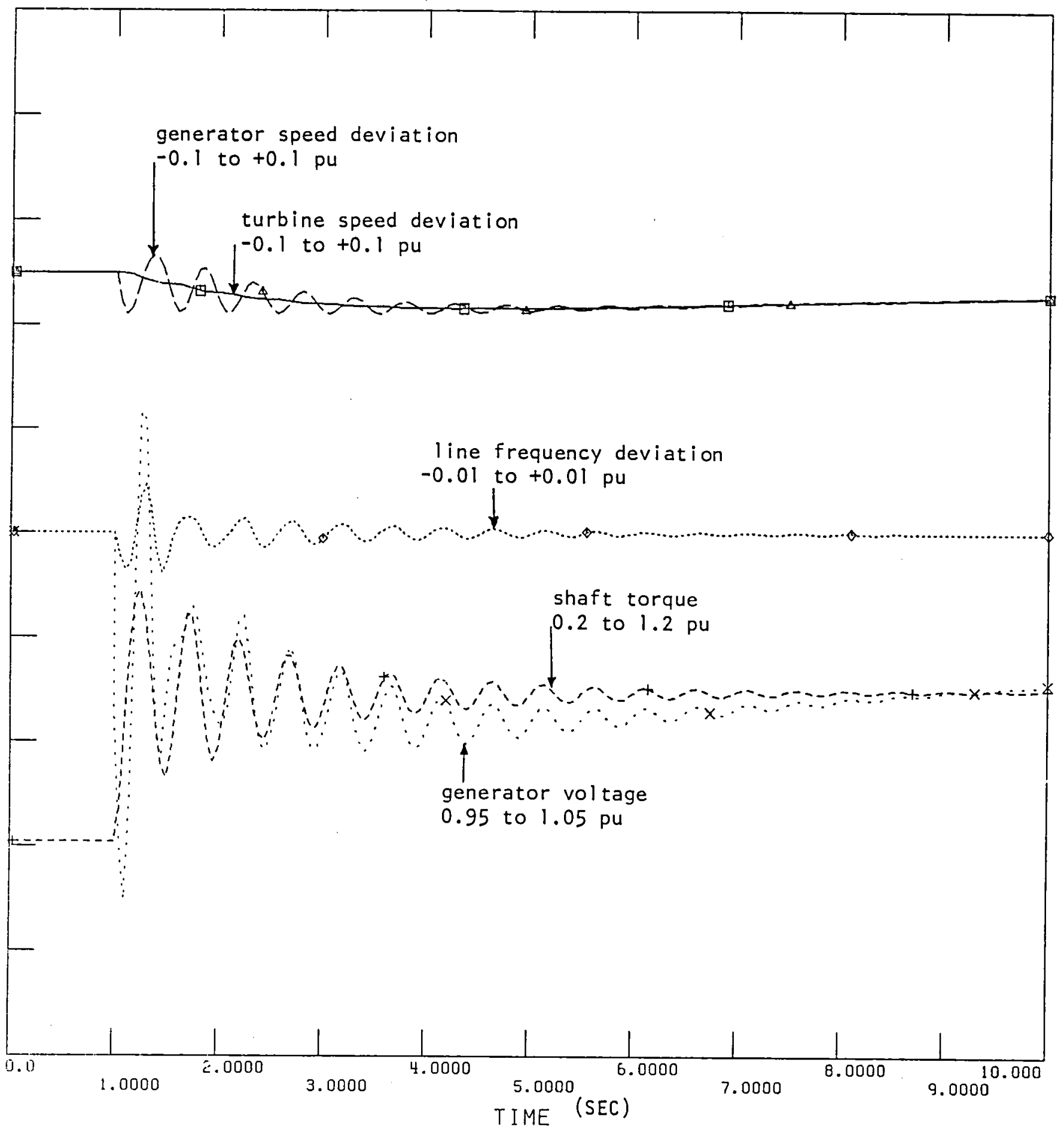

D2-B DOUBLY-FED GENERATOR

ISOLATED ELECTRICAL SYSTEM

LOAD INCREASE FROM 50 TO $75 \%$ of RATED 


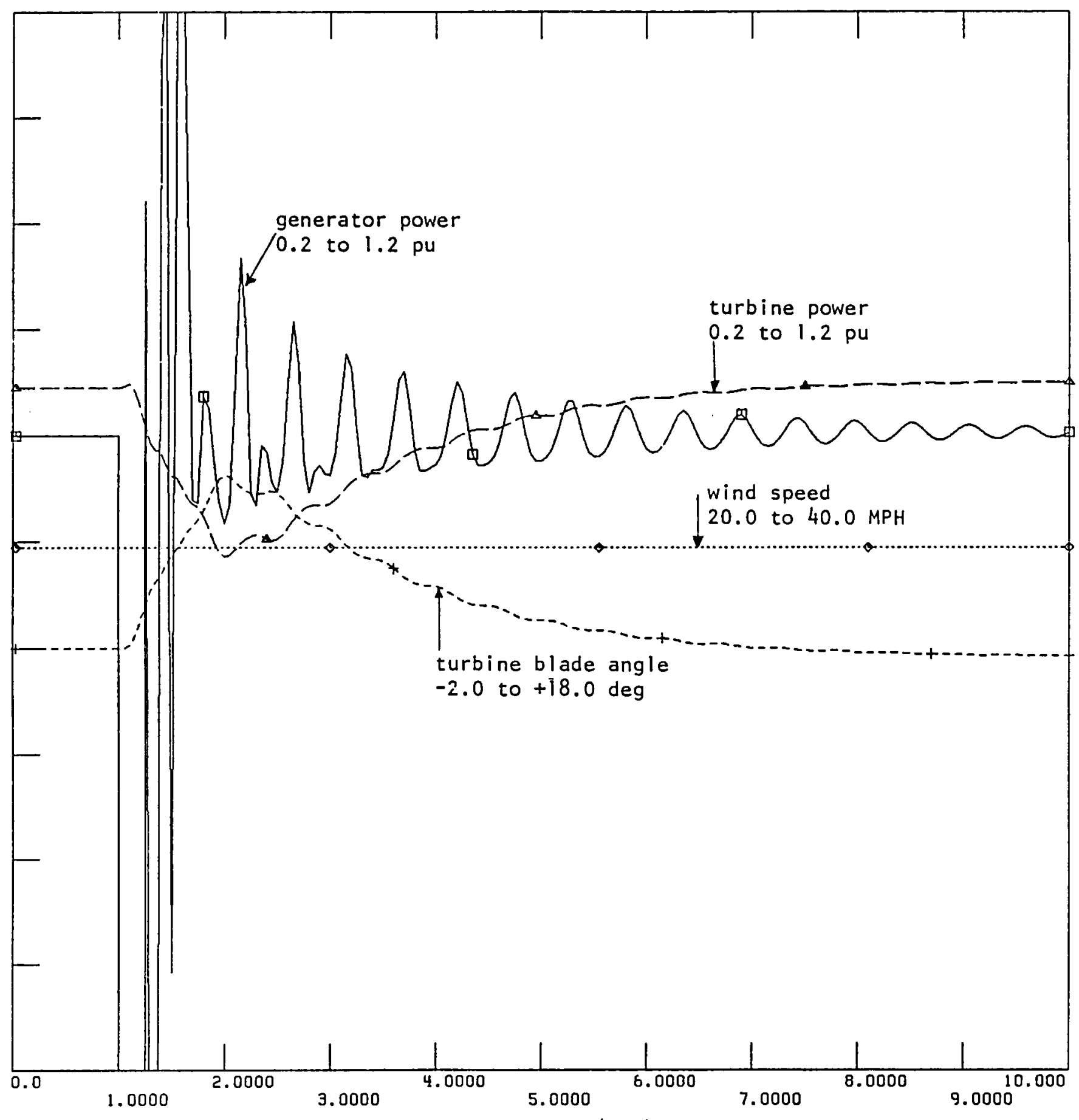

\section{TIME (SEC)}

D3-A DQUBLY-FED GENERATOR

STRONG ELECTRICAL SYSTEM

LOSS OF LOAD FOR 0.25 SEC 


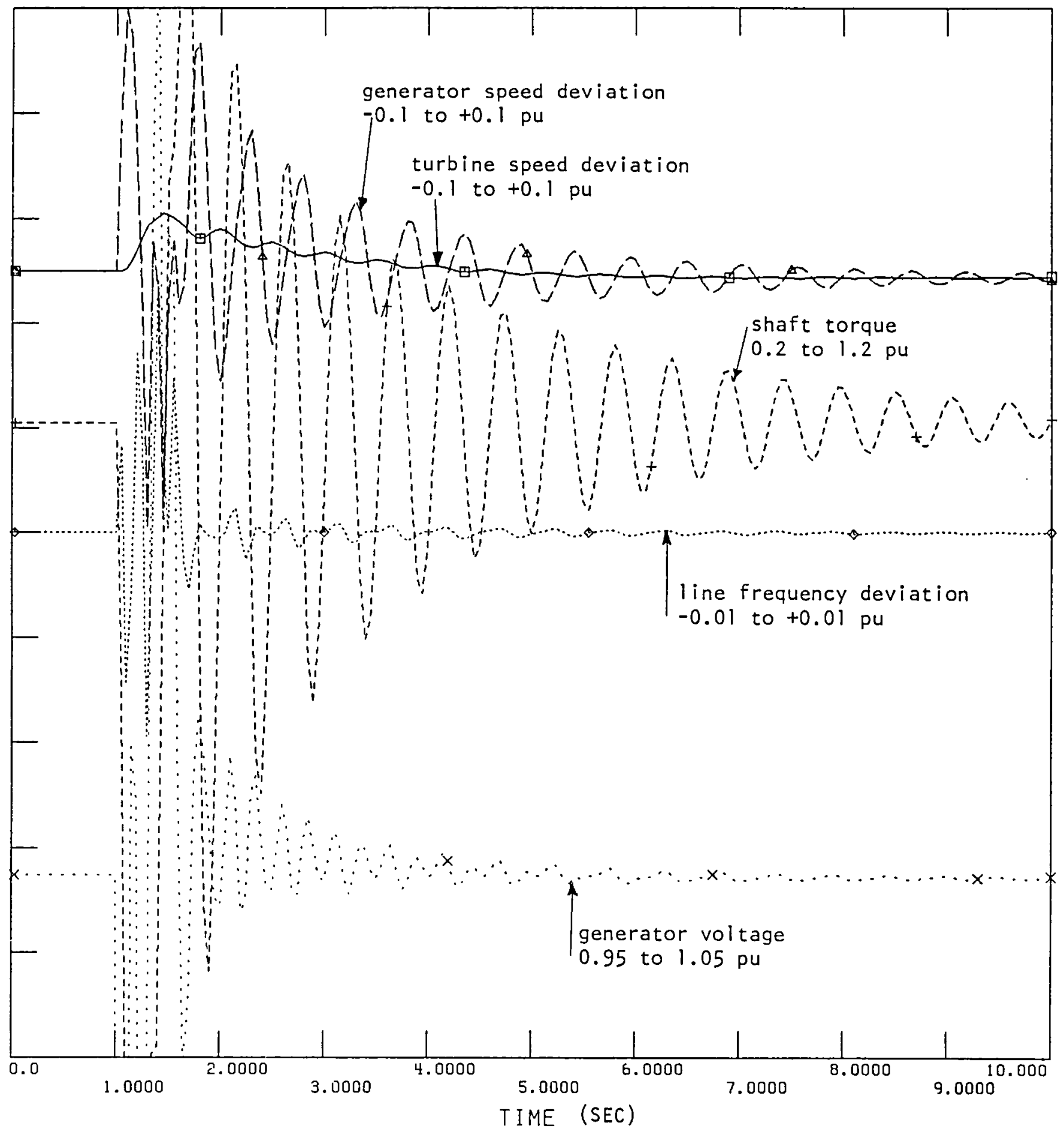

D3-B DOUBLY-FED GENERATOR

STRONG ELECTRICAL SYSTEM

LOSS OF LOAD FOR 0.75 SEC 



\subsection{APPENDIX - OPERATION OF MOD-0 WIND TURBINE WITH SPEED IN LIEU OE POWER CONTROL}

\subsection{Introduction}

In December 1982 tests were performed on the MOD-0 wind turbine at Plum Brook, Ohio to determine the feasibility of varying blade pitch to control turbine speed rather than generator power during on-line operation. Both low and high penetration cases were investigated. In the low penetration case, the wind turbine generator was connected to the local utility grid. In the high penetration case, the wind turbine generator was operated in parallel with a $187.5 \mathrm{kVA}, 0.8 \mathrm{PF}$ diesel generator set. The two generators supplied power to an isolated load consisting of resistor banks and a $40 \mathrm{HP}$ induction motor driving a centrifugal pump. The MOD-0 was equipped with an induction generator with approximately 5 percent slip at rated load. The diesel generator set had a voltage regulated synchronous generator and a conventional speed governor with approximately 4 percent speed droop from zero to full load.

Control of turbine speed by pitch angle changes was achieved by using the existing speed controller, which is normally active only prior to synchronization. Except for gain adjustments of the speed controller, no changes were made to the existing control system.

\subsection{Analysis}

Variable pitch wind turbines connected to utility networks presently use speed control prior to synchronization and power control after synchronization. During this test, speed control was used before as well as after synchronization. Such systems are common in utility turbine generators. Since the utility system usually dominates steady-state speed, the function of the speed controller after synchronization is not the same as before synchronization. Instead of setting speed, the speed controller now sets load, permits load sharing, and - in the case of wind turbines - can provide damping of drive train torsional modes.

Figure A.l shows a simplified block diagram and the steady-state speed-load characteristic of the classical speed controller for utility turbine generators applied to a wind turbine. The speed controller has proportional characteristics with a total forward gain of $k * \Delta T / \Delta \beta$. The gain is typically set to a value of 20.0. Given a constant speed reference and isolated operation, a 100 percent increase in load torque (electrical load) will cause a 5 percent decrease in speed. Given parallel operation with a strong electrical system and zero load, a 5 per- 
cent increase in speed reference will result in a load increase from zero to full load.

The purpose of droop in the speed-load characteristic is to establish a relationship between speed (frequency) and load. Droop can be introduced by a proportional speed controller (no reset) or by slip between turbine and generator which is proportional to torque (slip coupling or induction generator). If all turbine generators supplying power to a system have speed-load characteristics with the same droop from zero to full load, transient load changes will be divided between turbine generators in proportion to their rating. Machines with less droop than the average will pick up more than their share and machines with more droop than the average will pick up less than their share.

When a wind turbine is connected to a strong power system, the mode shape of the first torsional mode of the drive train is such that nearly all the torsional oscillation occurs at the turbine and very little at the generator. A speed controller, controlling blade pitch as a function of turbine speed deviations will provide damping of the torsional mode. This is a major source of damping in the MOD-2 and the WTS-4, when wind speed is above rated.

There are three considerations in selecting the gains of the speed controller:

- The droop of the speed - load characteristic is the inverse of gain, i.e. the steady-state gain should be selected to provide the conventional amount of droop. If there is slip in the drive train due to the presence of a slip coupling or an induction generator, the speed controller may not have to provide droop. If the droop introduced by slip in the drive train is adequate for load sharing (3-5 percent), selection of gain for the speed controller can be based on other considerations. In that case, the speed controller may also have integral (reset) characteristics.

- The gain desirable for maximum damping of the drive train torsional mode is usually higher than the gain required to produce the desired droop. This can be accomplished by a lead-lag network providing increased transient gain for damping. In the case of the 


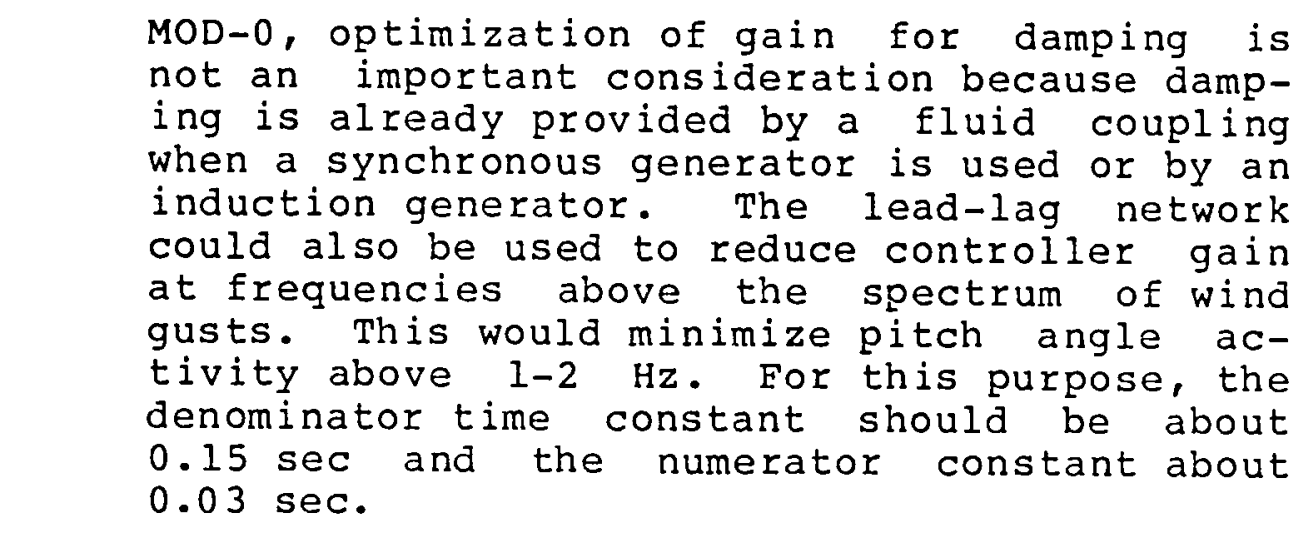

- The gain of the turbine transfer function $\Delta T / \Delta \beta$ is not a constant but increases with wind speed. If constant steady state gain were desired over the full range of wind speeds, the change in turbine transfer function with wind speed would have to be compensated in the controller. This would be a refinement of the speed controller, which was not considered during this test.

The proportional (and integral) gain of the speed controllex selected for off-line operation will also be satisfactory for the load setting function of the speed controller during on-line operation. Loading of the machine by raising the speed reference should be done with a speed ramp of approximately $0.05 \mathrm{rpm} / \mathrm{sec}$.

\subsection{Objectives}

The objectives of the tests are:

- High Penetration - The wind turbine operates in parallel with a diesel generator of comparable size and supplies power to an isolated resistive or mixed resistive-inductive load. The tests should demonstrate that the total load can be divided between wind turbine and diesel by adjusting the speed-load setter references of the two machines individually, and that system frequency can be modified by adjusting the two speed-load setters simultaneously. Load sharing in proportion to the ratings should be demonstrated by observing the response of the two machines to sudden load changes. 
- Low Penetration - The wind turbine operates in parallel with the utility system. Tests should demonstrate the load setting ability of the speed controller.

\subsection{Discussion of Test Results}

Tests were conducted on December 20, 1982 from 11:00 to 16:00 hours and on December 21, 1982 from 10:00 to 14:00 hours. on the first day, the wind speed was generally between 6 and 8 $\mathrm{m} / \mathrm{sec}(13.4$ and $17.9 \mathrm{mph})$, on the second day between 3 and 5 $\mathrm{m} / \mathrm{sec}(6.7$ and $11.2 \mathrm{mph})$.

Results were recorded on three 8 channel brush recorders and on FM tape. A test log was kept to record significant events.

During the first day, the emphasis was placed on meeting the objectives. During the second day, different speed controller gains were explored. Efforts during the second day were curtailed by low wind speeds. Low wind speed results in low gain of the control loop and makes it difficult to assess control performance.

The following excerpts from the test record demonstrate the behavior of the test system:

- Wind Turbine Connected to Utility - Turbine in speed Control Mode - Change of Power output by Adjustment of speed Setpoint 12-20-82, 14:04, Events 16 and 17, Figure A.2

The wind turbine generates approximately 30 $\mathrm{kW}$ at a blade angle of about -15 degrees and $a$ wind speed of approximately $6 \mathrm{~m} / \mathrm{sec}$ (13.4 mph). The speed setpoint is increased about 1 percent $(0.2 \mathrm{rpm})$, which increases the power generated by the wind turbine to $60 \mathrm{~kW}$. The blade angle changes from -15 degrees to -2 degrees. Turbine speed rises approximately $0.2 \mathrm{rpm}$, while system frequency remains constant, i.e., induction generator slip increases by about 1 percent.

- Isolated System - Turbine in Power Control Mode - Load Increase and Decrease - 12-20-82, 14:58, Events 29 and 30, Figure A.3 
The wind turbine generates approximately 30 $\mathrm{kW}$, the diesel about $60 \mathrm{~kW}$. Wind speed varies from 4 to $6 \mathrm{~m} / \mathrm{sec}$ ( 8.9 to $13.4 \mathrm{mph}$ ) and turbine blade angle varies from -10 degrees to -20 degrees. A $30 \mathrm{~kW}$ resistive load is switched on at Event 29 and off at Event 30 . Since the wind turbine is in the power control mode, the load changes only affect the diesel generator.

- Isolated System - Turbine in Speed Control Mode - Load Transfer from Diesel to Wind Turbine - 12-20-82, 15:05, Events 32 to 33, Figure A. 4

The diesel supplies about $75 \mathrm{~kW}$, the wind turbine about $15 \mathrm{kw}$. By raising the wind turbine speed setpoint, the load distribution is changed so that the total load is carried by the wind turbine. During the transfer, system frequency rises from 59 to $60 \mathrm{~Hz}$.

- Isolated System - Turbine in Speed Control Mode - $30 \mathrm{~kW}$ Load Decrease Shared by Diesel and Wind Turbine - 12-20-82, 15:10, Event 34, Eigure A.5

Prior to this event, total load is $100 \mathrm{~kW}$. The wind turbine generates $80 \mathrm{~kW}$, the diesel $20 \mathrm{~kW}$. Wind speed varies between 6 and 8 $\mathrm{m} / \mathrm{sec}$ ( 13.4 and $17.9 \mathrm{mph}$ ) and turbine blade angle between -6 degrees and -8 degrees. After the event, the wind turbine generates $60 \mathrm{~kW}$, the diesel $10 \mathrm{~kW}$. Wind speed is still in the same range and turbine blade angle is now between -12 degrees and -14 degrees. System frequency rises abruptly from 60 to 61 $\mathrm{Hz}$ when the load reduction occurs, and reaches a steady state value slightly above the initial value.

- Isolated System - Turbine in Speed Control Mode - Load Transfer from Wind Turbine to Diesel - 12-20-82, 15:13, Events 35 to 36 , Figure A.6

Prior to this transfer, total load is $70 \mathrm{~kW}$. The wind turbine generates $60 \mathrm{~kW}$, the diesel $10 \mathrm{~kW}$. Wind speed varies between 6 and 8 
$\mathrm{m} / \mathrm{sec}$ ( 13.4 and $17.9 \mathrm{mph}$ ) and turbine blade angle is approximately -14 degrees. The power transfer to the diesel is accomplished by lowering the setpoint of the wind turbine speed controller. After the transfer, the wind turbine generates $30 \mathrm{~kW}$, the diesel 40 $\mathrm{kW}$. Turbine blade angle has increased to -19 degrees. During the transfer, system frequency decreases from 60.0 to $59.3 \mathrm{~Hz}$.

- Isolated System - Turbine in speed Control Mode - Shared Increases in Load - 12-20-82, 15:16, Events 36 and 37 , Figure A.7

Load is increased in two $30 \mathrm{~kW}$ steps, at 15:16 and at 15:19 hours. Initial generation is $25 \mathrm{~kW}$ at the wind turbine and $40 \mathrm{~kW}$ at the diesel. Final generation is $50 \mathrm{~kW}$ at the wind turbine and $75 \mathrm{~kW}$ at the diesel, i.e. the load increase has been shared almost equally by the two machines. In this test, the differences in the speed of response of the two machines is noticeable. The diesel is considerably faster and picks up most of the load increment immediately after the event. However, as the wind turbine speed controller responds by adjusting turbine blade angle, nearly equal distribution of the load increment between the two machines is reached. During this sequence, the turbine blade angle changes from -19 degrees to -10 degrees, and system frequency decreases from 59.3 to $58.7 \mathrm{~Hz}$.

- Isolated System - Turbine in Speed Control Mode - Load Transfer from Diesel to wind Turbine - 12-20-82, 15:40, Events 42 and 43 , Figure A. 8

Load is transferred from diesel to wind turbine by lowering the speed setpoint of the diesel and by increasing the speed setpoint of the wind turbine. By adjusting both speed setpoints in opposite directions, the load is transferred while keeping steady state system frequency nearly constant. 


\subsection{Conclusions}

Stable operation of the MOD-0 with turbine speed control was accomplished in the low penetration case (parallel operation with a large utility system) as well as in the high penetration case (parallel operation with a diesel of equal size in an isolated system). The ability to load and unload the wind turbine by increasing and decreasing the speed setpoint was demonstrated. The sharing of load changes between parallel generators was also accomplished. It was shown that frequency of the isolated system could be controlled by manipulating the speed setpoints of both generator sets.

It was determined that the speed of response of the wind turbine was slower than that of the diesel. It is likely that wind turbine blade angle control is inherently slower than diesel fuel control.

The gain of wind turbine control loops operating on blade angle is a function of wind speed. Gain increases with wind speed. This gives wind turbines different response characteristics at different wind speeds.

\subsection{Future Work}

These tests demonstrate that speed control of wind turbines with variable pitch is feasible. Further work is required to determine the best adjustment of speed controller gains and to investigate whether there is a need for gain adjustment with wind speed.

\subsection{Data}

During the tests shown in Figures A2-A8, the following controller gains were used:

$$
\begin{array}{cc}
\frac{\text { Speed Control }}{A 2, A 4, A 5, A 6, A 7, A 8)} & \frac{\text { Power Control }}{(\text { Fig A3) }} \\
(\text { Fig A2 } & K_{p}=0.36 \mathrm{deg} / \mathrm{kW} \\
K_{p}=1.7 \mathrm{deg} / \mathrm{rpm} & \mathrm{K}_{I}=0.032 \mathrm{deg} / \mathrm{kW} \mathrm{sec} \\
\mathrm{K}_{I}=0.18 \mathrm{deg} / \mathrm{rpm} \mathrm{sec} &
\end{array}
$$

For these tests the MOD-0 was equipped with $60 \mathrm{ft}$. blades with 18 ft. movable tips. The rotor operated downwind with a teetered hub. Hub height was $120 \mathrm{ft}$. 

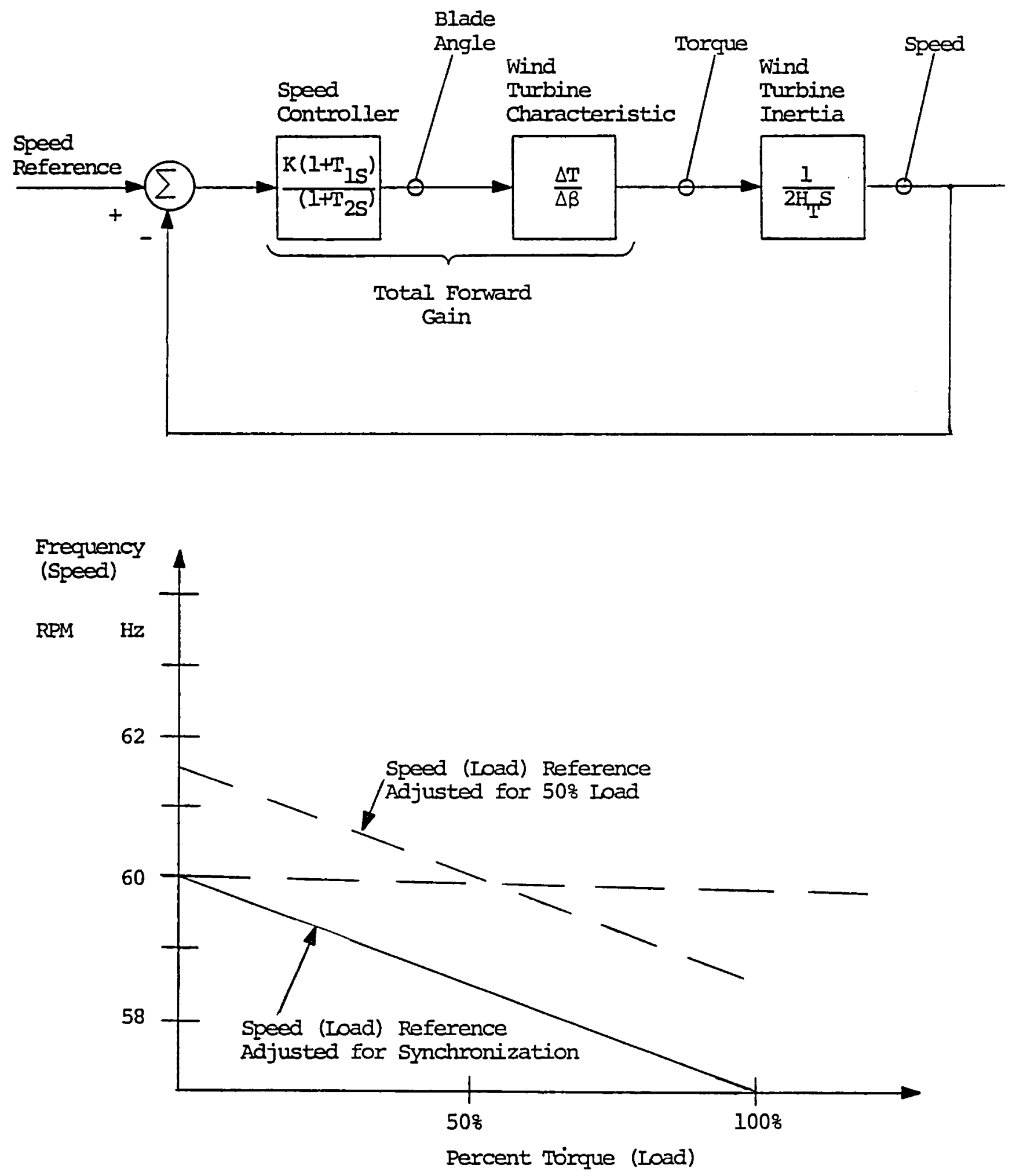

Figure A.1

On-Line Wind Turbine Speed Control 

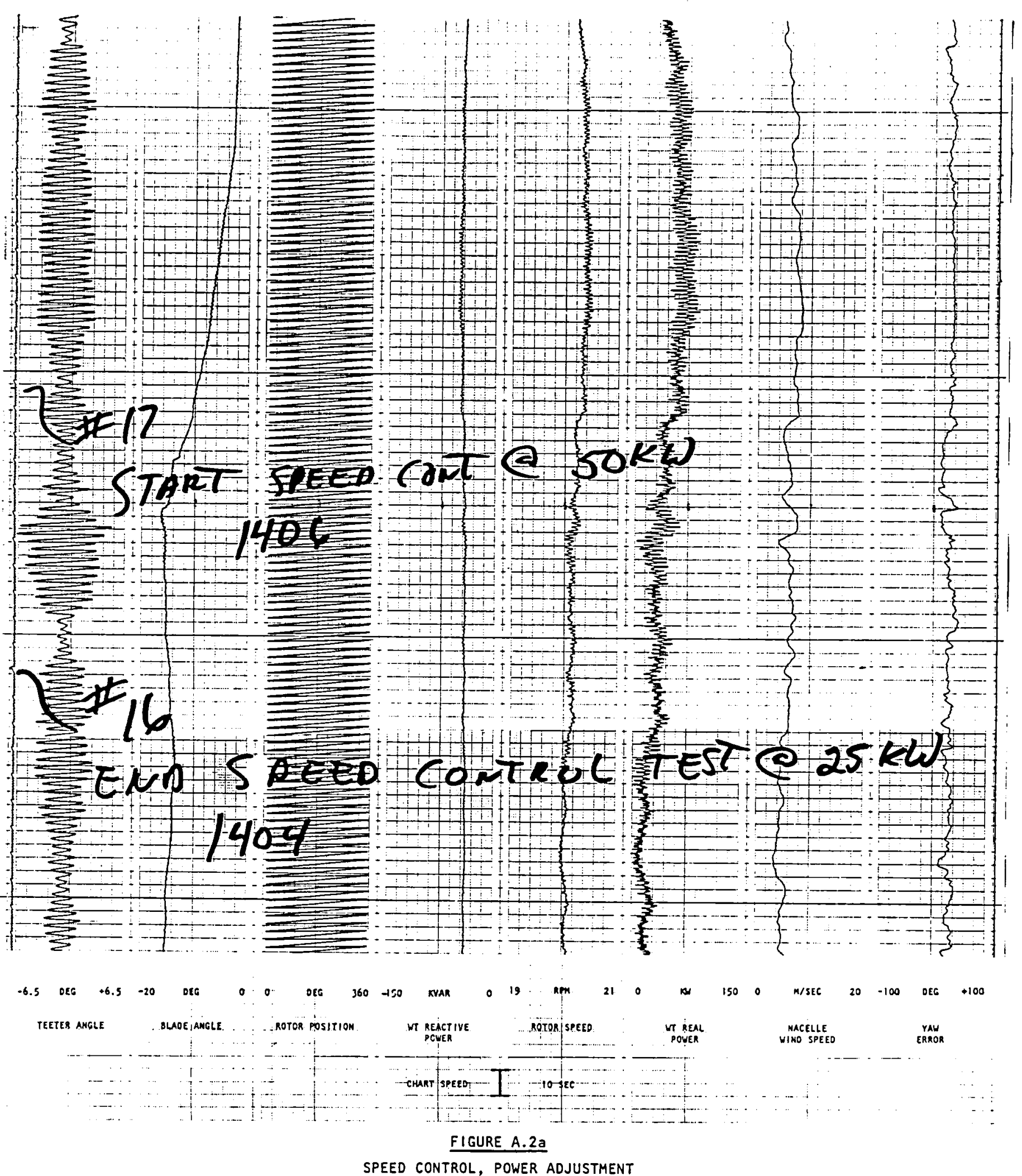


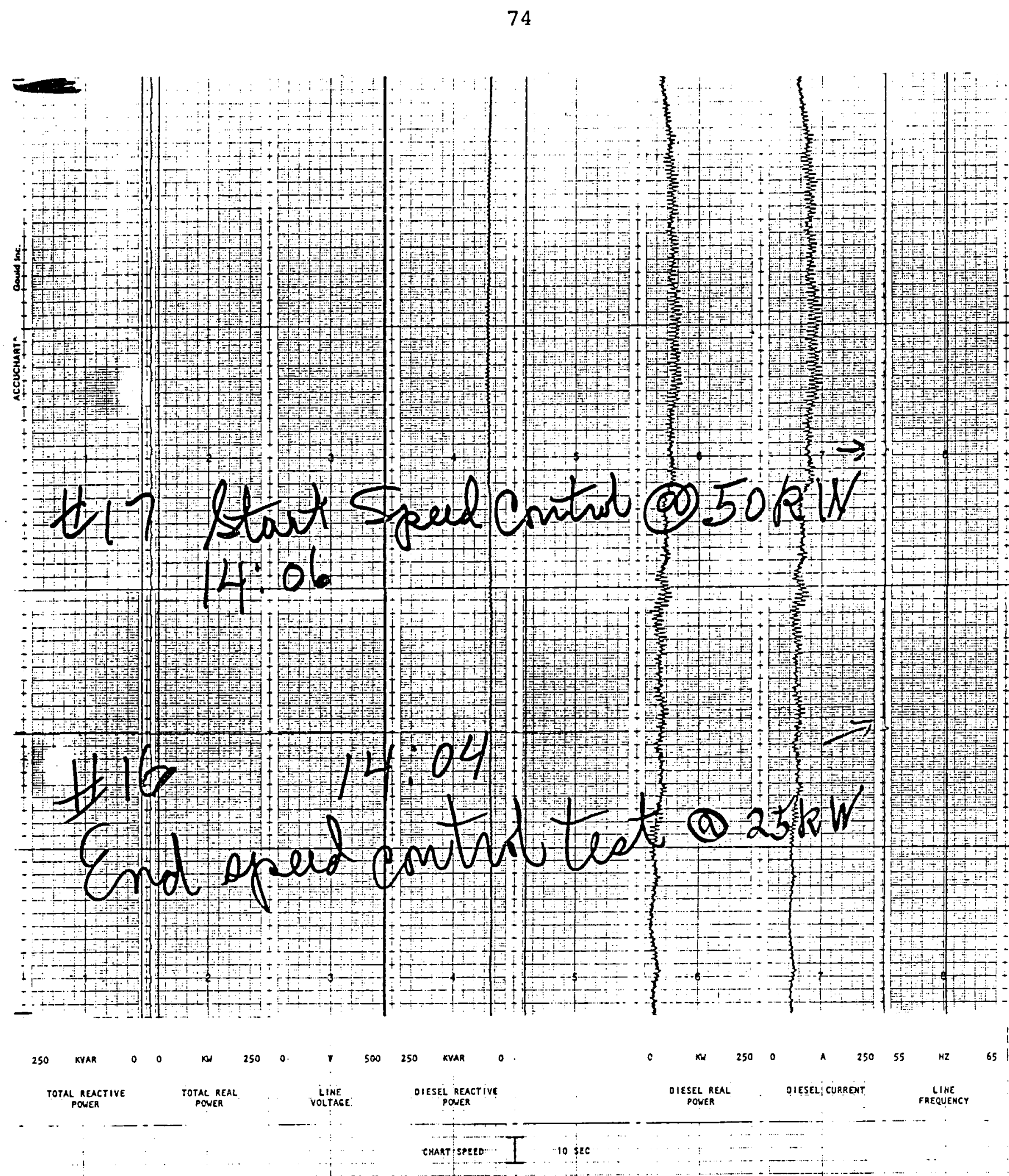




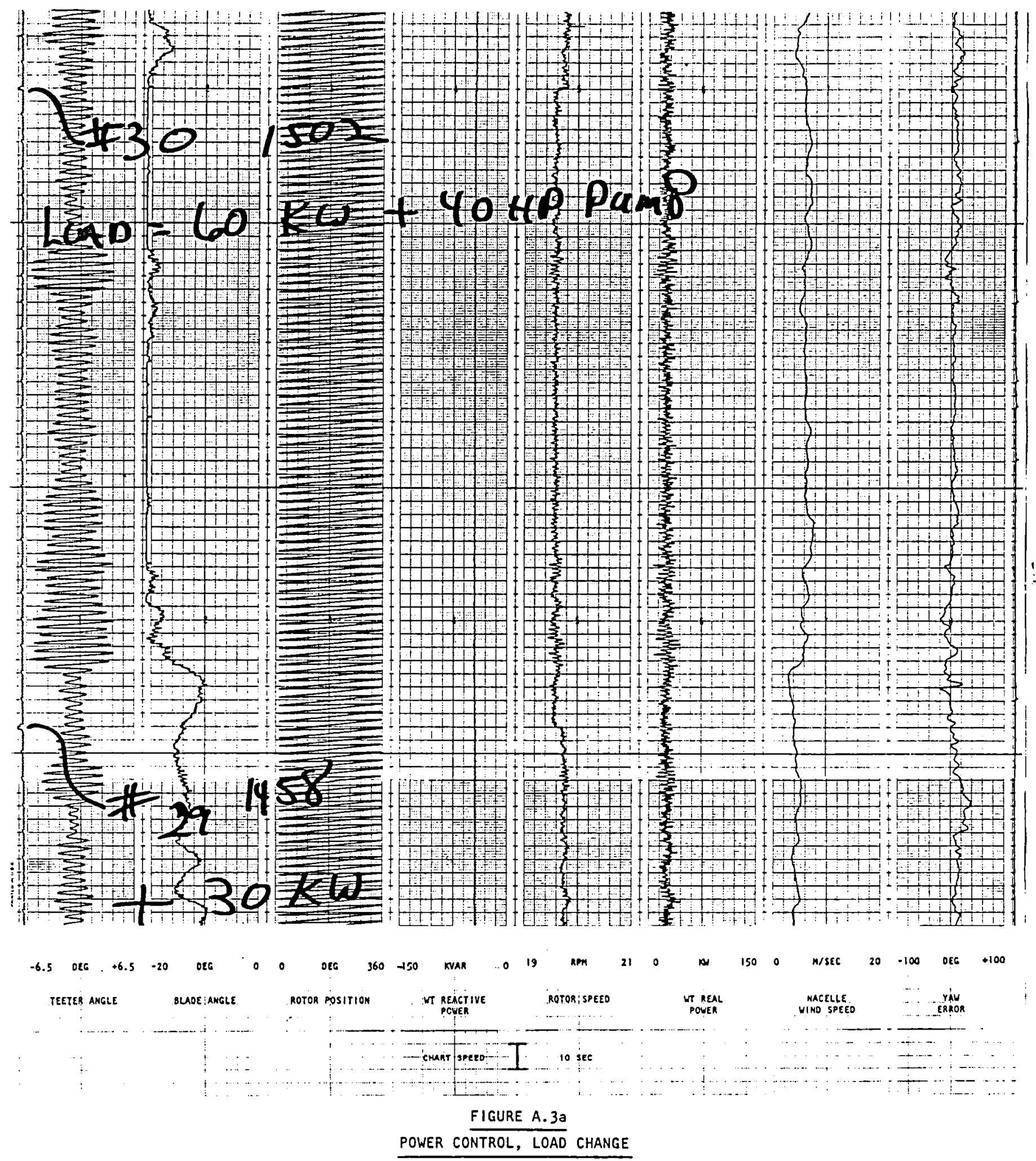




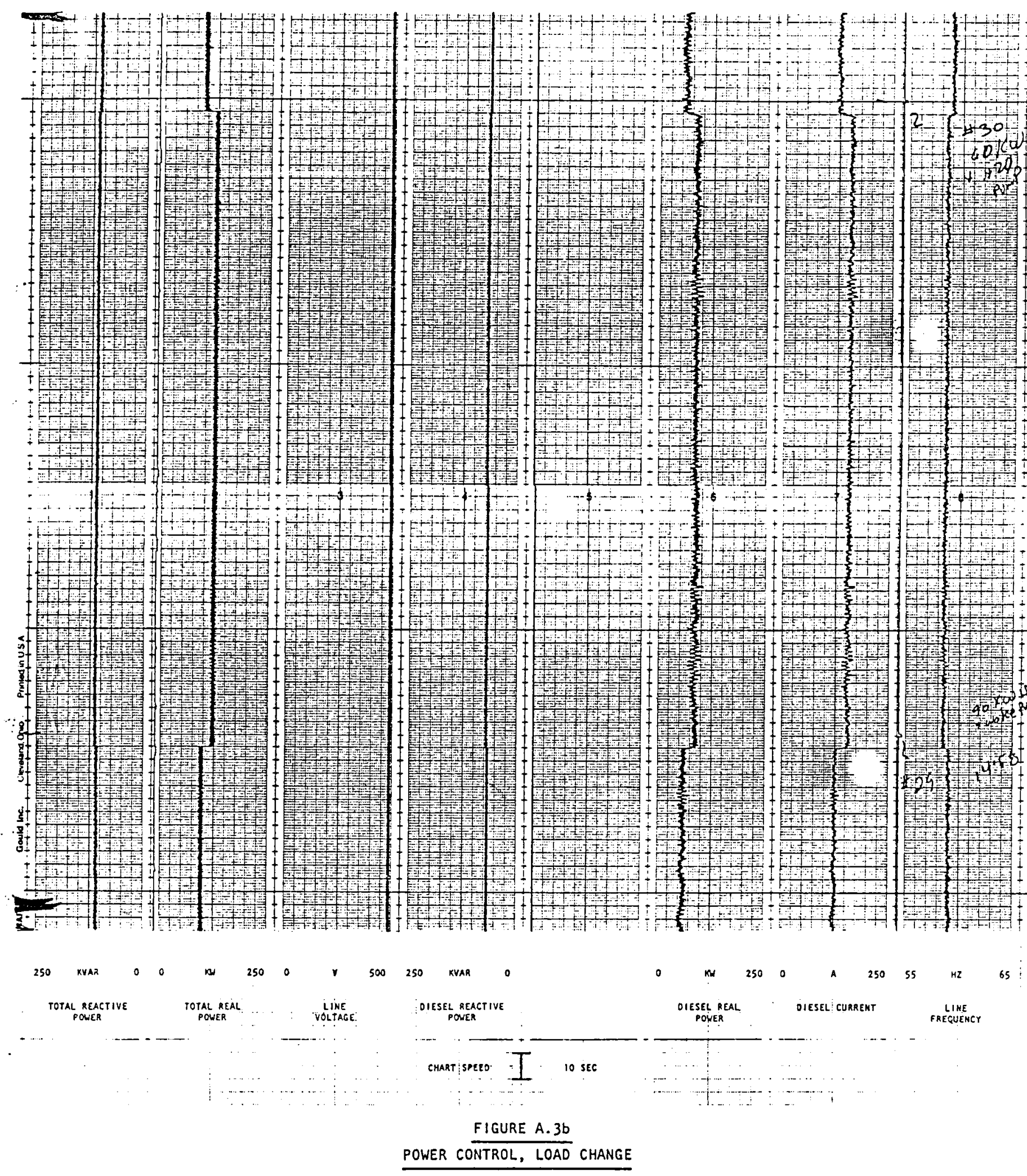




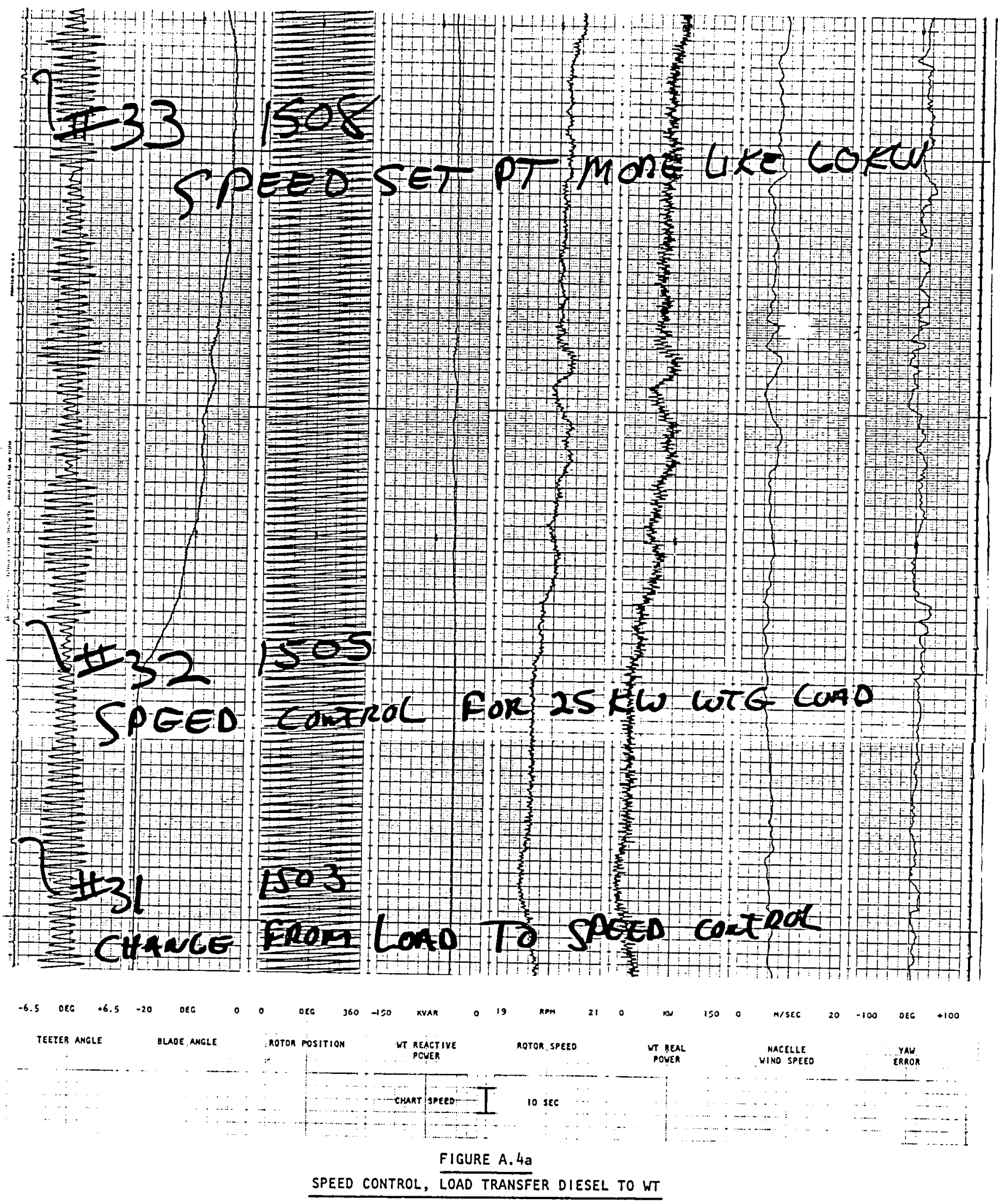




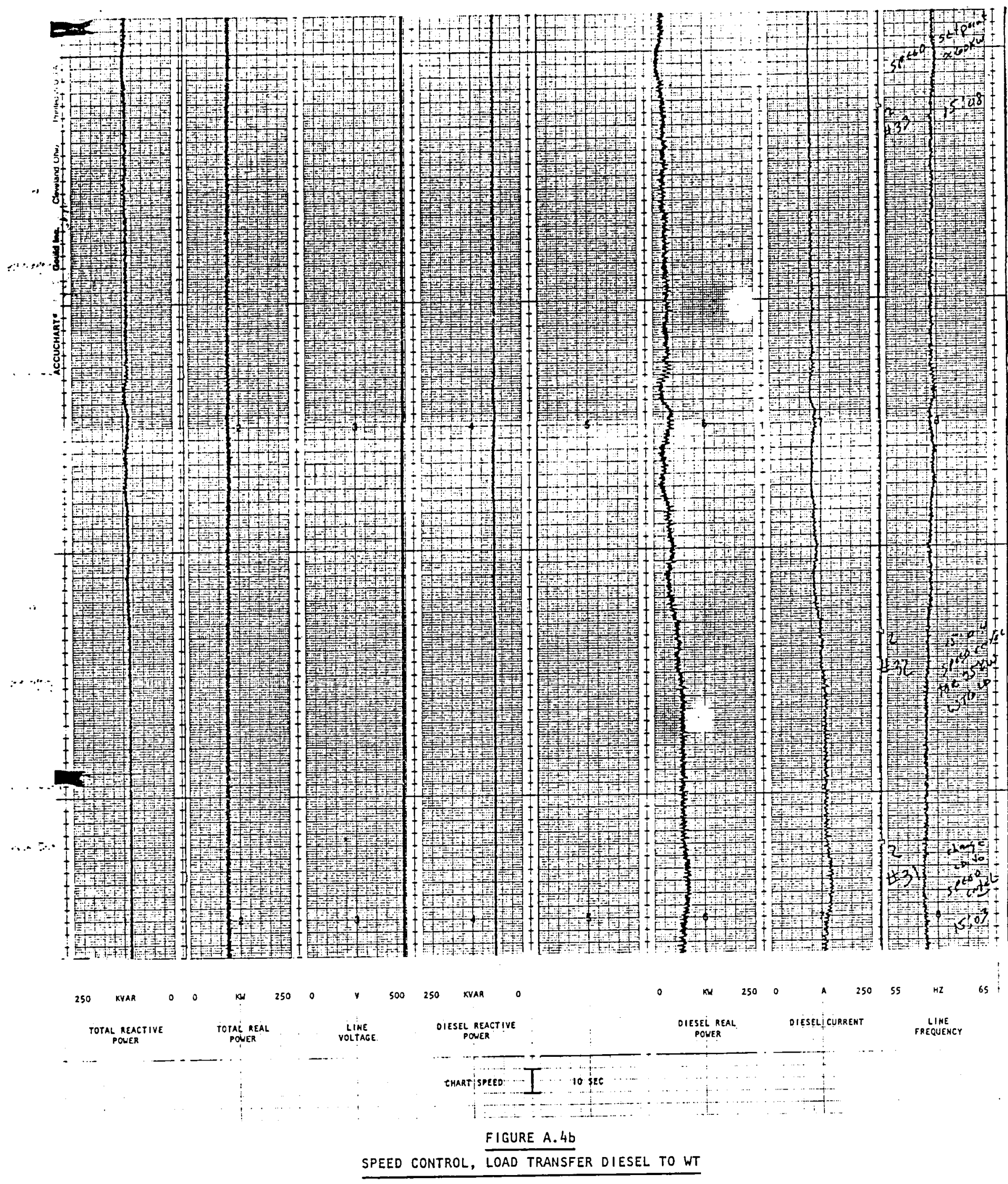



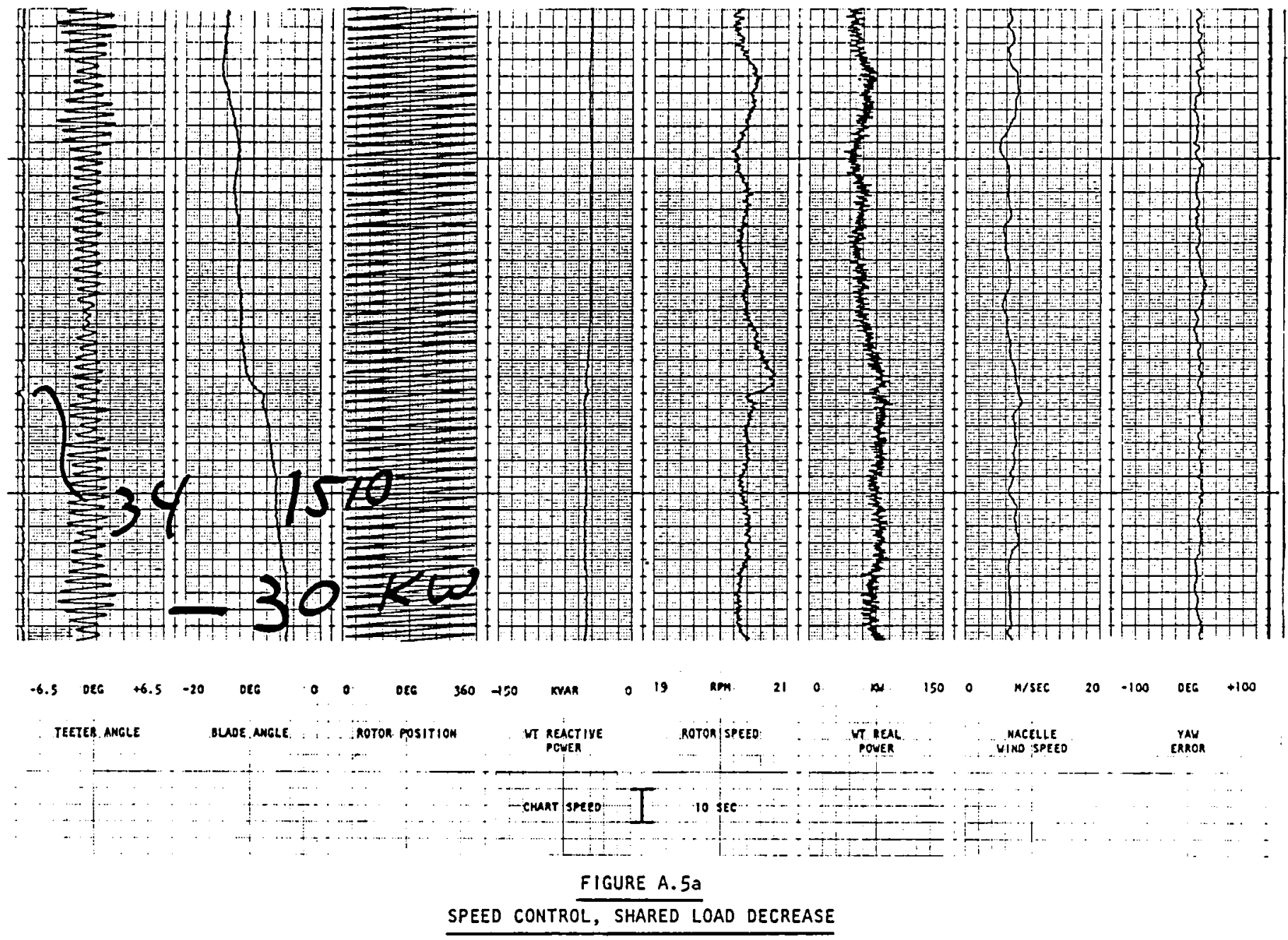


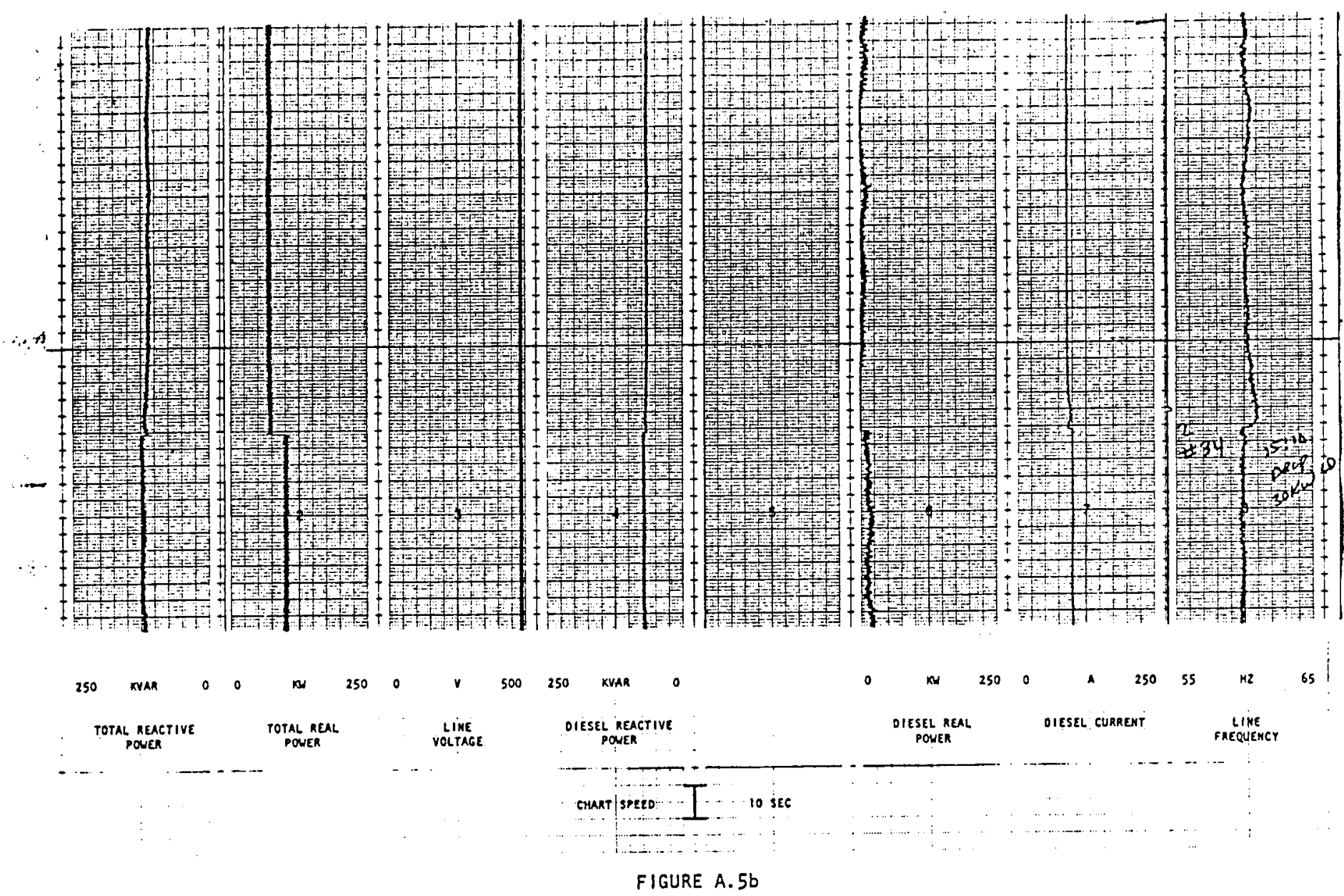

SPEED CONTROL, SHARED LOAD DECREASE 

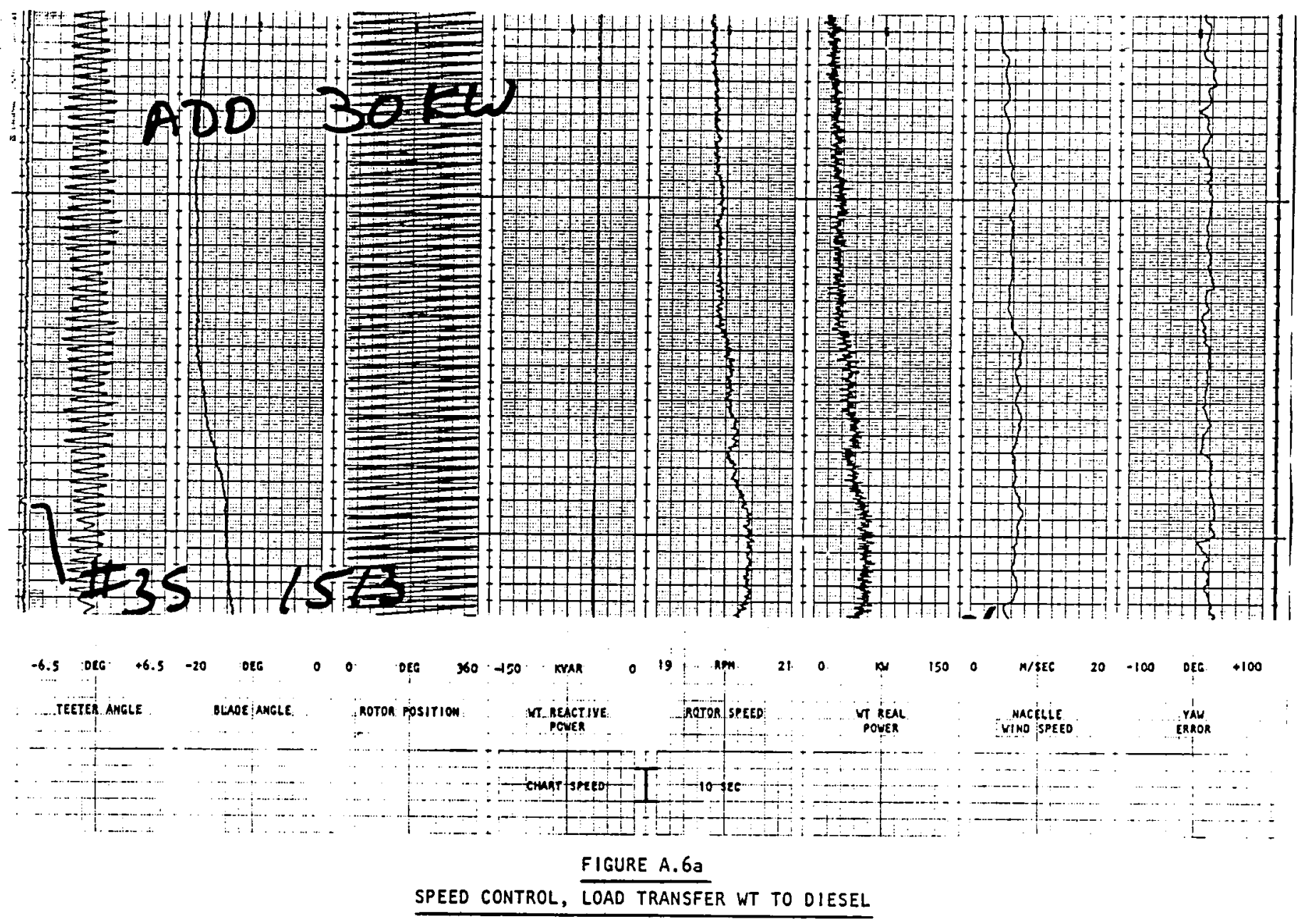


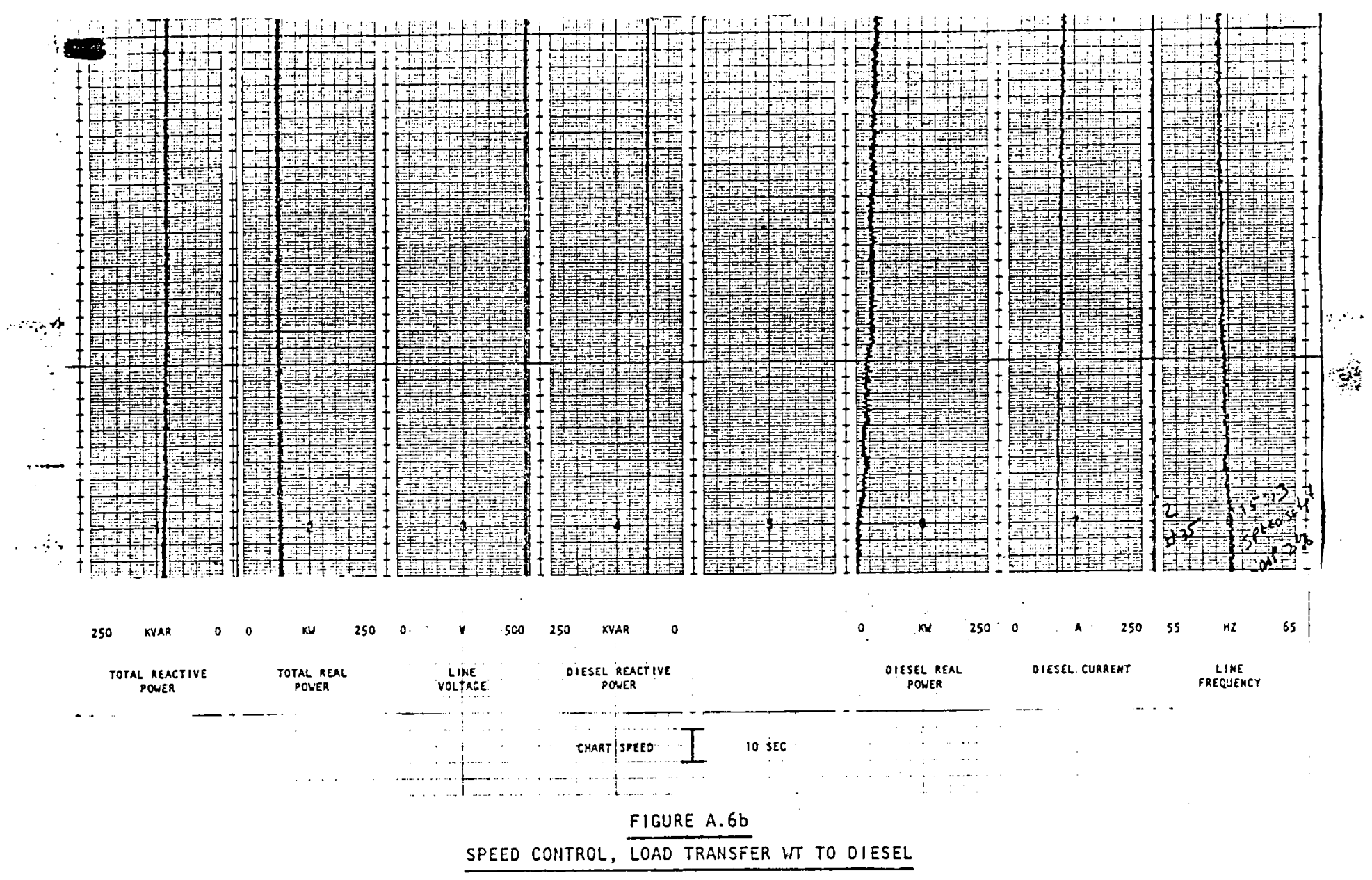



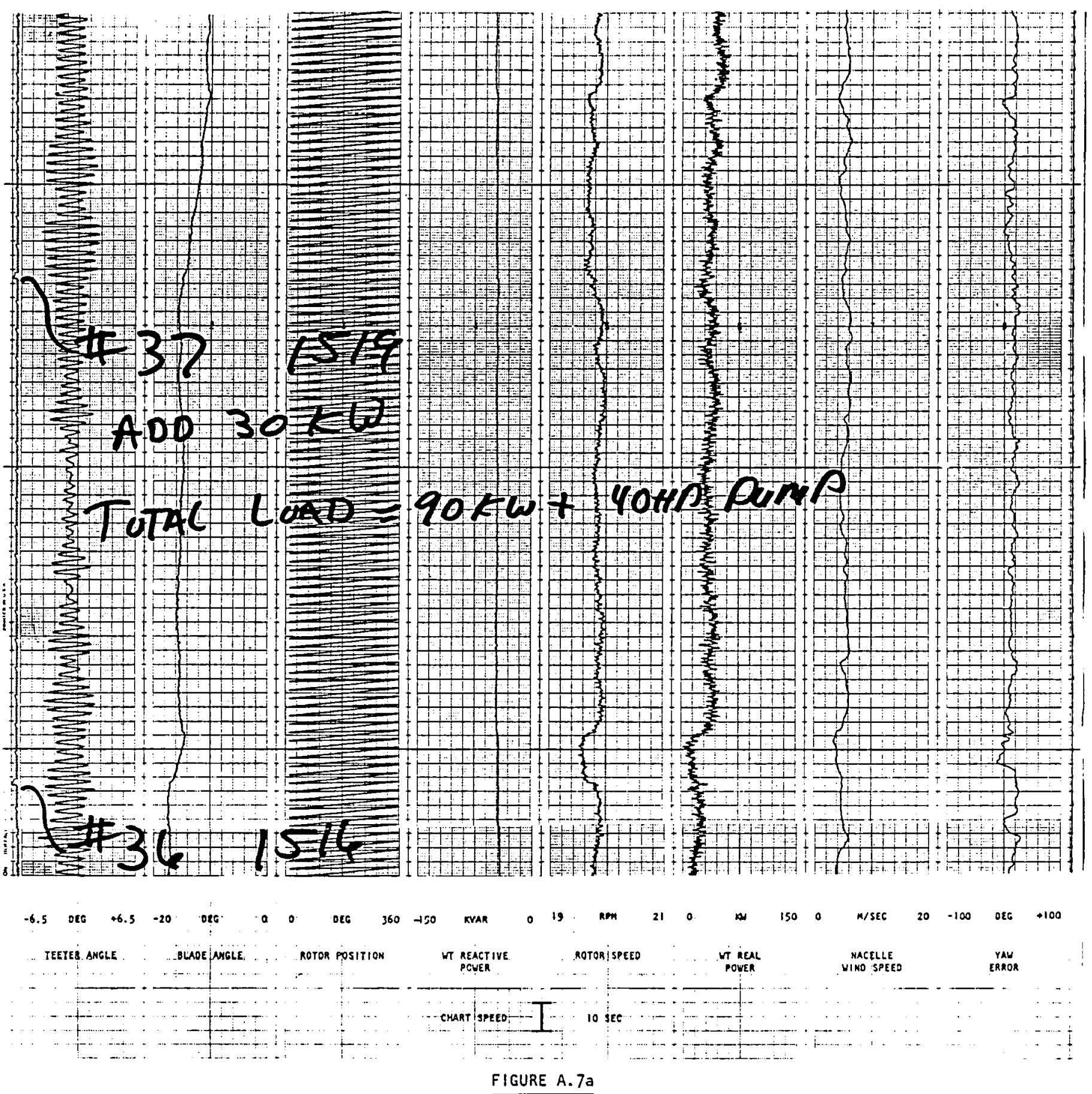

SPEED CONTROL, SHARED LOAD INCREASE 


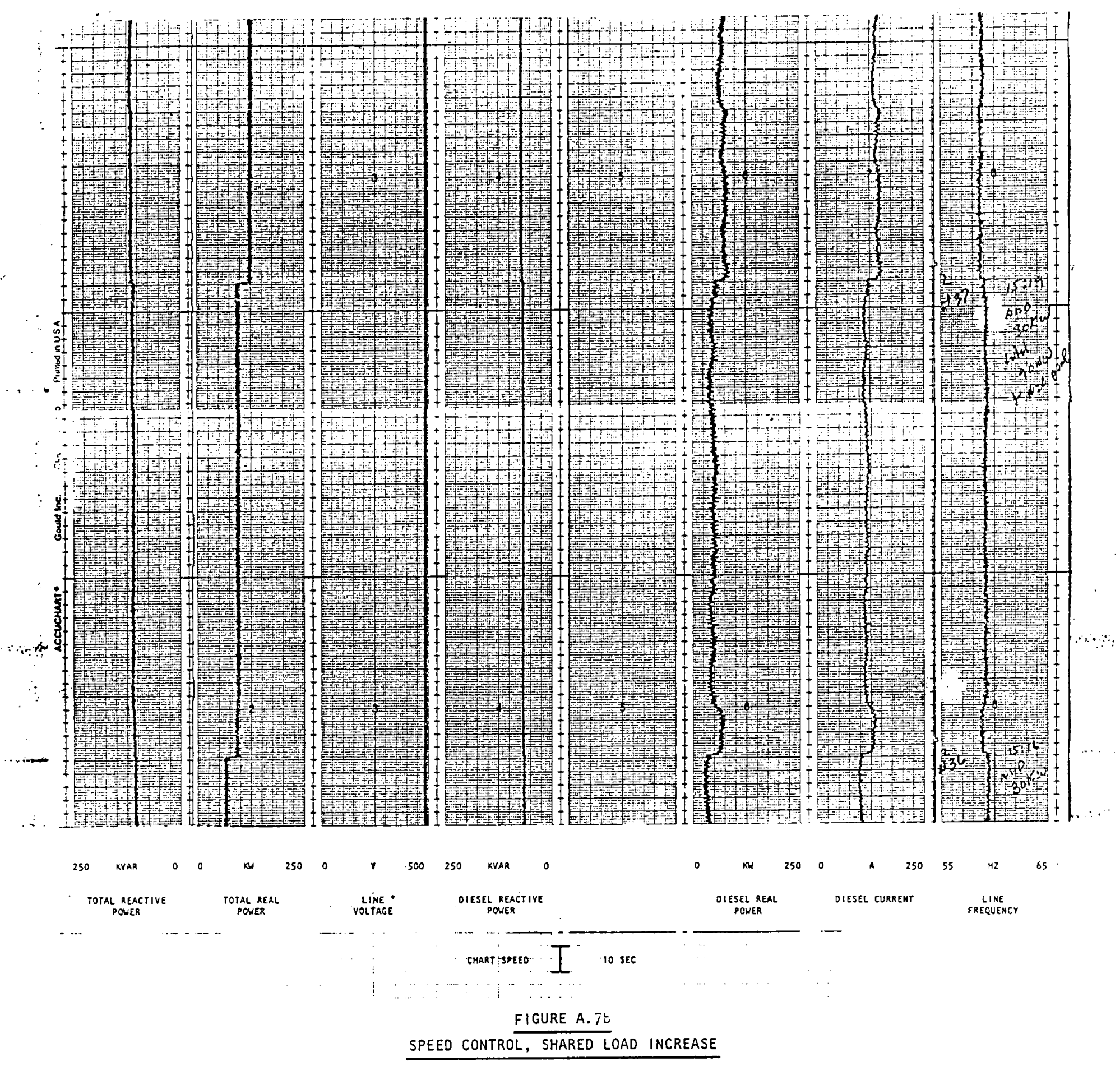



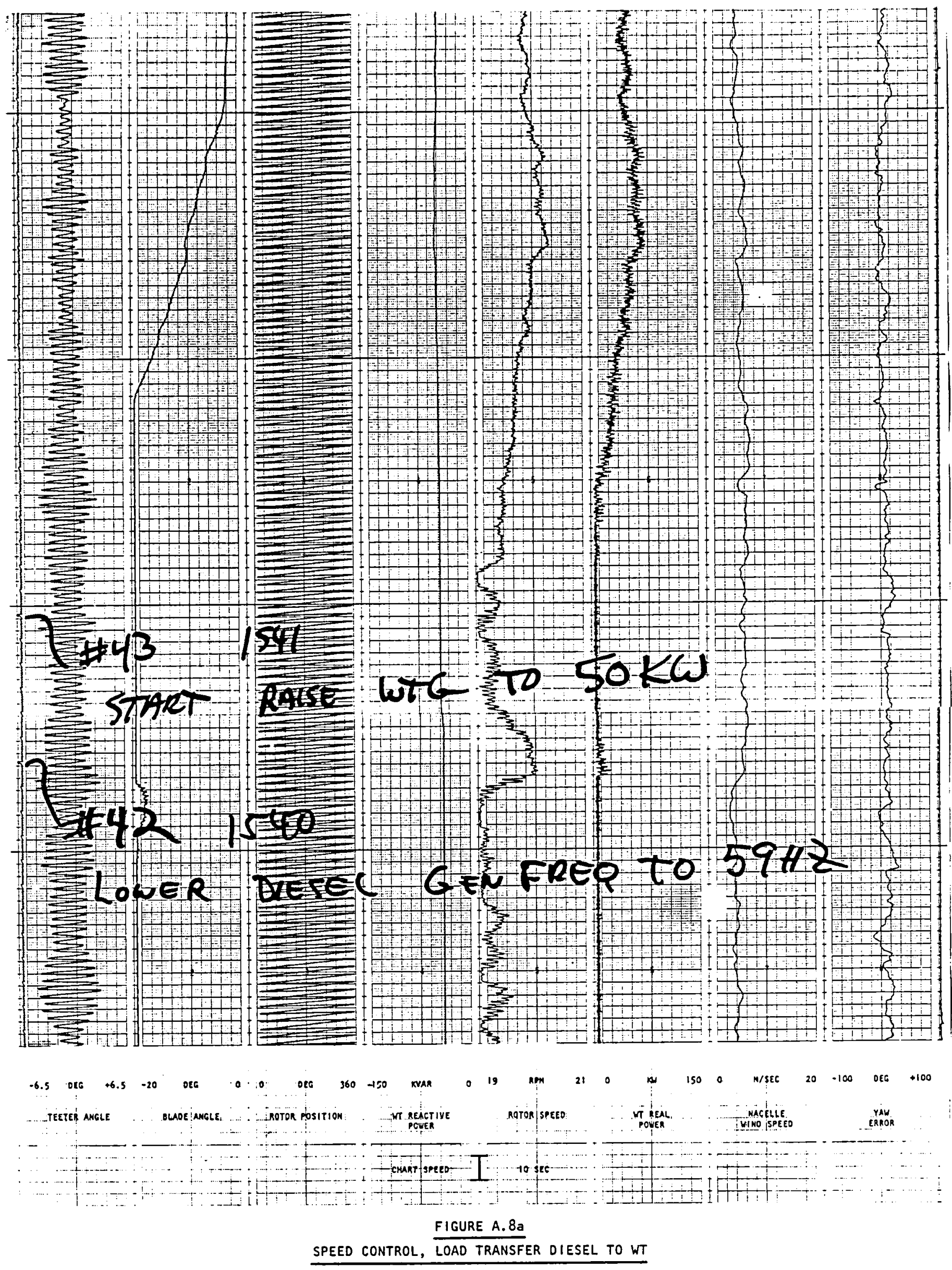

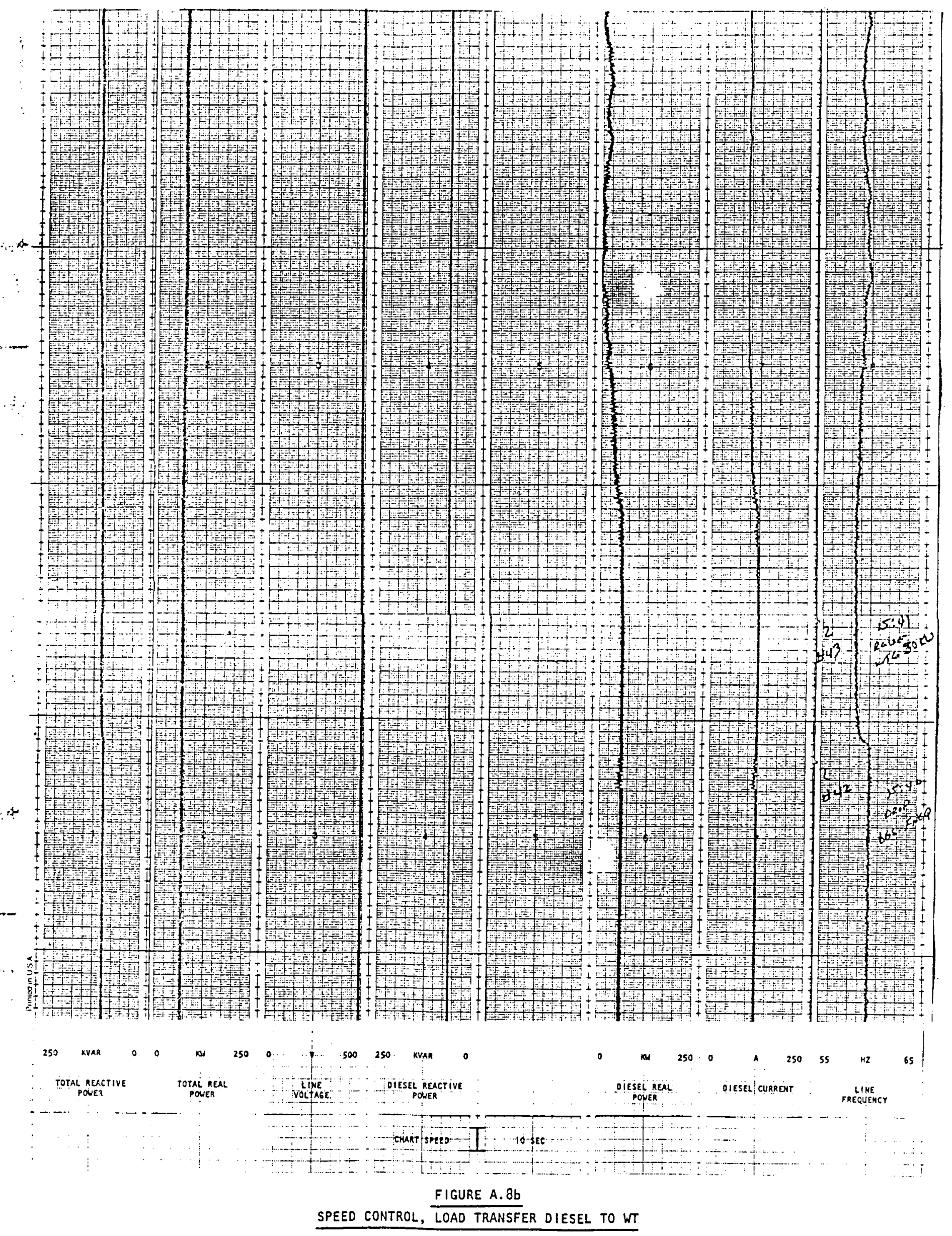



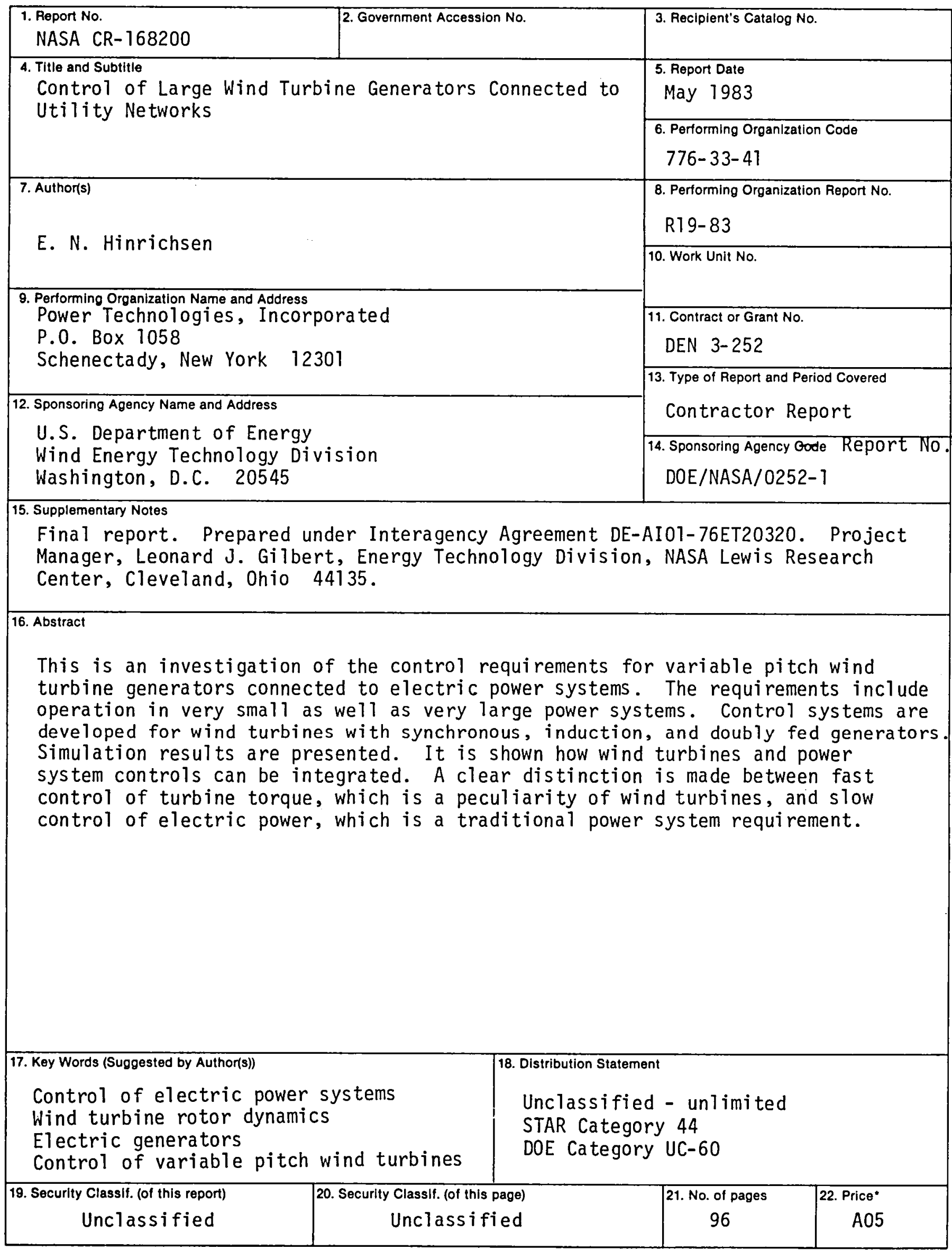

*For sale by the National Technical Information Service, Springfield, Virginia 22161 
